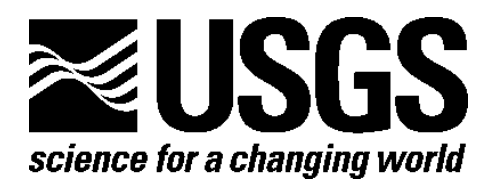

\title{
Audiomagnetotelluric Data, Taos Plateau Volcanic Field, New Mexico
}

By Chad E. Ailes and Brian D. Rodriguez

Open-File Report 2011-1264 


\section{U.S. Department of the Interior \\ KEN SALAZAR, Secretary}

\section{U.S. Geological Survey \\ Marcia K. McNutt, Director}

U.S. Geological Survey, Reston, Virginia: 2011

For product and ordering information:

World Wide Web: http://www.usgs.gov/pubprod

Telephone: 1-888-ASK-USGS

For more information on the USGS-the Federal source for science about the Earth, its natural and living resources, natural hazards, and the environment:

World Wide Web: http://www.usgs.gov

Telephone: 1-888-ASK-USGS

Suggested citation:

Ailes, C.E., and Rodriguez, B.D., 2011, Audiomagnetotelluric data, Taos Plateau Volcanic Field, New Mexico: U.S. Geological Survey Open-File Report 2011-1264, 65 p.

Any use of trade, product, or firm names is for descriptive purposes only and does not imply endorsement by the U.S. Government.

Although this report is in the public domain, permission must be secured from the individual copyright owners to reproduce any copyrighted material contained within this report. 


\section{Contents}

Abstract...

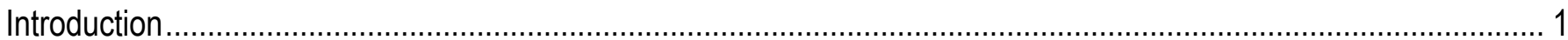

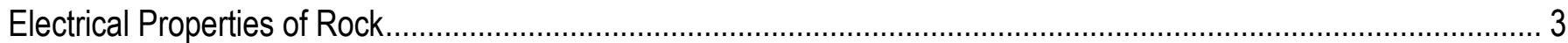

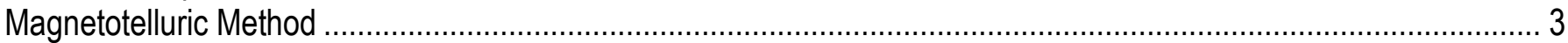

Audiomagnetotelluric Survey Across the Taos Plateau Volcanic Field .................................................................. 4

Audiomagnetotelluric Data Collected in the Taos Survey ........................................................................... 5

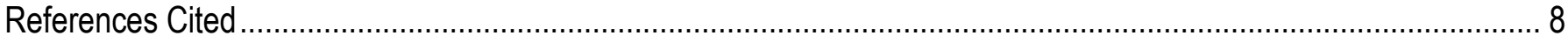

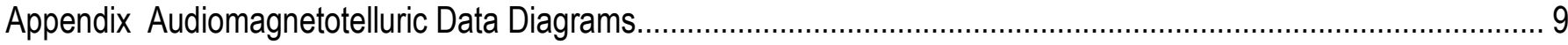

\section{Figure}

Figure 1. Audiomagnetotelluric profile across the Taos Plateau Volcanic Field, New Mexico................................. 2

\section{Table}

Table 1. Audiomagnetotelluric station coordinates. 


\section{Conversion Factors}

Inch/Pound to SI

\begin{tabular}{lll}
\hline \multicolumn{1}{c}{ Multiply } & \multicolumn{1}{c}{ By } & \multicolumn{1}{c}{ To obtain } \\
\hline foot (ft) & Length & \\
mile (mi) & 0.3048 & meter (m) \\
mile, nautical (nmi) & 1.609 & kilometer (km) \\
yard (yd) & 1.852 & kilometer (km) \\
\hline SI to Inch/Pound & 0.9144 & meter (m) \\
\hline \multicolumn{1}{c}{ Multiply } & & \\
\hline & By & \\
\hline meter $(\mathrm{m})$ & Length & To obtain \\
kilometer $(\mathrm{km})$ & 3.281 & foot (ft) \\
kilometer $(\mathrm{km})$ & 0.6214 & mile (mi) \\
meter $(\mathrm{m})$ & 0.5400 & mile, nautical (nmi) \\
\hline
\end{tabular}

Vertical coordinate information is referenced to the 1866 Clarke Spheroid.

Horizontal coordinate information is referenced to the North American Datum of 1927 (NAD 27).

Elevation, as used in this report, refers to distance above the vertical datum. 


\title{
Audiomagnetotelluric Data, Taos Plateau Volcanic Field, New Mexico
}

\author{
By Chad E. Ailes and Brian D. Rodriguez
}

\begin{abstract}
The U.S. Geological Survey is conducting a series of multidisciplinary studies of the San Luis Basin as part of the Geologic framework of the Rio Grande Basins project. Detailed geologic mapping, high-resolution airborne magnetic surveys, gravity surveys, audiomagnetotelluric surveys, and hydrologic and lithologic data are being used to better understand the aquifers. This report describes a regional east-west audiomagnetotelluric sounding profile acquired in late July 2009 across the Taos Plateau Volcanic Field. No interpretation of the data is included.
\end{abstract}

\section{Introduction}

The population of the San Luis Basin region of northern New Mexico is growing. Water shortfalls in this low rainfall region could have serious consequences. Decisions for future growth and land management in the region depend on an accurate assessment and protection of the region's groundwater resources. An important aspect of managing the groundwater resources is a better understanding of the hydrogeology of the Santa Fe Group and the nature of the sedimentary deposits that fill the Rio Grande Rift, which contain the principal groundwater aquifers. The shallow unconfined aquifer and the deeper confined Santa Fe Group aquifer in the San Luis Basin are the main sources of municipal water for the region.

The U.S. Geological Survey (USGS) is conducting a series of multidisciplinary studies of the San Luis Basin as part of the Geologic framework of the Rio Grande Basins project. Detailed geologic mapping, high-resolution airborne magnetic surveys, gravity surveys, audiomagnetotelluric (AMT) surveys, and hydrologic and lithologic data are being used to better understand the aquifers. This report describes a regional east-west AMT sounding profile acquired in late July 2009 across the Taos Plateau Volcanic Field where drillhole data are sparse (fig. 1). Resistivity modeling of the AMT data can be used to help map changes in electrical resistivity with depths that are related to differences in rock types. These various rock types help control the properties of aquifers. The purpose of this report is to release the AMT sounding data collected along the east-west profile. No interpretation of the data is included. 


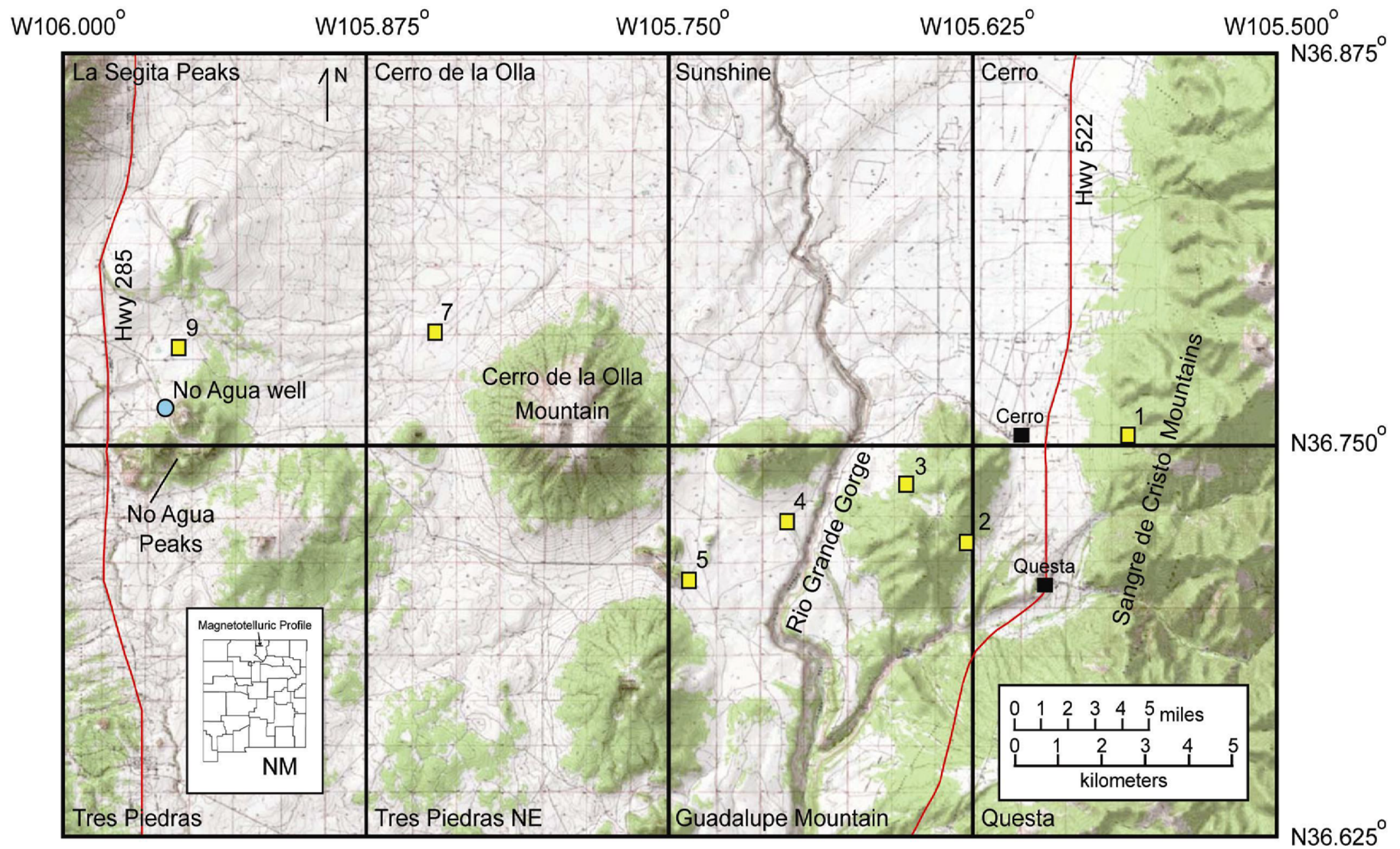

Figure 1. Audiomagnetotelluric profile across the Taos Plateau Volcanic Field, New Mexico. Audiomagnetotelluric stations acquired in late July 2009 are numbered yellow squares (stations 6 and 8 not acquired). Blue circle is No Agua well. Base map from La Segita Peaks, Cerro de la Olla, Sunshine, Cerro, Tres Piedras, Tres Piedras NE, Guadalupe Mountain, and Questa, New Mexico, 1:24,000 topographic quadrangles. 


\section{Electrical Properties of Rock}

Electromagnetic geophysical investigation methods detect variations in the electrical properties of rock units, in particular electrical resistivity measured in units of ohm-meters $(\Omega \mathrm{m})$, or its inverse, electrical conductivity measured in units of Siemens/meter $(\mathrm{S} / \mathrm{m})$. Electrical resistivity can be correlated with geologic units on the surface and at depth using lithologic logs to provide a three dimensional picture of subsurface geology. In the upper crust, the resistivities of geologic units are largely dependent upon their fluid content, pore volume porosity, interconnected fracture porosity, and conductive mineral content (Keller, 1987).

Although there is not a one-to-one relationship between lithology and resistivity, there are general correlations that can be made using typical values, even though values can be found at other geographic locations (Palacky, 1987) that may fall outside of the ranges presented below. Fluids within the pore spaces and fracture openings, especially if saline, can reduce resistivities in what would otherwise be a resistive rock matrix (Hallenburg, 1998; Hearst and Nelson, 1985; Hearst and others, 2000; Keller, 1987; Keller and Frischknecht, 1966; Palacky, 1987). Resistivity can also be lowered by the presence of electrically conductive clay minerals, graphitic carbon, and metallic mineralization. It is common, for example, for altered volcanic rocks to contain replacement minerals that have resistivities ten times lower than those of the surrounding rocks (Nelson and Anderson, 1992). Fine grained sediments - such as clay rich alluvium, marine shales, and other mudstones — are normally conductive, with resistivities ranging from a few ohm-m to tens of ohm-m (Keller, 1987; Palacky, 1987). Metamorphic rocks (non-graphitic) and unaltered, unfractured igneous rocks are normally moderately to highly resistive (a few hundred to thousands of ohm-m). Carbonate rocks can have similarly high resistivities depending on their fluid content, porosity, and impurities (Keller, 1987; Palacky, 1987). Fault zones may be moderately conductive (tens of ohm-m) when composed of rocks fractured enough to have hosted fluid transport and consequent mineralogical alteration (Eberhart-Phillips and others, 1995). At greater depths, higher subsurface temperatures cause higher ionic mobility that reduces rock resistivities (Keller, 1987; Palacky, 1987). Tables of electrical resistivity for a variety of rocks, minerals, and geological environments may be found in Keller (1989) and Palacky (1987).

\section{Magnetotelluric Method}

The magnetotelluric (MT) method is a passive surface geophysical technique that uses the Earth's natural electromagnetic fields to investigate the electrical resistivity structure of the subsurface from depths of tens of meters to tens of kilometers (Vozoff, 1991). Natural variations of the Earth's magnetic and electric fields are measured and recorded at each MT station. Worldwide lightning activity at frequencies of about 1 to 20,000 Hertz and geomagnetic micro-pulsations at frequencies of about 1 to 0.0001 Hertz provide the majority of the signal sensed by the MT method. The natural electromagnetic waves propagate vertically in the Earth because the large contrast between the resistivity of the air and the Earth causes a vertical refraction of the electromagnetic wave at the surface (Vozoff, 1972).

The orthogonal horizontal electric (Ex, Ey), magnetic (Hx,Hy), and vertical magnetic (Hz) field components are recorded in the magnetotelluric method. The resulting time-series signals are used to derive tensor apparent resistivities and phases after first converting them to complex cross-spectra using fast Fourier transform (FFT) techniques and least-squares, cross-spectral analysis (Bendat and Piersol, 1971) to solve for a tensor transfer function. If one assumes that the Earth consists of a two-input, twooutput linear system in which the orthogonal magnetic fields are input and the orthogonal electric fields are output, then a transfer function can be calculated that relates the observed electric fields to the magnetic fields. For resistivity modeling, data are normally rotated into directions that are parallel and perpendicular to the subsurface geologic strike. Subsurface geologic strike can be estimated by 
determining the horizontal direction ( $\mathrm{Hx}$ or $\mathrm{Hy}$ ) that the vertical magnetic field $(\mathrm{Hz})$ "tips" (the Tipper strike direction).

For a two-dimensional Earth, the MT fields can be decoupled into transverse electric (TE) and transverse magnetic (TM) modes. Two-dimensional resistivity modeling generally is computed to fit both modes. When the geology satisfies the two-dimensional assumption, the MT data for the TE mode are assumed to represent the electric field oriented along geologic strike, and the data for the TM mode are assumed to represent the electric field oriented across strike. The MT method is well suited for studying complicated geological environments because the electric and magnetic relations are sensitive to vertical and horizontal variations in resistivity. High-resolution shallow subsurface characterization is possible for closely spaced stations, but the resolution of the subsurface decreases for deeper measurements and for widely-spaced stations. The method is capable of establishing whether the electromagnetic fields are responding to subsurface rock bodies of effectively 1,2, or 3 dimensions. An introduction to the MT method and references for a more advanced understanding can be found in Kaufman and Keller (1981), Dobrin and Savit (1988), and Vozoff (1991).

\section{Audiomagnetotelluric Survey Across the Taos Plateau Volcanic Field}

Seven AMT soundings were collected in July 2009 along a 35-km-long east-west profile in northern New Mexico (fig. 1). The profile starts at station 9, which is north of the No Agua Peaks about $2.5 \mathrm{~km}$ east of State Highway 285. From station 9 it continues easterly until it bends south of Cerro de la Olla Mountain; it then continues east across the Rio Grande Gorge and ends at station 1 (in the Sangre de Cristo Mountains) about $3 \mathrm{~km}$ east of State Highway 522 and the town of Cerro and about $4 \mathrm{~km}$ northeast of the town of Questa, New Mexico. The profile location was selected to map electrical resistivity with depth related to the properties of aquifers beneath the Taos Plateau Volcanic Field.

Station locations were chosen for proximity to roads and in order to avoid electrical noise from power lines. All data at the stations were collected with a portable Electromagnetic Instruments, Inc. (EMI) MT-1 system (Electromagnetetic Instruments, Inc., 1996). Horizontal electric fields were recorded using titanium electrodes placed in an L-shaped, three-electrode array with dipole lengths of 30 meters. The orthogonal horizontal magnetic fields were measured in the direction of the electric-field array and were sensed using high magnetic permeability mu-metal-cored induction coils. Frequencies were sampled from about 4 Hertz to about 23,000 Hertz at each station. Station 9 was located close to the No Agua well to help calibrate future resistivity modeling of the AMT data. The No Agua well is a 354 meter deep test well with lithologic descriptions; granite was encountered at 350 meters. Table 1 lists the seven AMT station locations. Stations 6 and 8 (not shown) were not acquired because of site access problems. Remote reference stations were not used because manmade noise sources were assumed to be minimal in this remote area. 


\section{Table 1. Audiomagnetotelluric station coordinates}

[Coordinates are referenced to the 1866 Clarke spheroid and North American 1927 Western United States datum. Longitude and latitude format is degrees:minutes:seconds. Universal Transverse Mercator (UTM Zone 13) units and station elevations are in meters. The accuracy of the north and east component is $\pm 5 \mathrm{~m}$ and is $\pm 10 \mathrm{~m}$ for the elevation. $\mathrm{X}$ direction (X Dir.) is in degrees clockwise from true north]

\begin{tabular}{ccccccc}
\hline Station & X Dir. & Longitude & Latitude & North $(\boldsymbol{m})$ & East $(\mathrm{m})$ & Elevation $(\mathrm{m})$ \\
\hline 01 & 295 & $-105: 33: 40$ & $36: 45: 11$ & $4,067,415$ & 449,925 & 2,608 \\
02 & 004 & $-105: 37: 38$ & $36: 43: 09$ & $4,063,693$ & 443,996 & 2,325 \\
03 & 171 & $-105: 39: 08$ & $36: 44: 15$ & $4,065,746$ & 441,778 & 2,353 \\
04 & 041 & $-105: 42: 05$ & $36: 43: 32$ & $4,064,453$ & 437,367 & 2,300 \\
05 & 005 & $-105: 44: 30$ & $36: 42: 25$ & $4,062,421$ & 433,753 & 2,317 \\
07 & 279 & $-105: 50: 48$ & $36: 47: 10$ & $4,071,274$ & 424,446 & 2,363 \\
09 & 141 & $-105: 57: 08$ & $36: 46: 52$ & $4,070,799$ & 415,019 & 2,537 \\
\hline
\end{tabular}

\section{Audiomagnetotelluric Data Collected in the Taos Survey}

The recorded time-series data were converted to the frequency domain and processed to determine the impedance tensor, which is used to derive apparent resistivities and phases at each site. Rotation of the impedance tensor allows for decoupling into the TE and TM modes. The data provided here have not been rotated from the original acquisition orientation (X Dir.) listed in table 1 above. During the analysis and interpretation process, each station should be rotated to a fixed angle determined by the given nominal profile orientation. Cross-power files were sorted to select optimal signal-to-noise time-series data sets (see appendix 1).

Cultural features - such as fences, pipelines, communication lines, moving vehicles and trains, and other manmade sources of electromagnetic noise — can contaminate the responses of the AMT system. Care is taken to avoid these sources of noise when acquiring the data.

The figures in Appendix 1 represent the field-processed AMT data for each station, after the time-series data were converted to the frequency domain and the tensor-transfer function was developed. They include some data scatter and poor signal-to-noise ratios. The only effort aimed at removing noisy data points was to visually inspect and select the best signal-to-noise field data to combine into the final data plots.

For each station, eight separate diagrams are given:

1. Apparent Resistivity ( $\mathrm{x}$ and $\mathrm{o}$ symbols are $\mathrm{xy}$ and $\mathrm{yx}$ components)

2. Impedance Phase ( $\mathrm{x}$ and $\mathrm{o}$ symbols are $\mathrm{xy}$ and $\mathrm{yx}$ components)

3. Impedance Skew

4. Multiple Coherency ( $\mathrm{x}$ and o symbols are $\mathrm{xy}$ and $\mathrm{yx}$ components)

5. Impedance Polar Plots

6. Tipper Magnitude

7. Tipper Strike

8. HzHx (x symbol) and HzHy (o symbol) Coherency 
Error bars (],[) on the Apparent Resistivity, Impedance Phase, Impedance Skew, Tipper Magnitude, and Tipper Strike diagrams represent probable errors within one standard deviation of the sample variance (Gamble and others, 1979).

Apparent resistivity is the ratio at a given frequency of the electric field strength magnitude to the magnetic field strength magnitude. The impedance phase is proportional to the slope of the apparent resistivity curve on a log-log plot, relative to a baseline at $-45^{\circ}$ (Vozoff, 1991). A measure of the dimensionality for AMT data is provided by the impedance skew of the impedance tensor (Vozoff, 1972). If the effective, measured resistivity response to the geology beneath an AMT station is truly one-or two-dimensional, then the skew will be zero. Both instrumental and environmental sources of noise contribute to non-zero skew values but are typically small (about 0.1 ) for relatively low-noiselevel recordings. Higher skews (more than 0.2) indicate either the resistivity response to 3-D geology or higher levels of noise.

In the study area, noise from a number of small powerlines and small moving vehicles was negligible at distances of $0.25 \mathrm{~km}$ and farther from the noise source. Powerline amplitude levels were measured at each site and were typically less than 20 percent of the maximum recordable signals. Noise from larger power lines, power generators, pipelines, and trains was negligible at distances greater than $5 \mathrm{~km}$. Local lightning, wind, and rainstorms also can degrade data quality, but these noise sources were avoided by not recording during active thunderstorm periods. Burying the magnetic induction coils and keeping the electric dipole wires flat on the ground helped to minimize wind noise.

Predicted values of the electric field can be computed from the measured values of the magnetic field (Vozoff, 1991). The coherence of the predicted electric field with the measured electric field is a measure of the signal-to-noise ratio provided in the multiple coherency plots. Values are normalized between 0 and 1 , where values at 0.5 signify signal levels equal to noise levels. For this data set, coherencies were generally above 0.75 , except in the middle frequencies (from about 0.1 Hertz to 5 Hertz) at most stations, and also in the lower frequencies for station 7 , where a nearby thunderstorm made it difficult to collect low-frequency data with high amplifier gains.

The figures in appendix 1 represent the field-processed AMT data at each station and include some data scatter and poor signal-to-noise ratios. The only effort aimed at removing noisy data points was to visually inspect and digitally select the best signal to noise field data to combine into the final data diagrams.

The impedance polar diagrams provide a measure of the AMT data dimensionality (Reddy and others, 1977). For 1-D resistivity structures, the principal impedance (off-diagonal elements) polar diagram (dashed line) is a circle. For 2-D or 3-D resistivity structures, the principal impedance polar diagram (dashed line) elongates either parallel to or perpendicular to strike direction. Over resistors, the principal impedance polar diagram elongates perpendicular-to-strike direction; while over conductors, the principal impedance polar diagram elongates parallel-to-strike direction. For 2-D resistivity structures, the additional impedance polar diagram (solid line) attains the shape of a symmetric clover leaf. For 3-D resistivity structures, the additional impedance polar diagram (solid line) elongates in one direction, and its amplitude is comparable to that of the principal impedance polar diagram (dashed line); although, high noise levels can produce the same effect on the polar diagram. A 3-D analysis of polar plots at each frequency should also take into account the corresponding coherence and skew values along with their associated error levels. The polar plots computed for the data show the electromagnetic response for all stations was 3-D over the middle to low frequencies measured at acceptable noise levels. The electromagnetic response for stations 2, 3, and 4 was 3-D over all frequencies. 
The tipper can be calculated from the vertical component of the magnetic field. The tipper magnitude is a measure of the tipping of the magnetic field out of the horizontal plane (Vozoff, 1991). The magnitude is 0 for the 1-D case, typically increases between 0.1 to 0.5 , and rarely is as large as 1 as it responds to vertical and subvertical structures. The tipper strike typically is used to help resolve the $90^{\circ}$ ambiguity in the impedance rotation angle. The tipper magnitude of these stations were all above 0.1 indicating vertical and sub-vertical structure at depth.

The HzHx and HzHy coherency is a measure of the signal-to-noise ratio of the vertical magnetic field with respect to each of the orthogonal, horizontal magnetic field directions. Values are normalized between 0 and 1 , where values of 0.5 signify signal levels equal to noise levels. These three components of magnetic-field coherence provide a check on the quality of the measured values in the tipper magnitude and tipper strike plots. 


\section{References Cited}

Bendat, J.S., and Piersol, A.G., 1971, Random data-analysis and measurement procedures: New York, N.Y., Wiley Interscience, 407 p.

Dobrin, M.D., and Savit, C.H., 1988, Introduction to geophysical prospecting (4th ed.): New York, McGraw-Hill, 867 p.

Eberhart-Phillips, Donna, Stanley, W.D., Rodriguez, B.D., and Lutter, W.J., 1995, Surface seismic and electrical methods to detect fluids related to faulting: Journal of Geophysical Research, v. 100, no. B7, p. 12919-12936.

Electromagnetic Instruments, Inc., 1996, MT-1 magnetotelluric system operation manual, version 3.2: Richmond, Calif., Electromagnetic Instruments, Inc., 220 p.

Gamble, T.D., Goubau, W.M., and Clarke, J., 1979, Error analysis for remote reference magnetotellurics: Geophysics, v. 44, no. 5, p. 959-968.

Hallenburg, J.K., 1998, Non-hydrocarbon methods of geophysical formation evaluation: Boca Raton, Fla., Lewis Publications, 265 p.

Hearst, J.R., and Nelson, P.H., 1985, Well logging for physical properties: New York, McGraw-Hill Book Co., $571 \mathrm{p}$.

Hearst, J.R., Nelson, P.H., and Paillet, F.L., 2000, Well logging for physical properties, 2nd edition: New York, John Wiley \& Sons, 483 p.

Kaufman, A.A., and Keller, G.V., 1981, The magnetotelluric sounding method, in Methods in geochemistry and geophysics, 15: Amsterdam, Elsevier Scientific Publishing Company, 595 p.

Keller, G.V., 1987, Rock and mineral properties, in Nabighian, M.N., ed., Electromagnetic methods in applied geophysics theory: Tulsa, Okla., Society of Exploration Geophysicists, v. 1, p. 13-51.

Keller, G.V., 1989, Electrical properties, in Carmichael, R.S., ed., Practical handbook of physical properties of rocks and minerals: Boca Raton, Fla., CRC Press, p. 359-427.

Keller G.V., and Frischknecht F.C., 1966, Electrical methods in geophysical prospecting: Oxford, Pergamon Press Inc., 519 p.

Nelson, P.H., and Anderson, L.A., 1992, Physical properties of ash flow tuff from Yucca Mountain, Nevada: Journal of Geophysical Research, v. 97, no. B5, p. 823-841.

Palacky, G.J., 1987, Resistivity characteristics of geologic targets, in Nabighian, M.N., ed., Electromagnetic methods in applied geophysics: Tulsa, Okla., Society of Exploration Geophysicists, v. 1, p. 53-129.

Reddy, I.K., Rankin, David, and Phillips, R.J., 1977, Three-dimensional modelling in magnetotelluric and magnetic variational sounding: Geophysics Journal of the Royal Astronomical Society, v. 51, p. 313-325.

Vozoff, Keeva, 1972, The magnetotelluric method in the exploration of sedimentary basins: Geophysics, v. 37, p. 980-141.

Vozoff, Keeva, 1991, The magnetotelluric method, in Nabighian, M.N., ed., Electromagnetic methods in applied geophysics: Tulsa, Okla., Society of Exploration Geophysicists, v. 2, pt. B, p. 641-711. 


\section{Appendix 1. Audiomagnetotelluric Data Diagrams}

There are eight separate plots for each station:

1. Apparent Resistivity for the unrotated xy (x symbol) and yx (o symbol) modes

2. Impedance Phase for the unrotated $x y(x$ symbol) and yx (o symbol) modes

3. Impedance Skew for the impedance tensor

4. Multiple Coherency for the xy (x symbol) and minimum (o symbol) modes of the electric field

5. Impedance Polar Plots (at 12 selected frequencies)

6. Tipper Magnitude for the vertical magnetic field

7. Tipper Strike for the vertical magnetic field

8. HzHx (x symbol) and HzHy (o symbol) Coherency

Error bars (],[) on the apparent resistivity, impedance phase, skew, tipper magnitude, and tipper strike plots represent probable errors within one standard deviation of the sample variance (Gamble and others, 1979). Refer to the "Audiomagnetotelluric Data Collected in the Taos Survey" section in this report for an explanation of these plots. 


\section{Station 1}

APPARENT RESISTIVITY Wheeler Peak Quad, NM

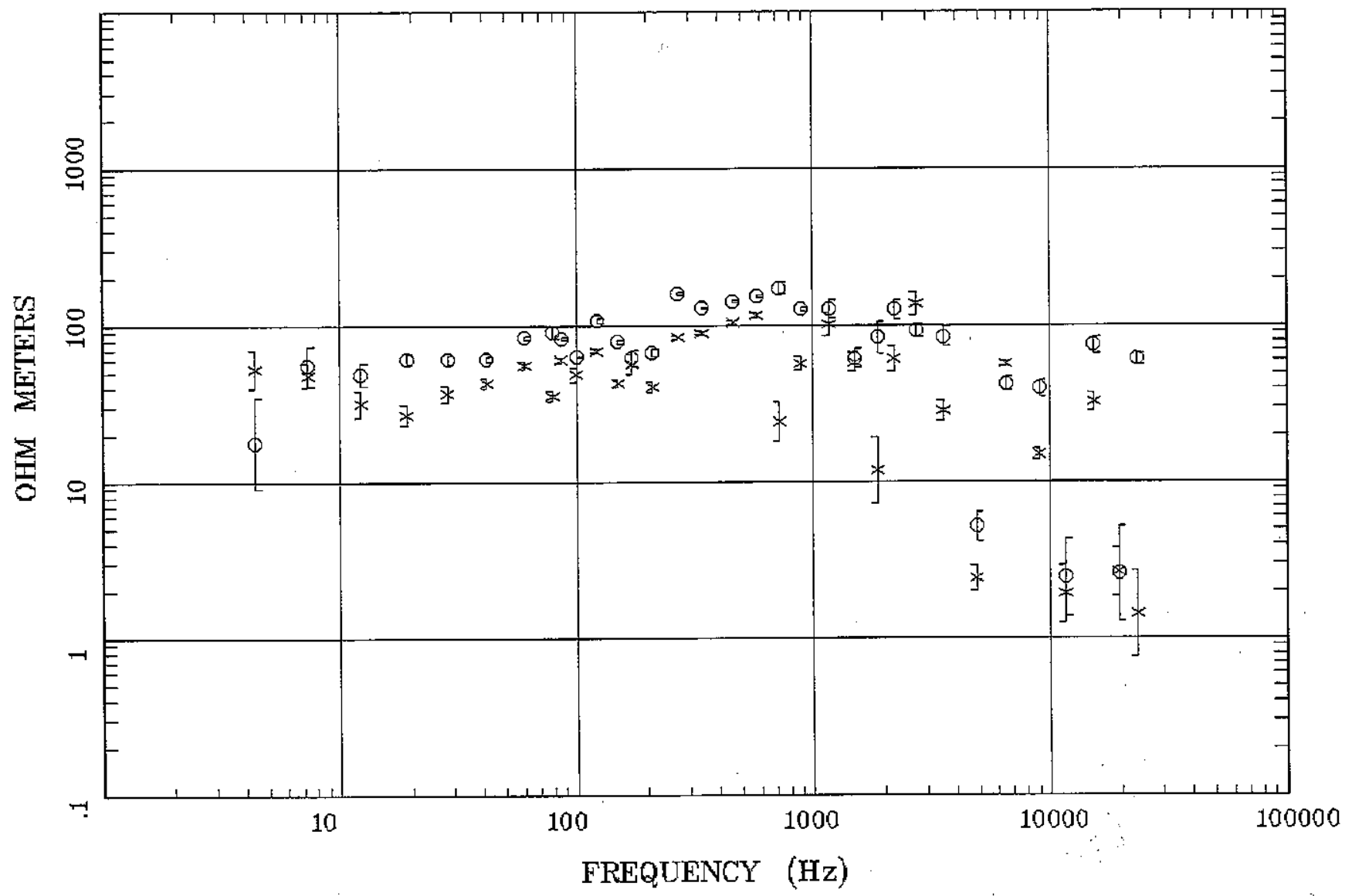

Client:

Remote: none

Acquired: 09:4 Jan 03, 2011

Survey Co:USGS

\section{Rotation:}

Filename: wp01a4.avg

Channels: Ch1 Ch2 Ch3 Ch4 Ch5 Ch3 Ch4 Plotted: 13:29 Jan 05, 2011

< EMI - ElectroMagnetic Instruments > 


\section{Station 1}

IMPEDANCE PHASE

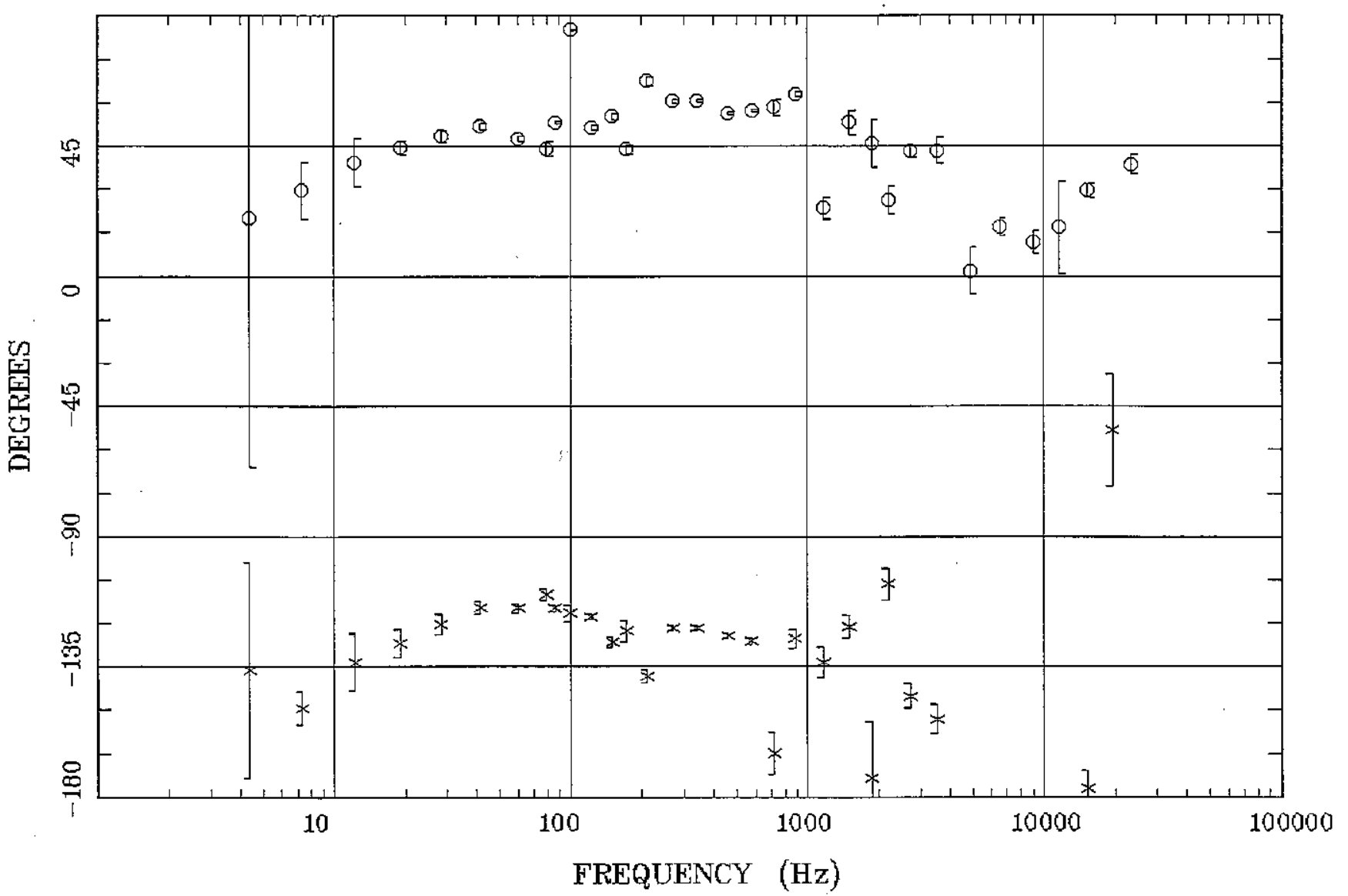

Client:

Remote: none

Acquired: 09:4 Jan 03, 2011

Survey Co:USGS
Rotation:

Filename: wp01a4.avg

Channels: Ch1 Ch2 Ch3 Ch4 Ch5 Ch3 Ch4

Plotted: 13:29 Jan 05, 2011

$<$ EMI - ElectroMagnetic Instruments 


\section{Station 1}

IMPEDANCE SKEW

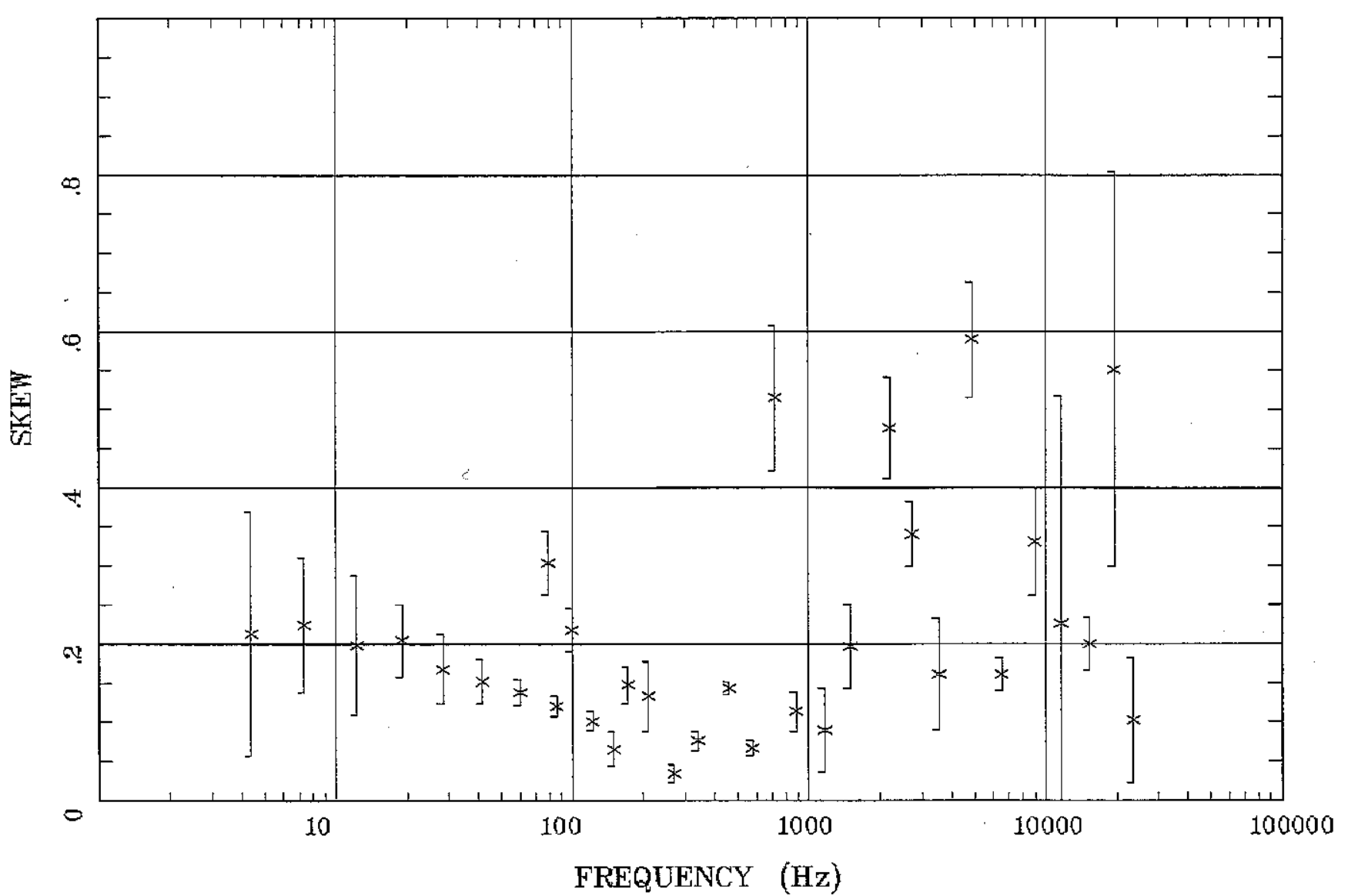

Client:

Remote: none

Acquired: 09:4 Jan 03, 2011

Survey Co:USGS
Rotation:

Filename: wp01a4.avg

Channels: Ch1 Ch2 Ch3 Ch4 Ch5 Ch3 Ch4

Plotted: 13:29 Jan 05, 2011

< EMI - ElectroMagnetic Instruments 


\section{Station 1}

E MULT Coh.

Wheeler Peak Quad, NM

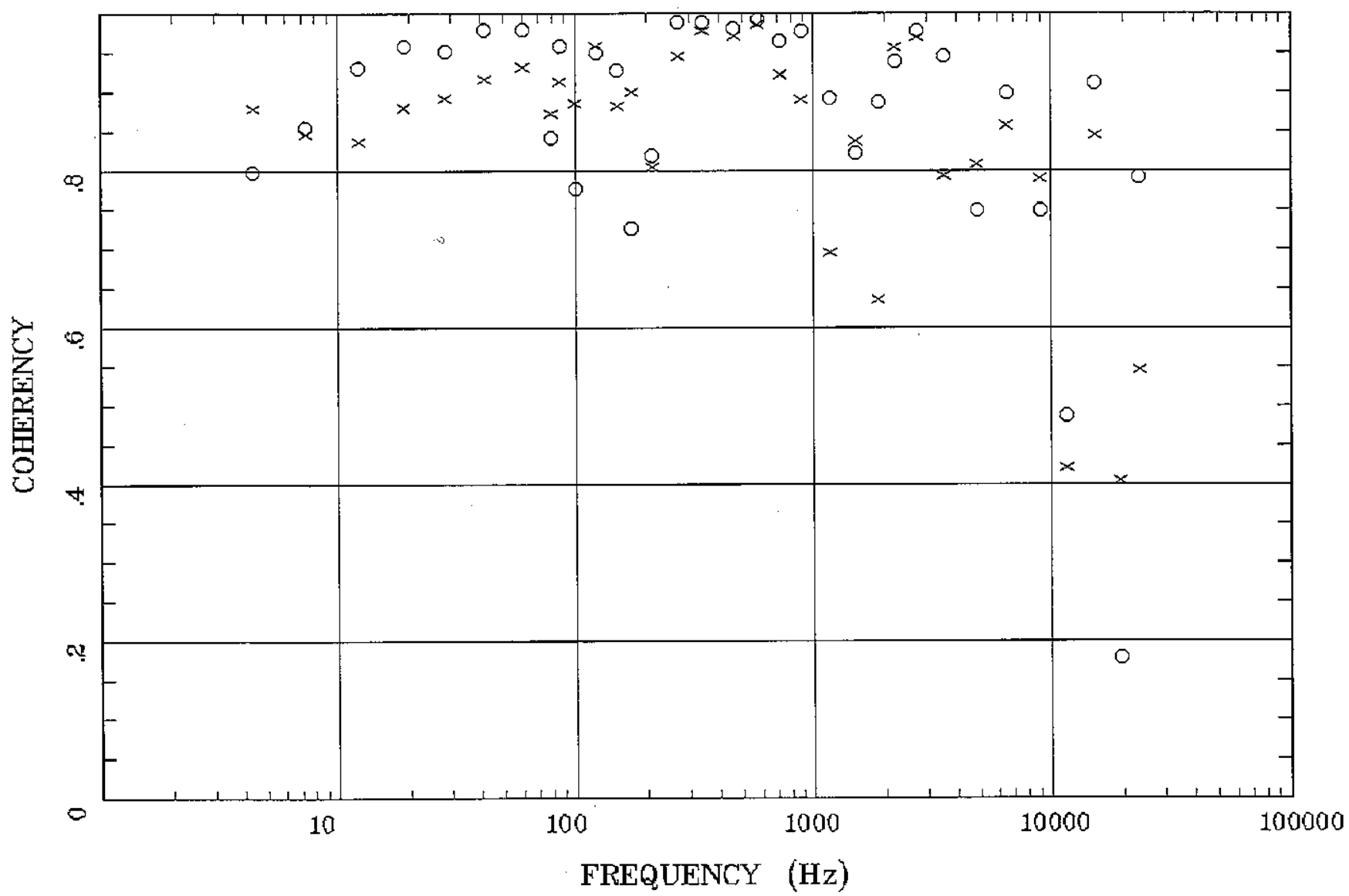

Client:

Remote: none

Acquired: 09:4 Jan 03, 2011

Survey Co:USGS
Rotation:

Filename: rp01a4.avg

Channels: Ch1 Ch2 Ch3 Ch4 Ch5 Ch3 Ch4

Plotted: 13:29 Jan 05, 2011

< EMI - ElectroMagnetic Instruments 


\section{Station 1}

POLAR PLOTS

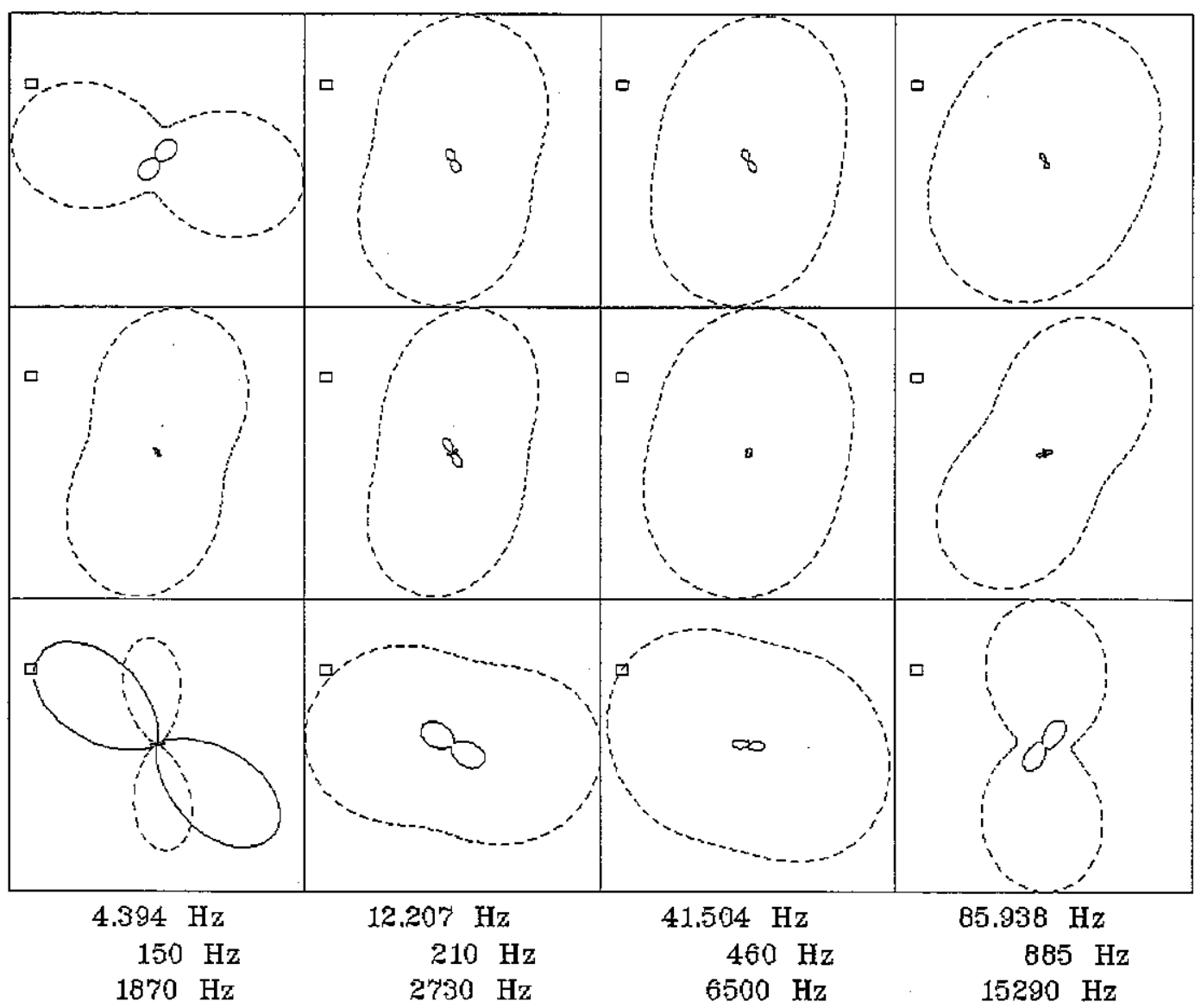

Rotation:

Filename: Tp01a4.avg

Channels: Ch1 Ch2 Ch3 Ch4 Ch5 Ch3 Ch4

Plotted: 13:29 Jan 05, 2011.

$<$ EMI - ElectroMagnetic Instruments
Acquired: 09:4 Jan 03, 2011

Survey Co:USGS
Wheeler Peak Quad, NM 
Station 1

TIPPER MAGNITUDE

Wheeler Peak Quad, NM

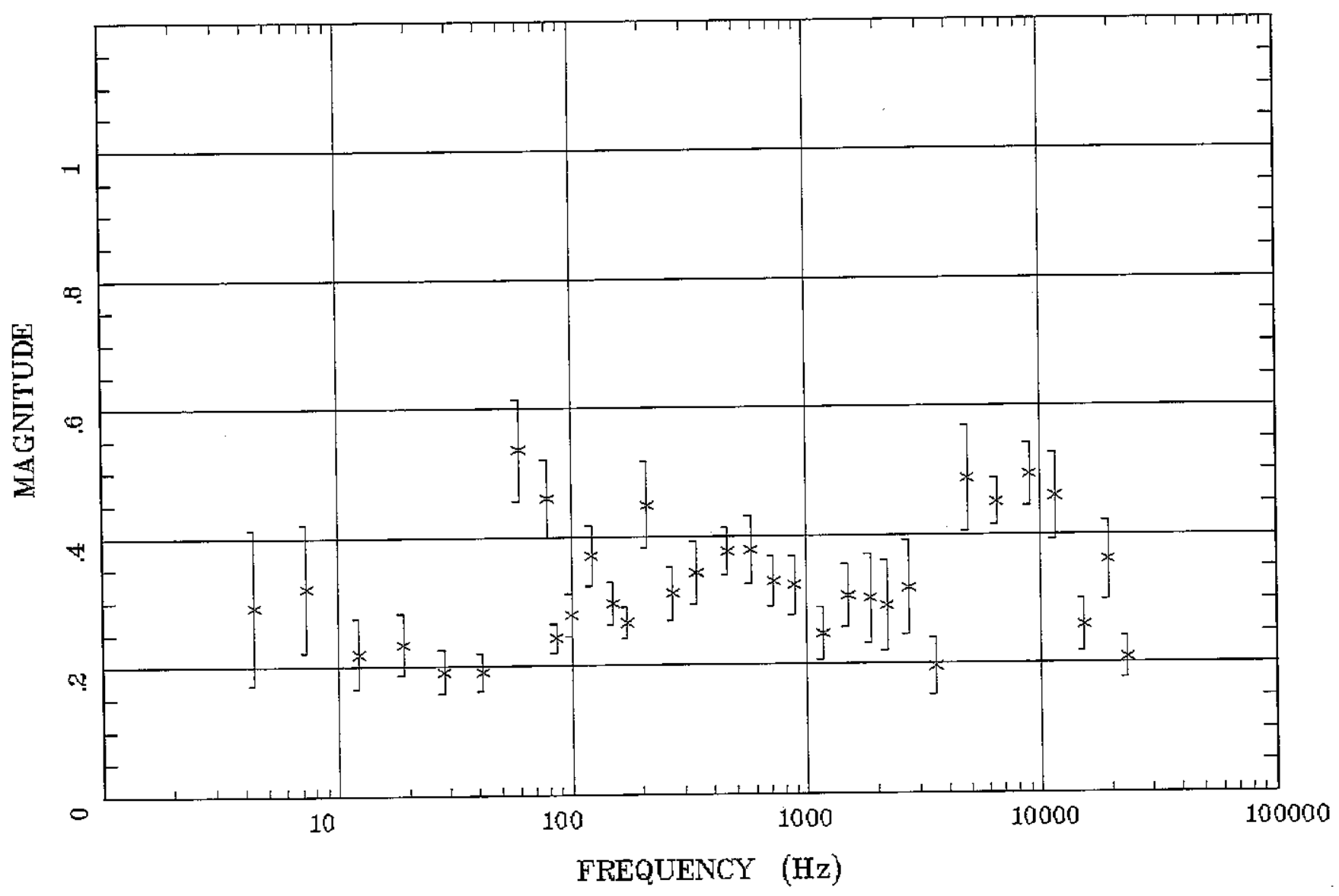

Client:

Remote: none

Acquired: 09:4 Jan 03, 2011

Survey Co:USGS

Rotation:

Filename: wp01a4.avg

Channels: Ch1 Ch2 Ch3 Ch4 Ch5 Ch3 Ch4

Plotted: 13:37 Jon 05, 2011

< EMI - ElectroMagnetic Instruments > 
Station 1

TIPPER STRIKE

Wheeler Peak Quad, NM

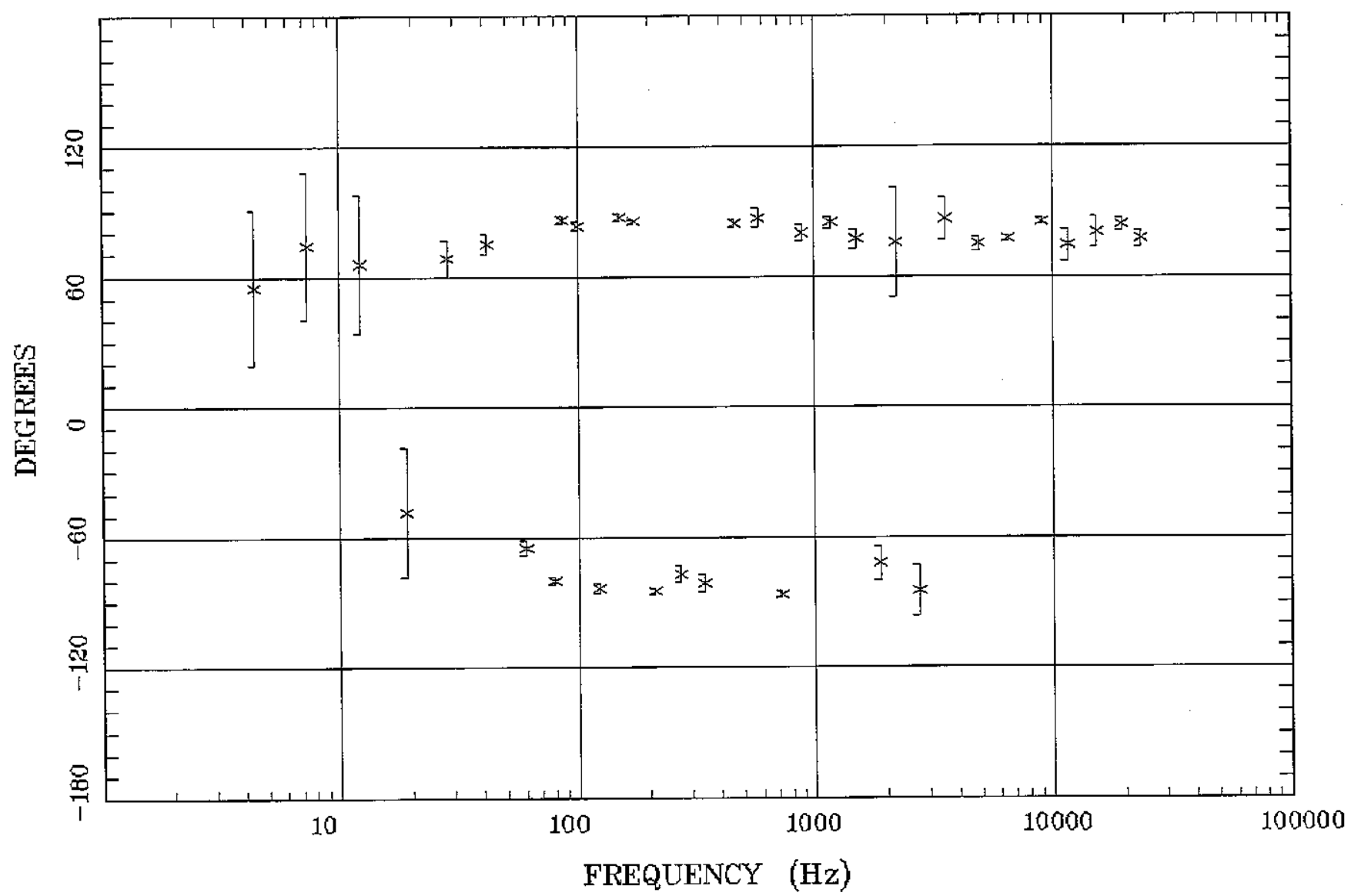

Client:

Remote: none

Acquired: 09:4 Jan 03, 2011

Survey Co:USGS

Rotation:

Filename: wp01a4.avg

Channels: Ch1 Ch2 Ch3 Ch4 Ch5 Ch3 Ch4

Platted: 13:37 Jan 05, 2011

< EMI - ElectroMagnetic Instruments 


\section{Station 1}

HzHx.x Coh HzHy.O

Wheeler Peak Quad, NM

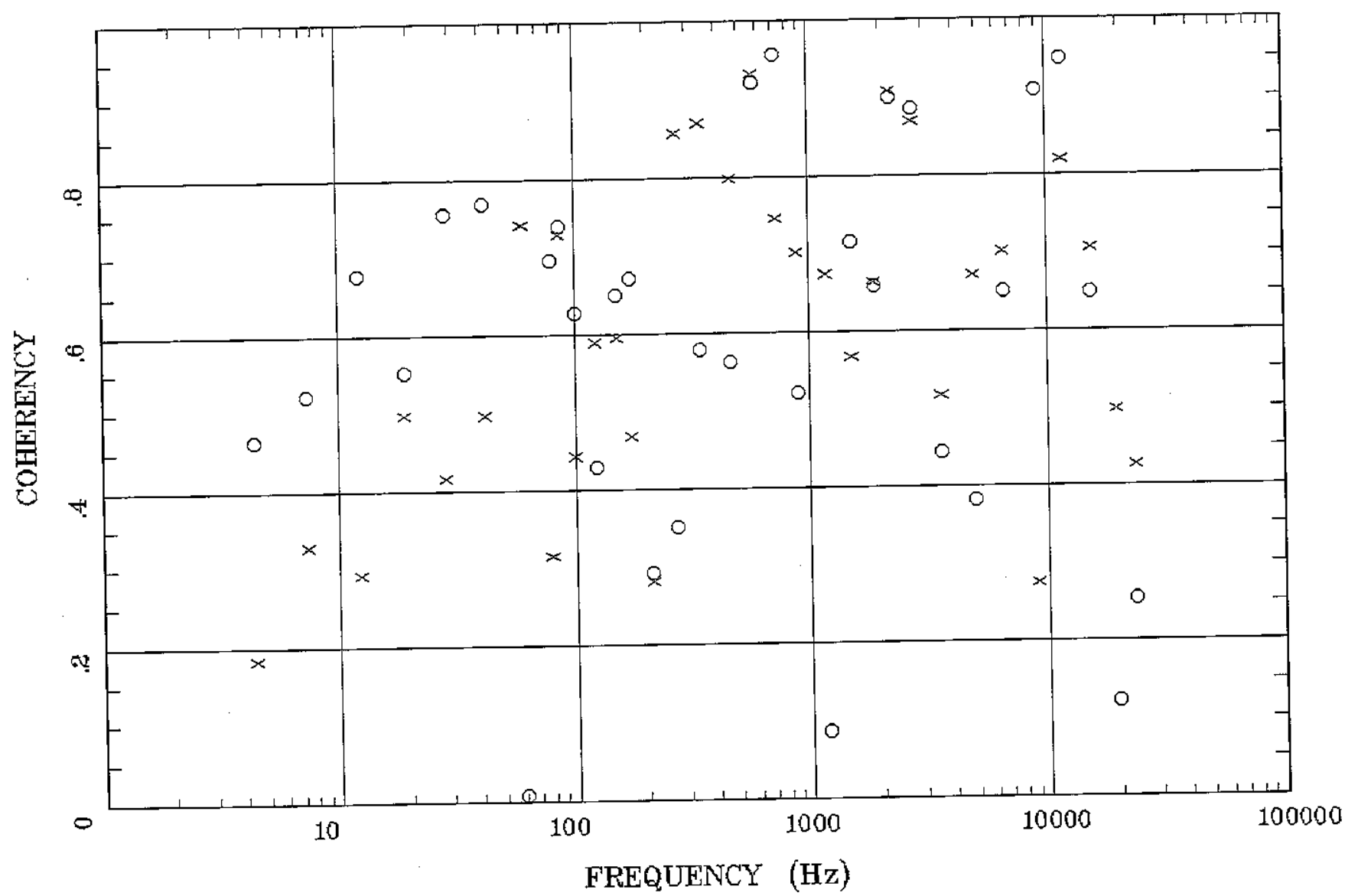

Rotation:

Client:

Remote: none

Acquired: 09:4 Jan 03, 2011

Survey Ca:USGS

Filename: Fp01a4.avg

Channels: $\mathrm{Ch} 1 \mathrm{Ch} 2 \mathrm{Ch} 3 \mathrm{Ch} 4 \mathrm{Ch} 5 \mathrm{Ch} 3 \mathrm{Ch} 4$

Plotted: 13:37 Jan 05, 2011

< EMI - ElectroMagnetic Instruments > 


\section{Station 2}

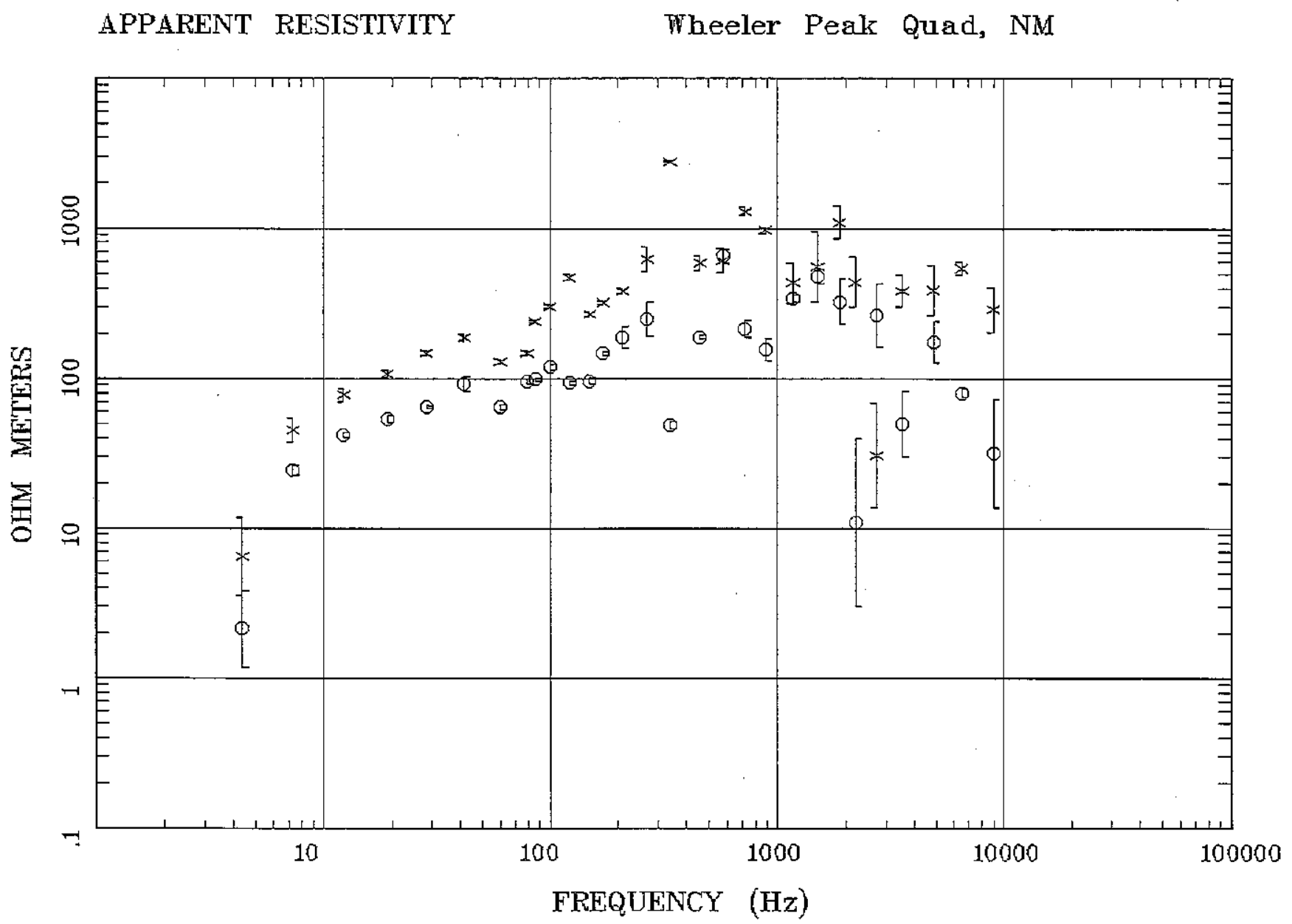

Client:

Remote: none

Acquired: 11:2 Jul 24, 2009 Survey Co:USGS
Rotation:

Filename: wp02a3.arg

Channels: Ch1 Ch2 Ch3 Ch4 Ch5 Ch3 Ch4

Plotted: 10:24 Dee 03, 2010

< EMI - ElectroMagnetic Instruments > 


\section{Station 2}

IMPEDANCE PHASE

Wheeler Peak Quad, NM

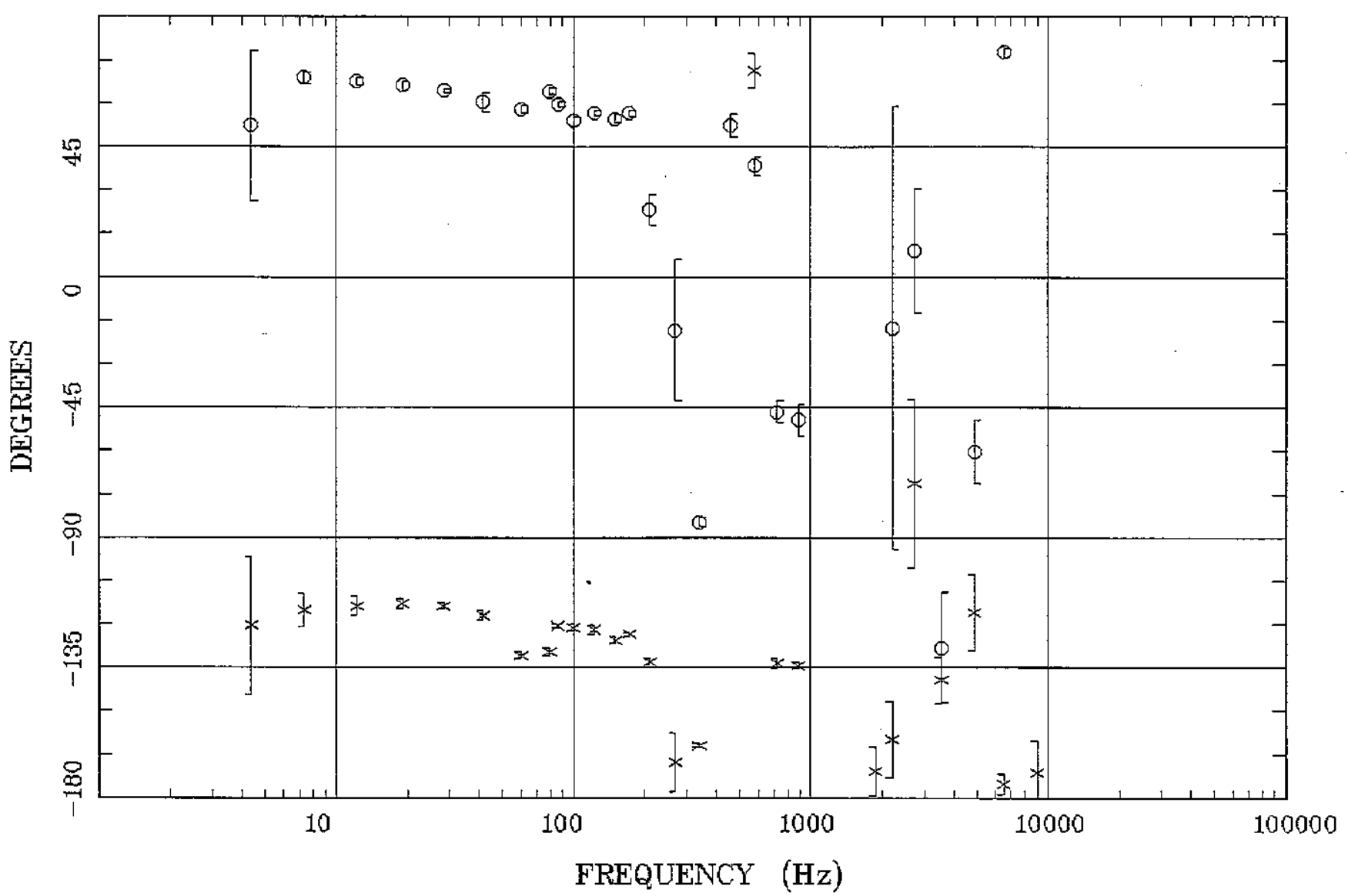

Client:

Remate: none

Acquired: 11:2 Jul 24, 2009 Survey Co:USGS
Rotation:

Filename: Tp02a3.arg

Channels: Ch1 Ch2 Ch3 Ch4 Ch5 Ch3 Ch4

Plotted: 10:24 Dee 03, 2010

< EMI - ElectroMagnetic Instruments > 


\section{Station 2}

IMPEDANCE SKEW

Wheeler Peak Quad, NM

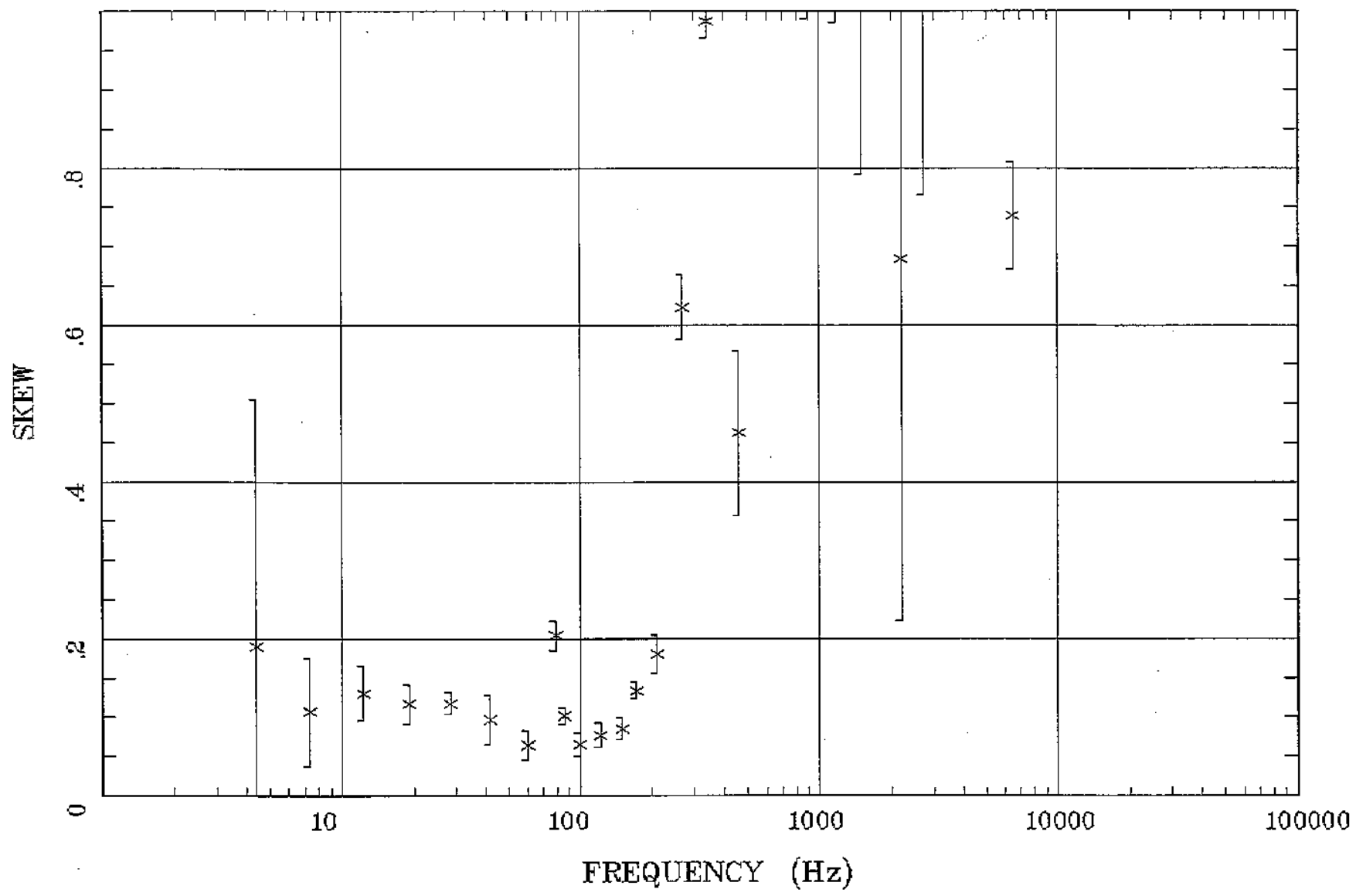

Client:

Remate: none

Rotation:

Acquired: 11:2 Iul 24, 2009

Tilename: 203. avo

Channels: Ch1 Ch2 Ch3 Ch4 Ch5 Ch3 Ch4

Plotted: 10:24 Dec 03, 2010

Survey Co:USGS

< EMI - ElectroMagnetic Instruments 
Station 2

E MULT Coh. Wheeler Peak Quad, NM

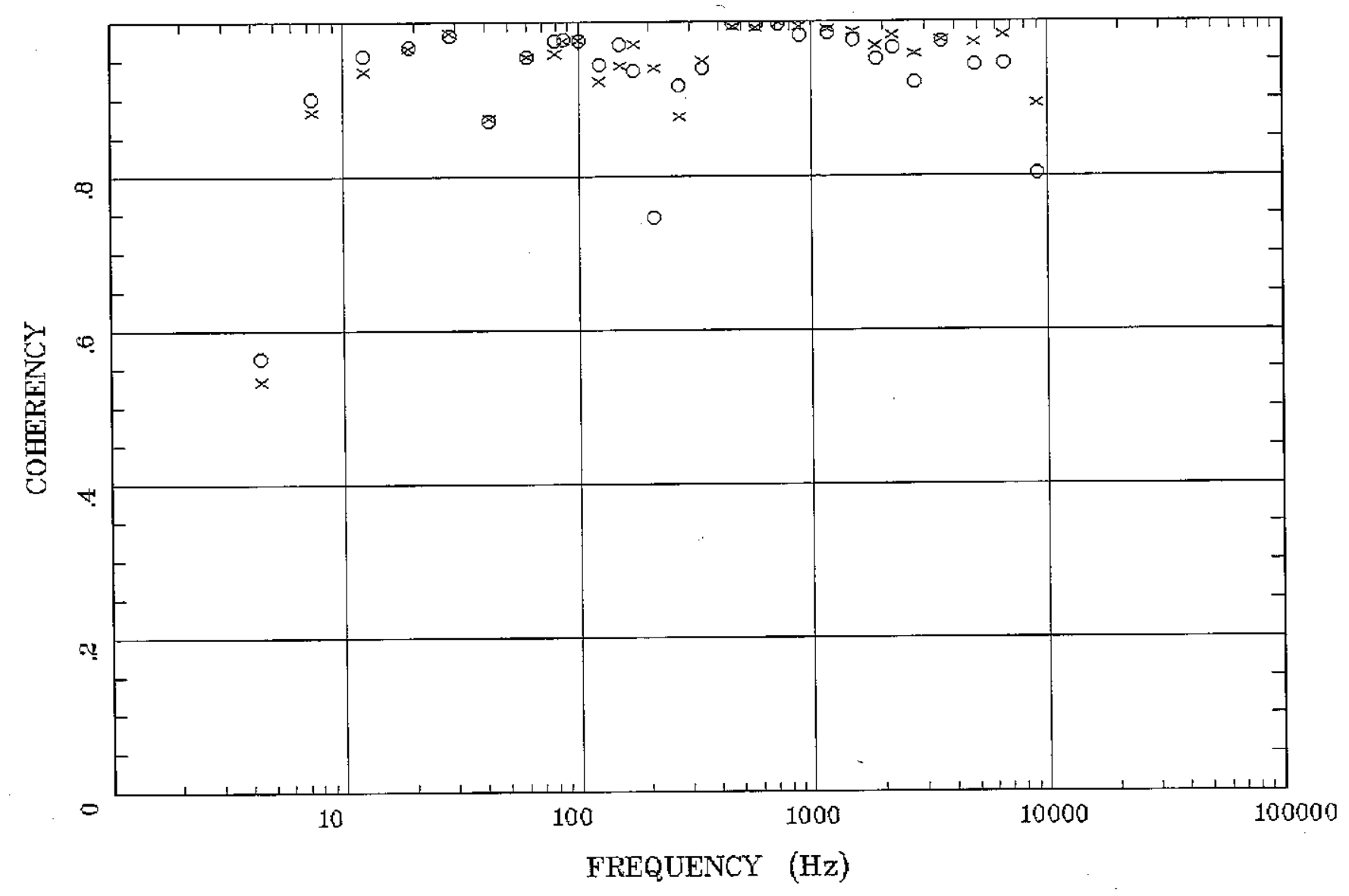

Client:

Reraote: none

Acquired: 11:2 Jul 24, 2009

Survey Co:USGS

Rotation:

Filename: rp02a3.avg

Channels: Ch1 Ch2 Ch3 Ch4 Ch5 Ch3 Ch4

Plotted: 10:24 Dec 03, 2010

< EMI - ElectroMagnetic Instruments > 


\section{Station 2}

POLAR PLOTS

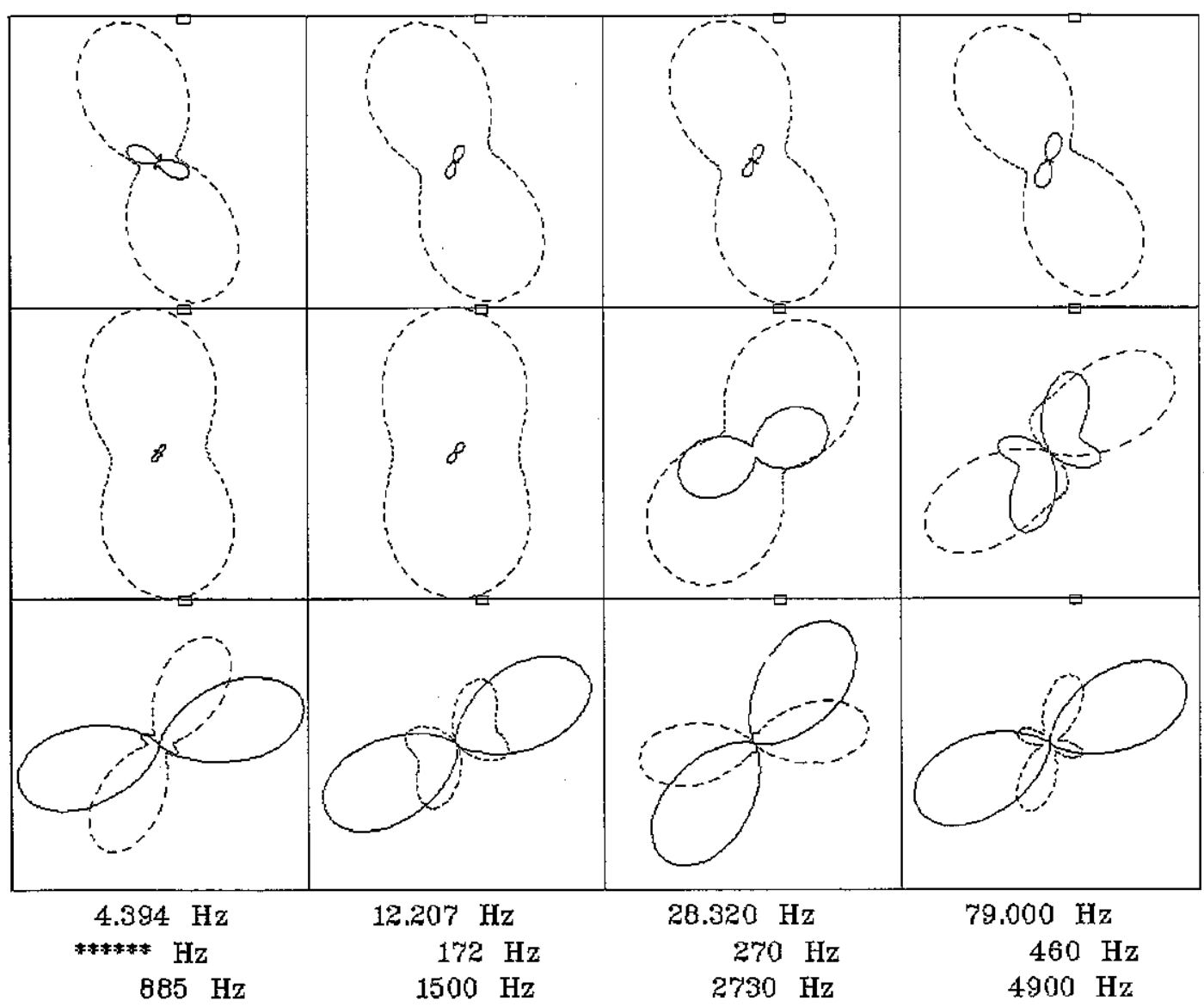

\section{Client:}

Remote: none

Acquired: 11:2 Jul 24, 2009 Survey Co:USGS
Wheeler Peak Quad, NM

Rotation:

Filename: พp02a3.arg

Channels: Ch1 Ch2 Ch3 Ch4 Ch5 Ch3 Ch4

Plotted: 14:55 Jan 06, 2011

< EMI - ElectroMagnetic Instruments > 


\section{Station 2}

TIPPER MAGNITUDE

Wheeler Peak Quad, NM

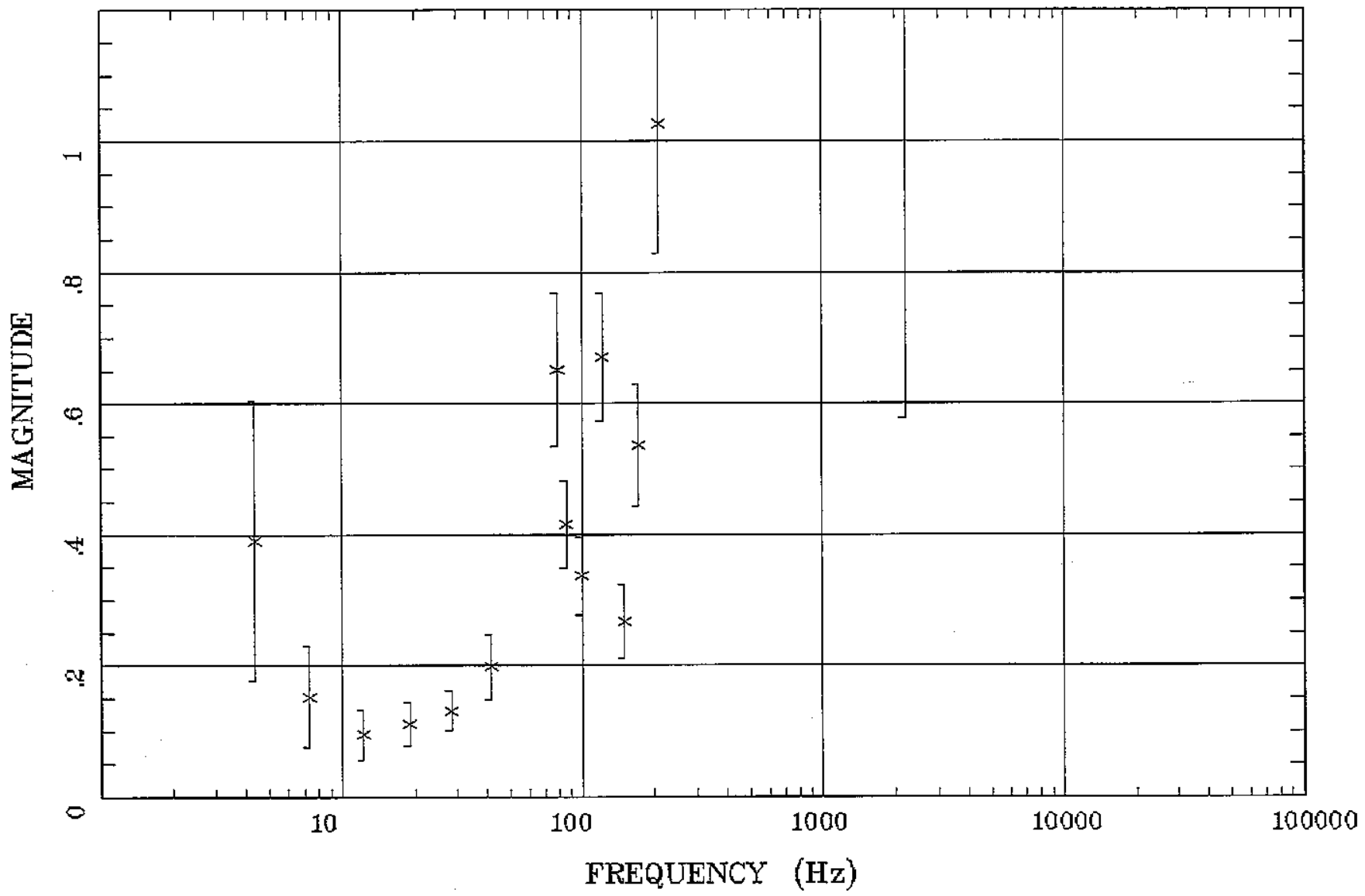

Client:

Remote: none

Acquired: 11:2 Jul 24, 2009

Survey Ca:USGS

Rotation:

Filename: ppoza3.avg

Channels: Ch1 Ch2 Ch3 Ch4 Ch5 Ch3 Ch4 Plotted: 14:54 Jan 06, 2011

< EMI - ElectroMagnetic Instruments 
Station 2

TIPPER STRIKE

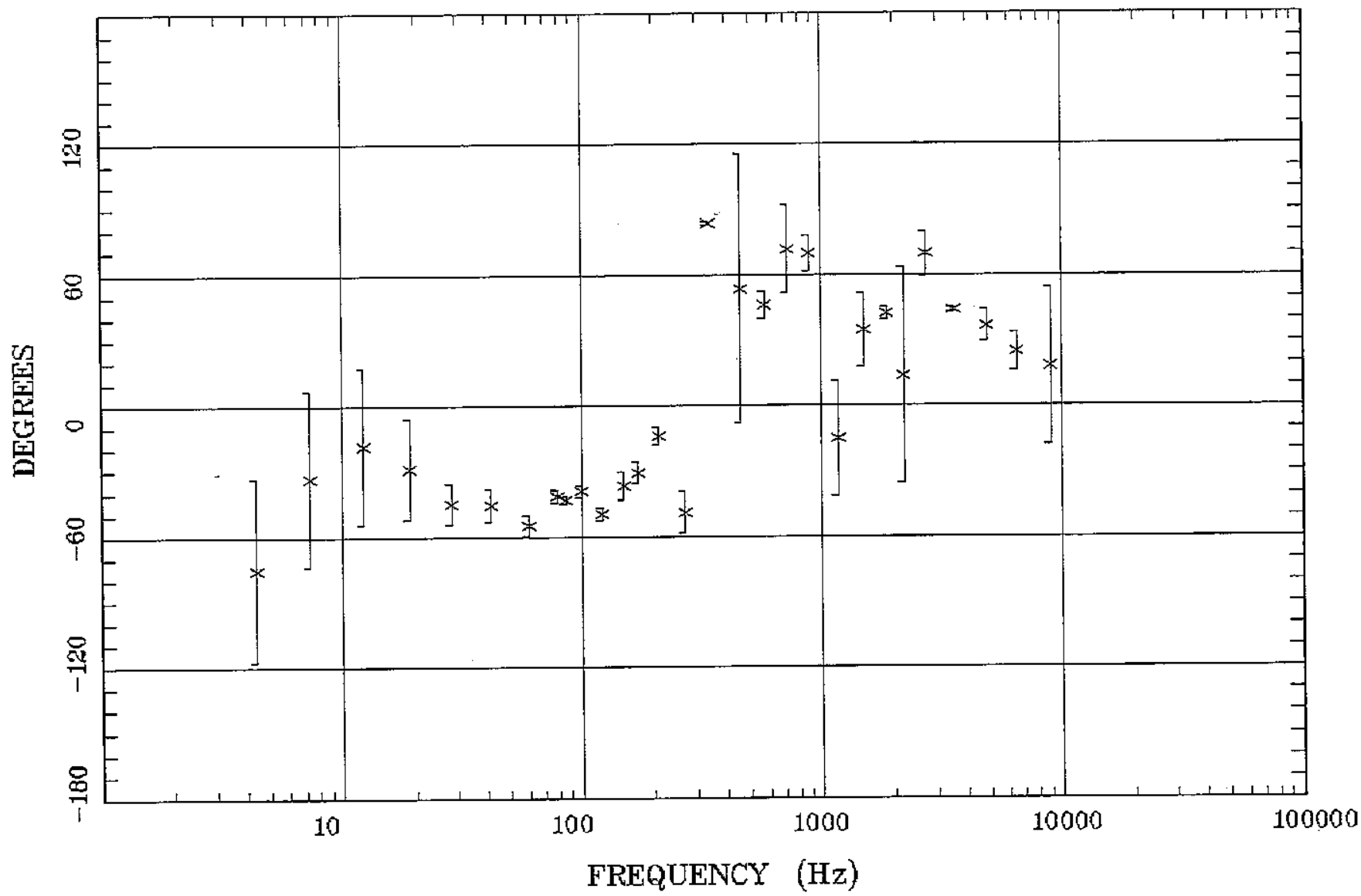

Client:

Remote: none

Acquired: 11:2 Jul 24, 2009

Survey Co:USGS
Wheeler Peak Quad, NM

Rotation:

Filename: rp02a3.avg

Channels: Ch1 Ch2 Ch3 Ch4 Ch5 Ch3 Ch4 Plotted: $14: 54$ Jan 06, 2011

< EMI - ElectroMagnetic Instruments > 


\section{Station 2}

HzHx.x Coh HzHy.o

Wheeler Peak Quad, NM

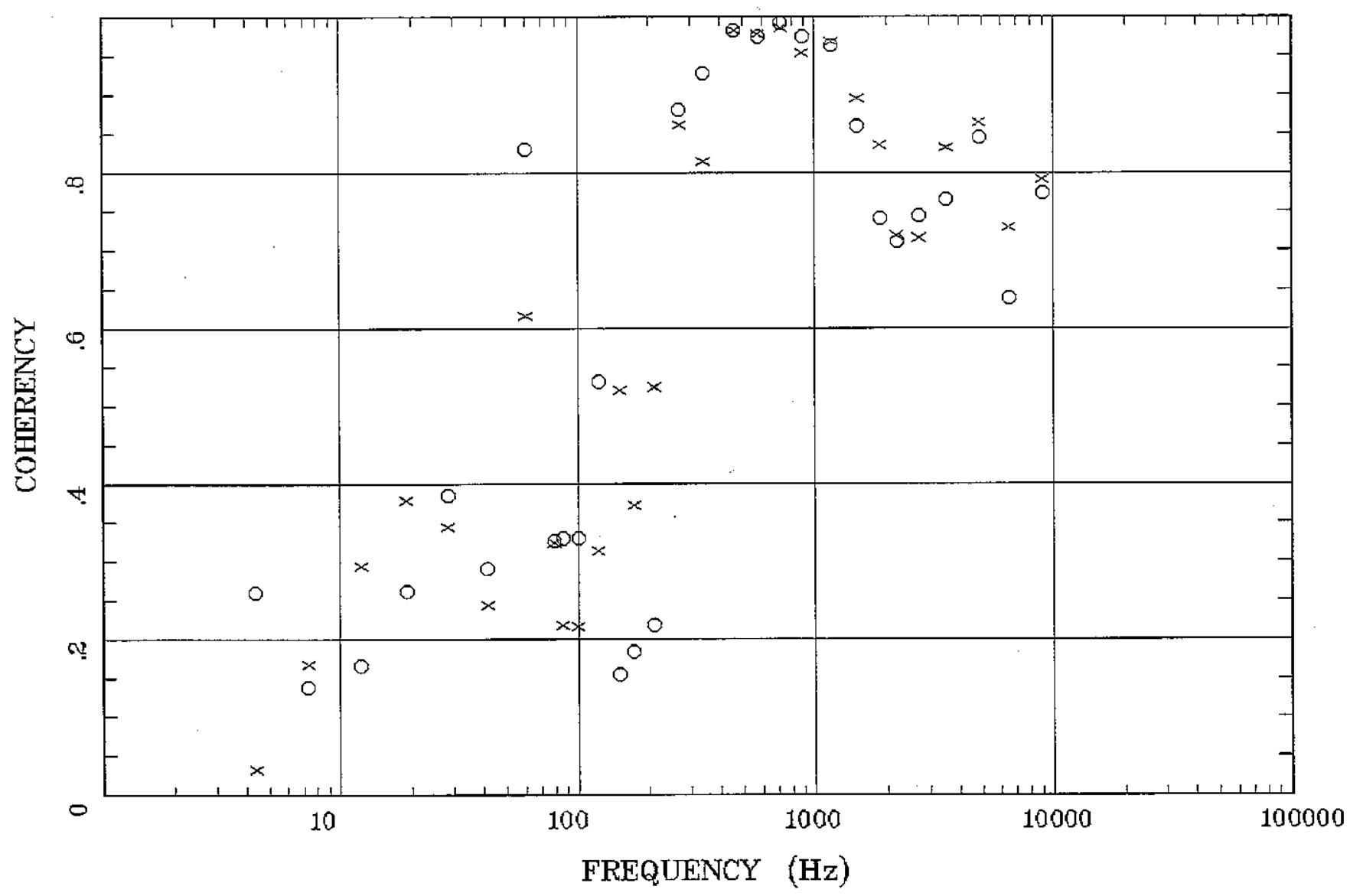

Client:

Remote: none

Acquired: 11:2 Jul 24, 2009

Survey Co:USGS
Rotation:

Filename: wp02a3.arg

Channels: Ch1 Ch2 Ch3 Ch4 Ch5 $\mathrm{Ch} 3 \mathrm{Ch} 4$

Plotted: 14:55 Jan 06, 2011

< EMI - ElectroMagnetic Instruments 
Station 3

APPARENT RESISTIVITY

Wheeler Peak Quad, NM

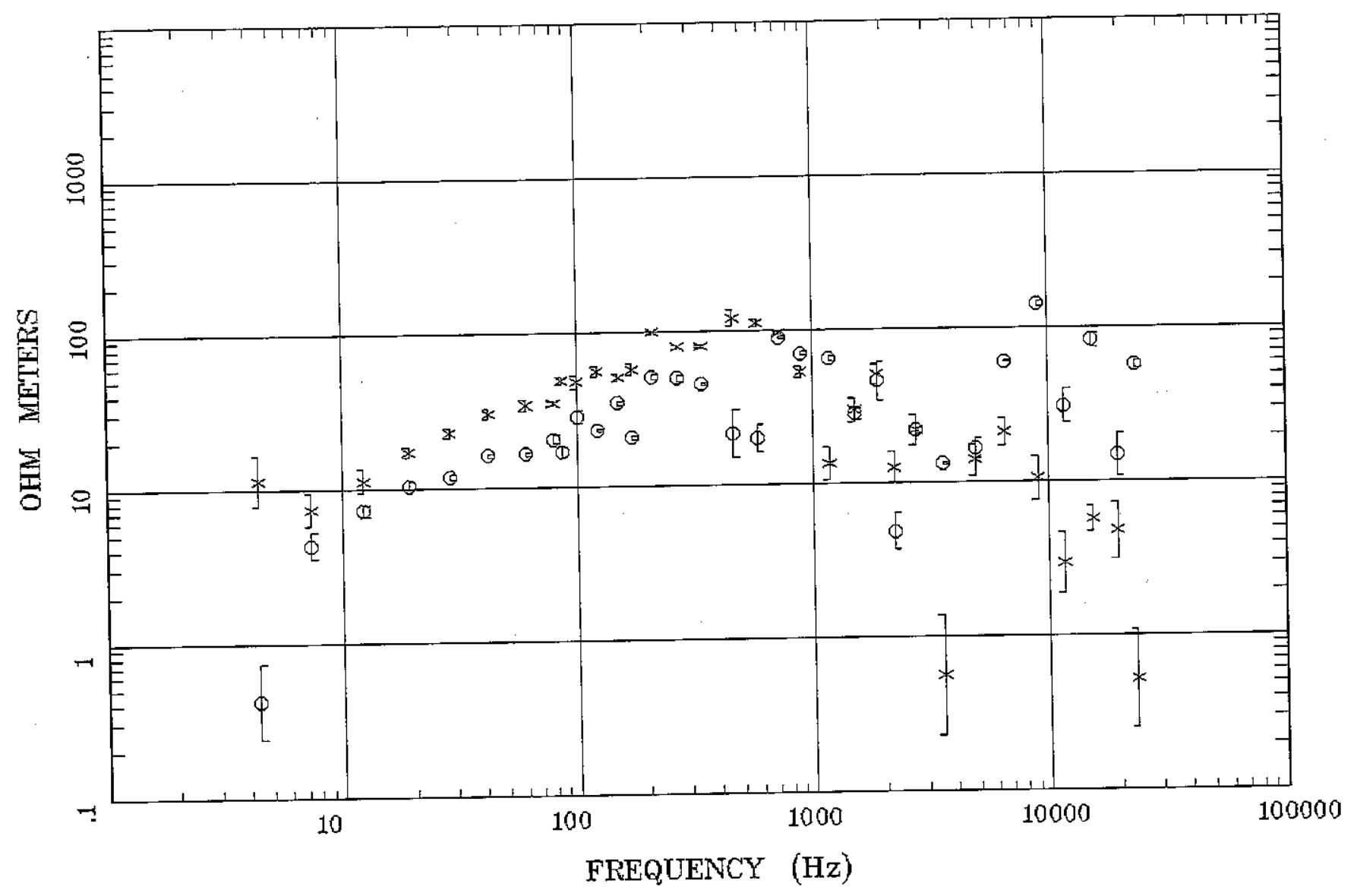

Client:

Remote: none

Acquired: 11:3 Jul 22, 2009

Survey Co:USGS

Rotation:

Filename: Fp03a3.avg

Channels: Ch1 Ch2 Ch3 Ch4 Ch5 Ch3 Ch4

Plotted: 11:00 Dec 03, 2010

< EMI - ElectroMagnetic Instruments > 


\section{Station 3}

IMPEDANCE PHASE

Wheeler Peak Quad, NM

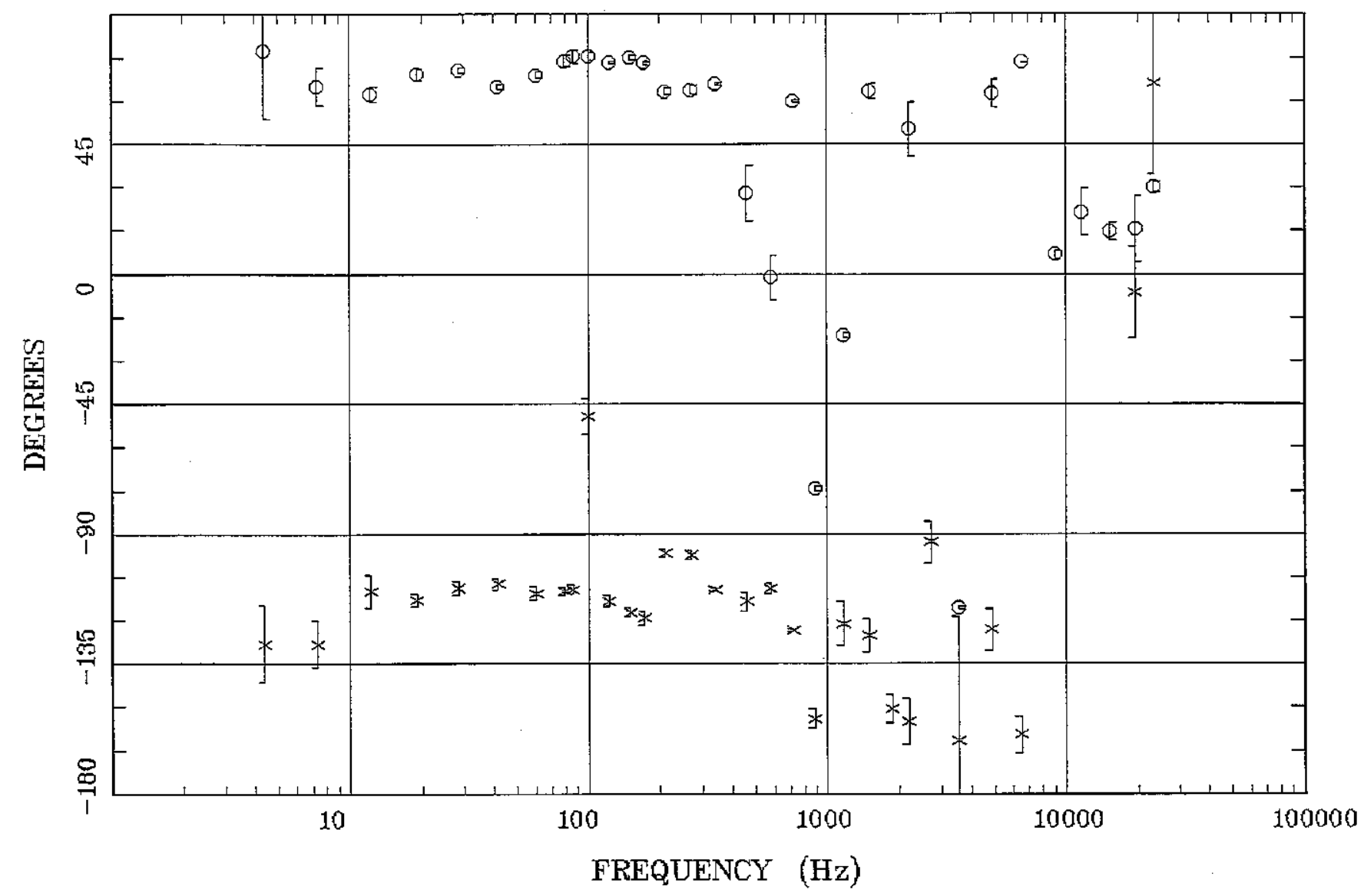

Client:

Remote: none

Acquired: 11:3 Jul 22, 2009

Filename: Fp03a3avg

Channels: Ch1 Ch2 Ch3 Ch4 Ch5 Ch3 Ch4

Plotted: 14:57 Jan 06, 2011

Survey Co:USGS

< EMI - ElectroMagnetic Instruments > 
Station 3

IMPEDANCE SKEW Wheeler Peak Quad, NM

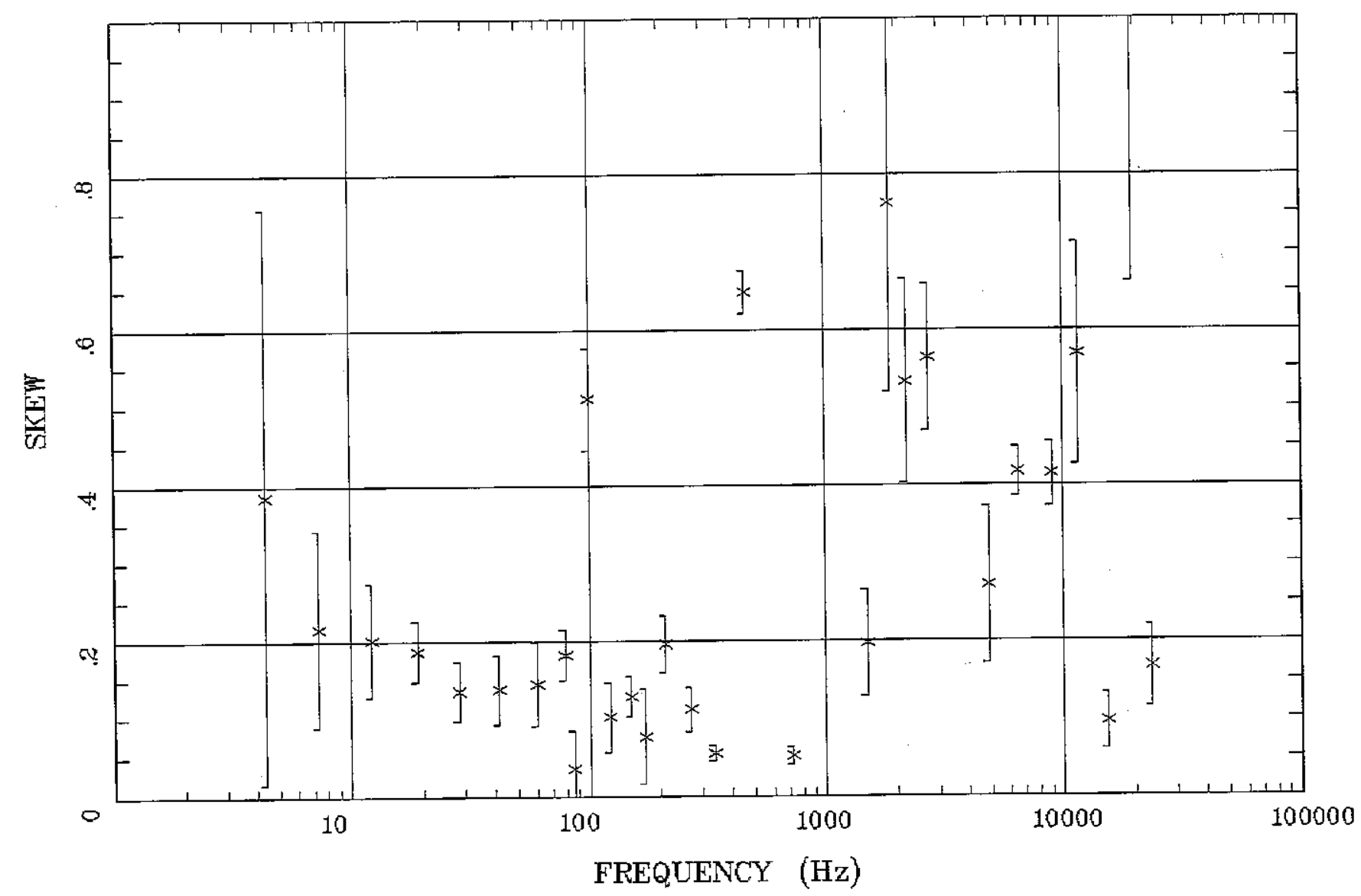

Client:

Remote: none

Acquired: 11:3 Jul 22, 2009

Survey Co:USGS

Rotation:

Filename: p03a3.apg

Channels: Ch1 Ch2 Ch3 Ch4 Ch5 Ch3 Ch4

Plotted: 11:00 Dec 03, 2010

< EMT - ElectroMagnetic Instruments > 
Station 3

E MULT Coh.

Wheeler Peak Quad, NM

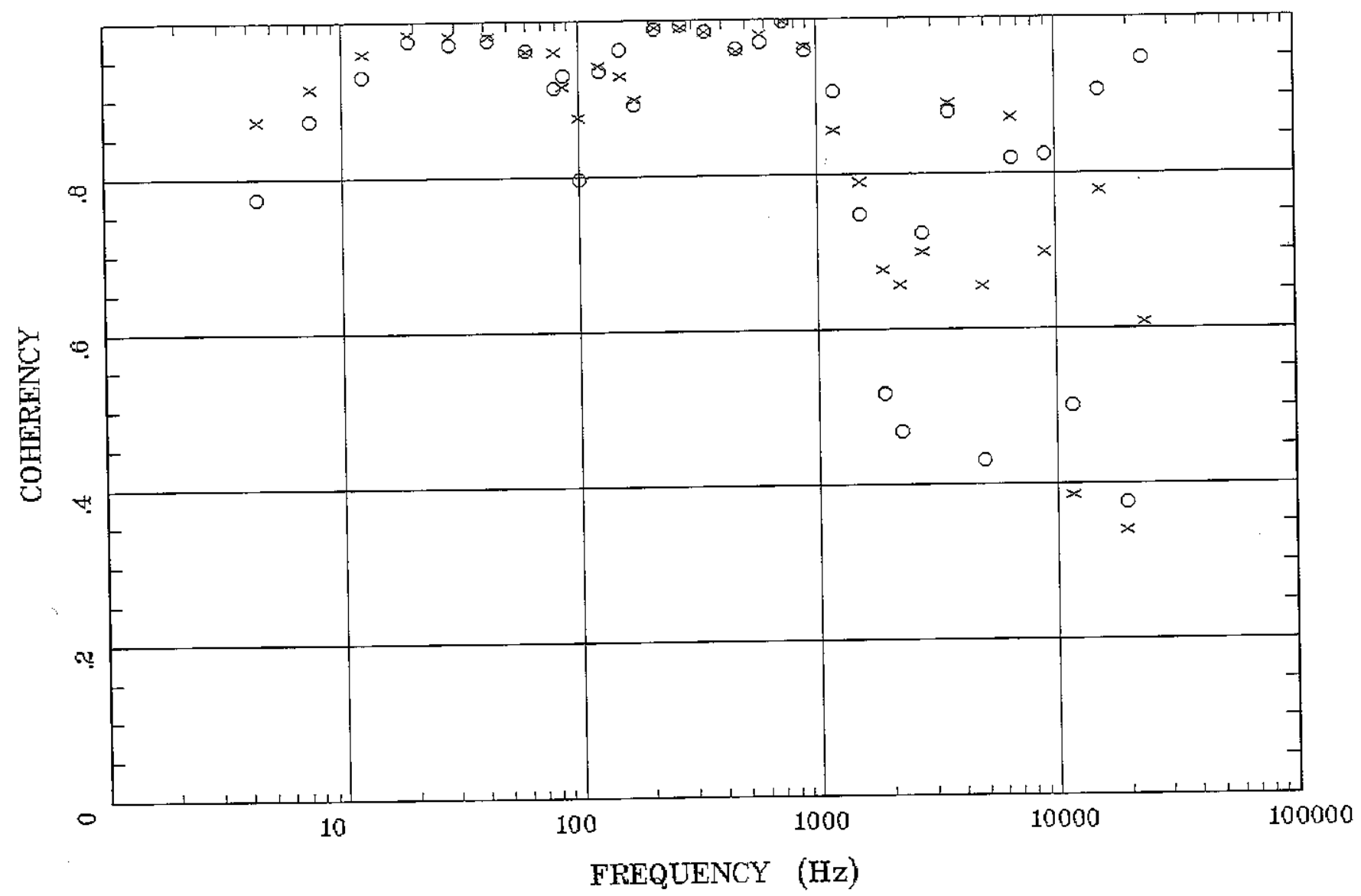

Client:

Rotation:

Filename: wp03a3.avg

Remote: none

Acquired: 11:3 Jul 22, 2009

Channels: Ch1 Ch2 Ch3 Ch4 Ch5 Ch3 Ch4

Plotted: 11:00 Dec 03, 2010

Survey Co:USGS

< EMI - ElectroMagnetic Instruments 
Station 3

POLAR PLOTS

Wheeler Peak Quad, NM

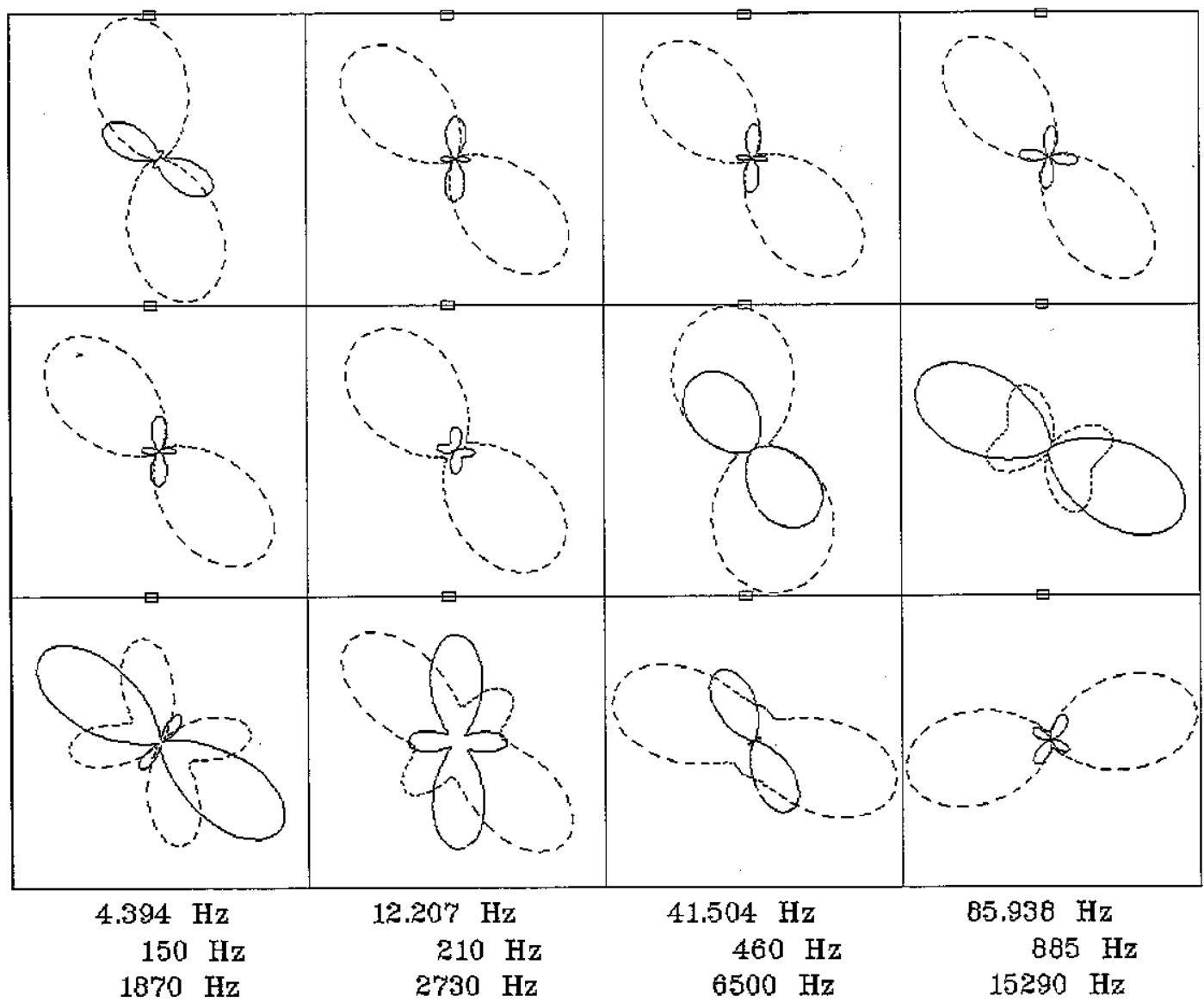

Client:

Remote: none

Acquired: 11:3 Jul 22, 2009 Survey Co:USGS

Rotation:

Filename: Tp03a3.avg

Channels: Ch1 Ch2 Ch3 Ch4 $4^{5} \mathrm{Ch} 5$ Ch3 Ch4

Platted: 14:56 Jan 06, 2011

$<$ EMI - ElectroMagnetic Instruments > 


\section{Station 3}

TIPPER MAGNITUDE

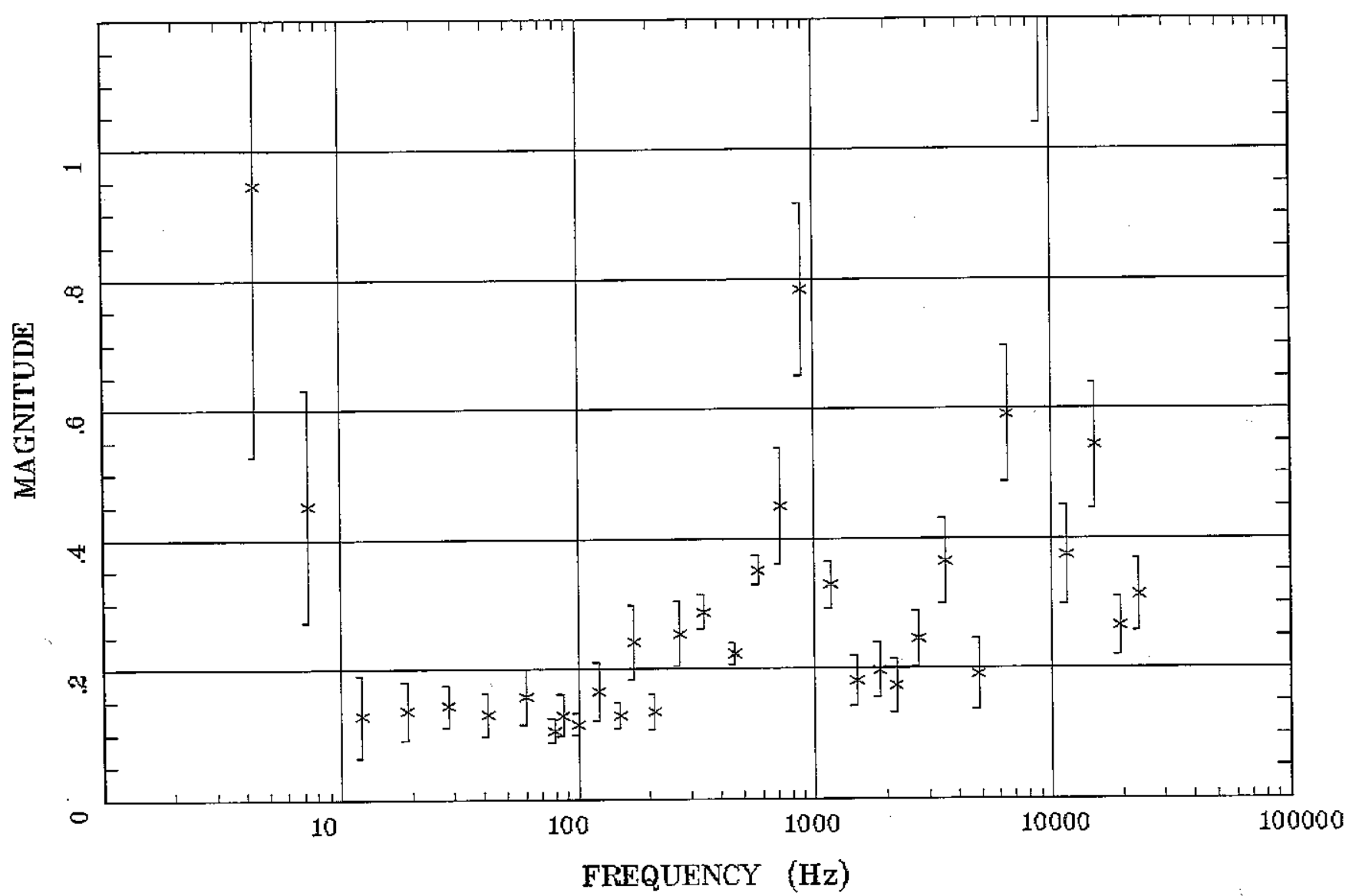

Client:

Remote: none

Acquired: 11:3 Jul 22, 2009

Survey Co:USGS
Rotation:

Filename: Fp3a3.avg

Channels: Ch1 Ch2 Ch3 Ch4 Ch5 Ch3 Ch4

Plotted: 15:39 Jan 06, 2011

< EMI - ElectroMagnetic Instruments > 
Station 3

TIPPER STRIKE

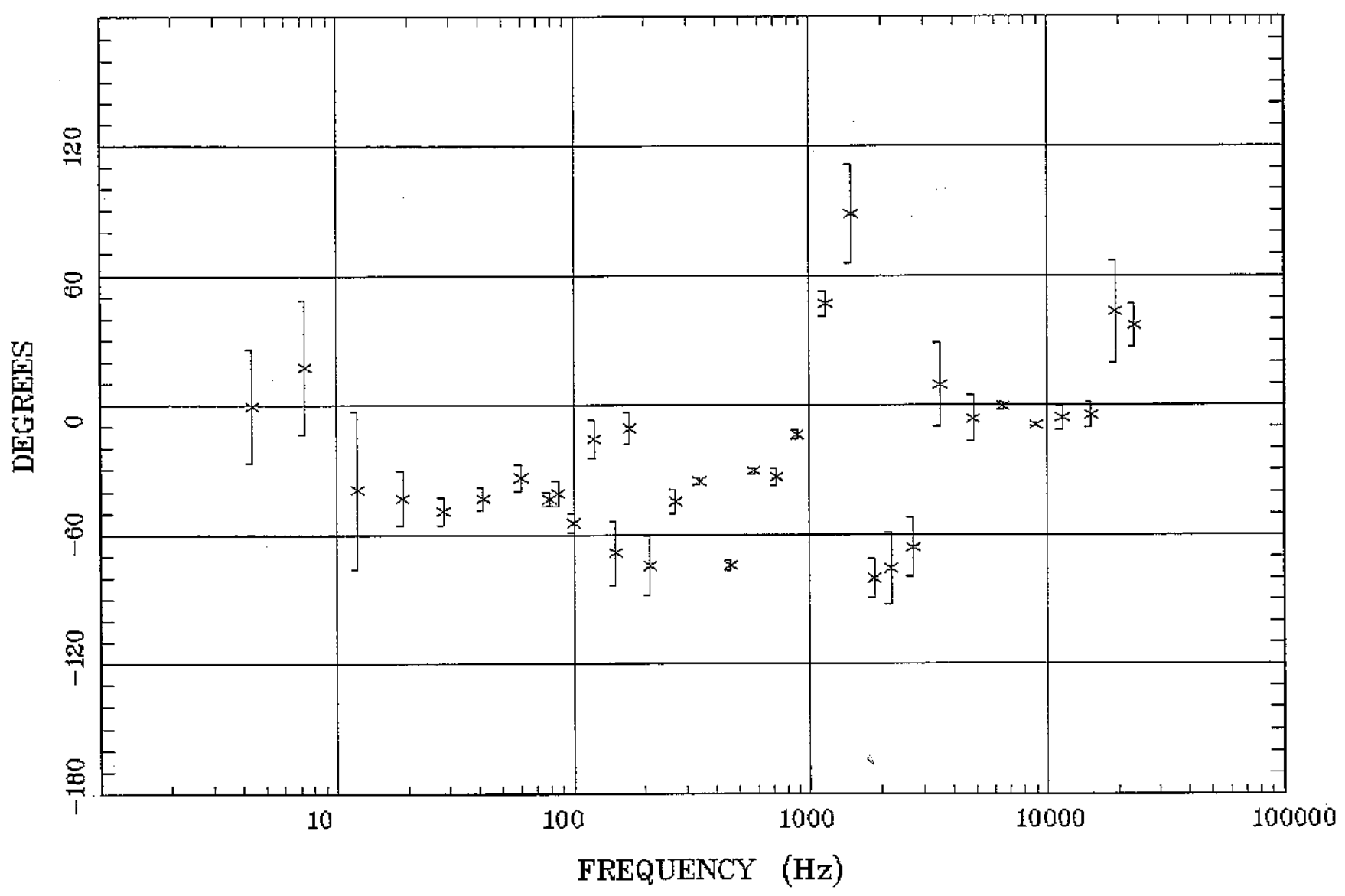

Rotation:

Client:

Remote: none

Acquired: 11:3 Jul 22, 2009

Survey Co:USGS
Filename: wp03a3.avg

Channels: Ch1 Ch2 Ch3 Ch4 Ch5 Ch3 Ch4

Plotted: 15:39 Jan 06, 2011

< EMI - ElectroMagnetic Instruments > 


\section{Station 3}

$\mathrm{HzHx} . \mathrm{Coh} \mathrm{HzHy.O}$

Wheeler Peak Quad, NM

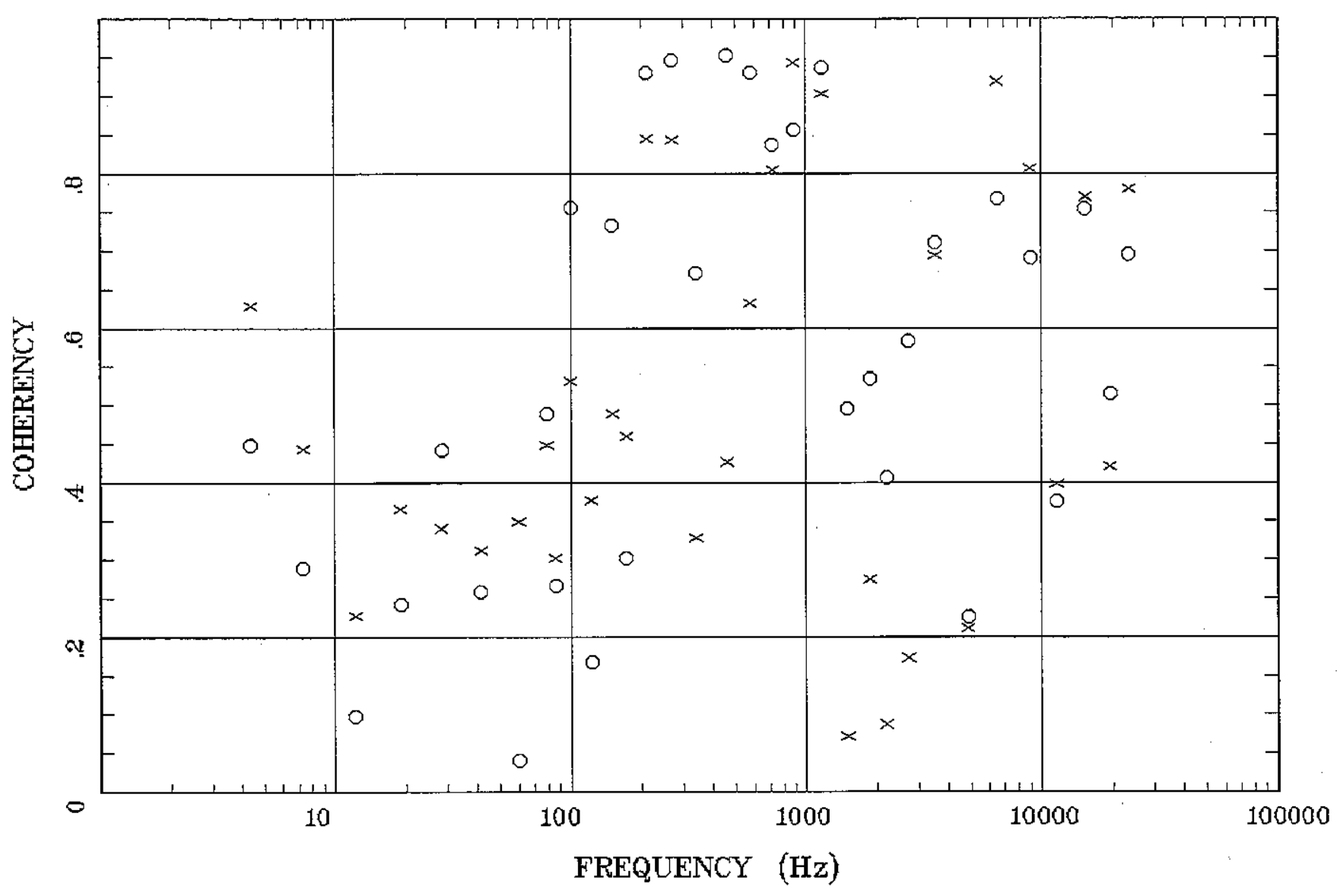

Client:

Remote: none

Acquired: 11:3 Jul 22, 2009 Survey Co:USGS
Rotation:

Filename: "p03a3.avg

Channels: Ch1 Ch2 Ch3 Ch4 Ch5 Ch3 Ch4

Plotted: 15:39 Jan 06, 2011

< EMI - ElectroMagnetic Instruments 


\section{Station 4}

APPARENT RESISTIVITY

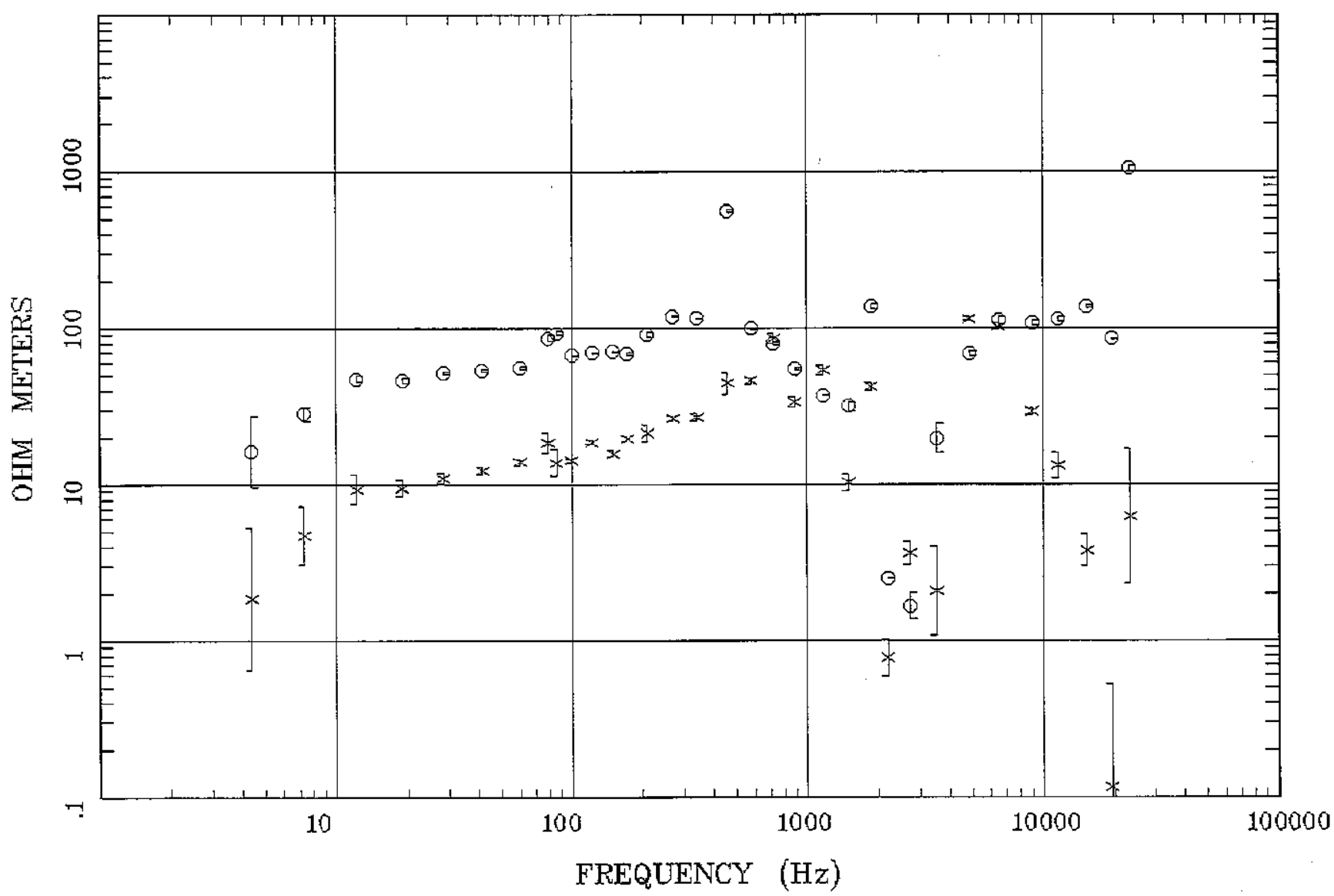

Client:

Remote: none

Acquired: 12:4 Jul 25, 2009 Survey Co:USGS
Rotation:

Filename: fop 04a4.avg

Channels: Ch1 Ch2 Ch3 Ch4 Ch5 Ch3 Ch4

Plotted: 15:10 Jan 04, 2011

< EMI - ElectroMagnetic Instruments > 


\section{Station 4}

\section{IMPEDANCE PHASE}

Wheeler Peak Quad, NM

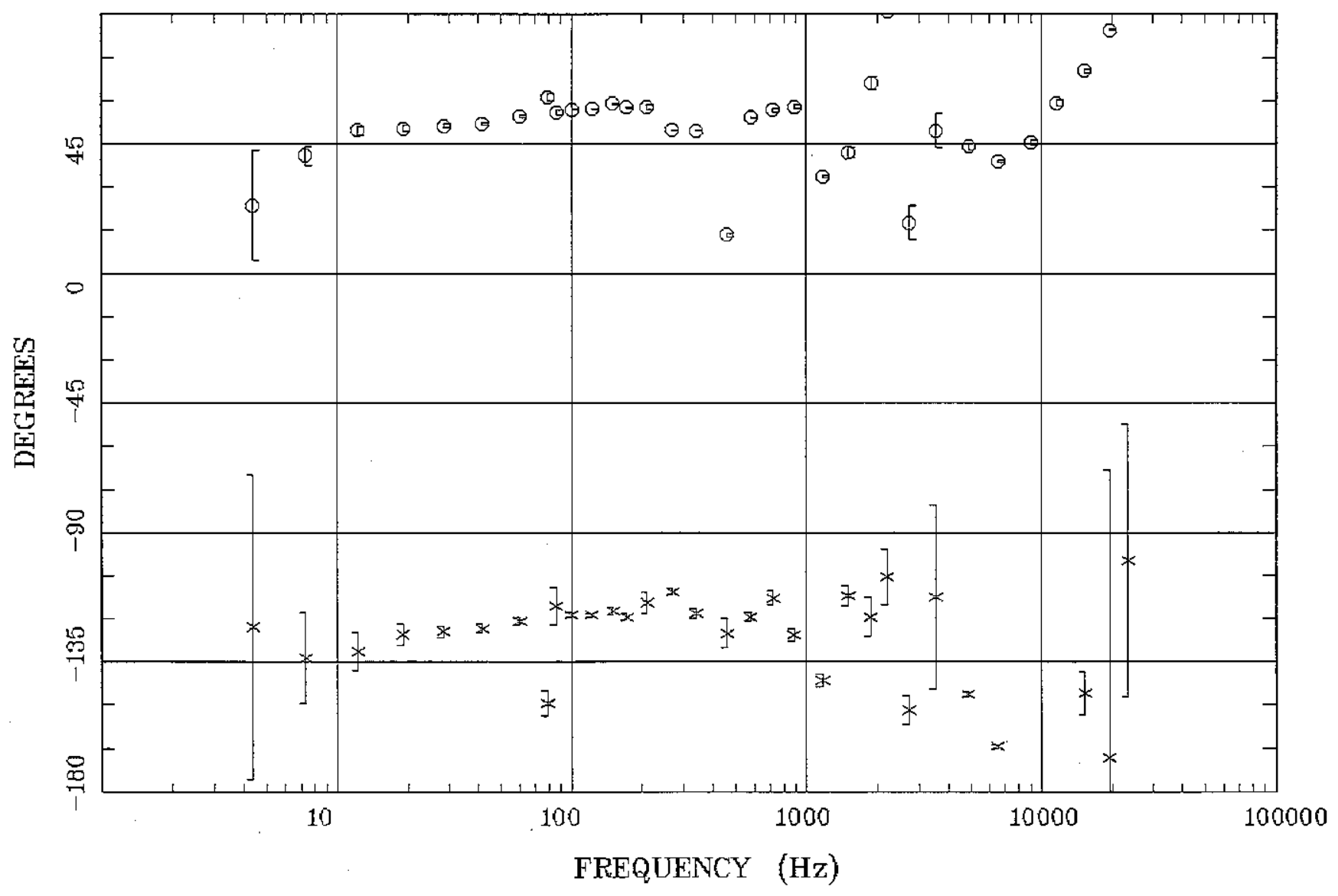

\section{Client:}

Remote: none

Acquired: 12:4 Jul 25, 2009 Survey Co:USGS
Rotation:

Filename: wp04a4,avg

Channels: Ch1 Ch2 Ch3 Ch4 Ch5 Ch3 Ch4

Plotted: 15:10 Jan 04, 2011

< EMI - ElectroMagnetic Instruments > 


\section{Station 4}

IMPEDANCE SKEW

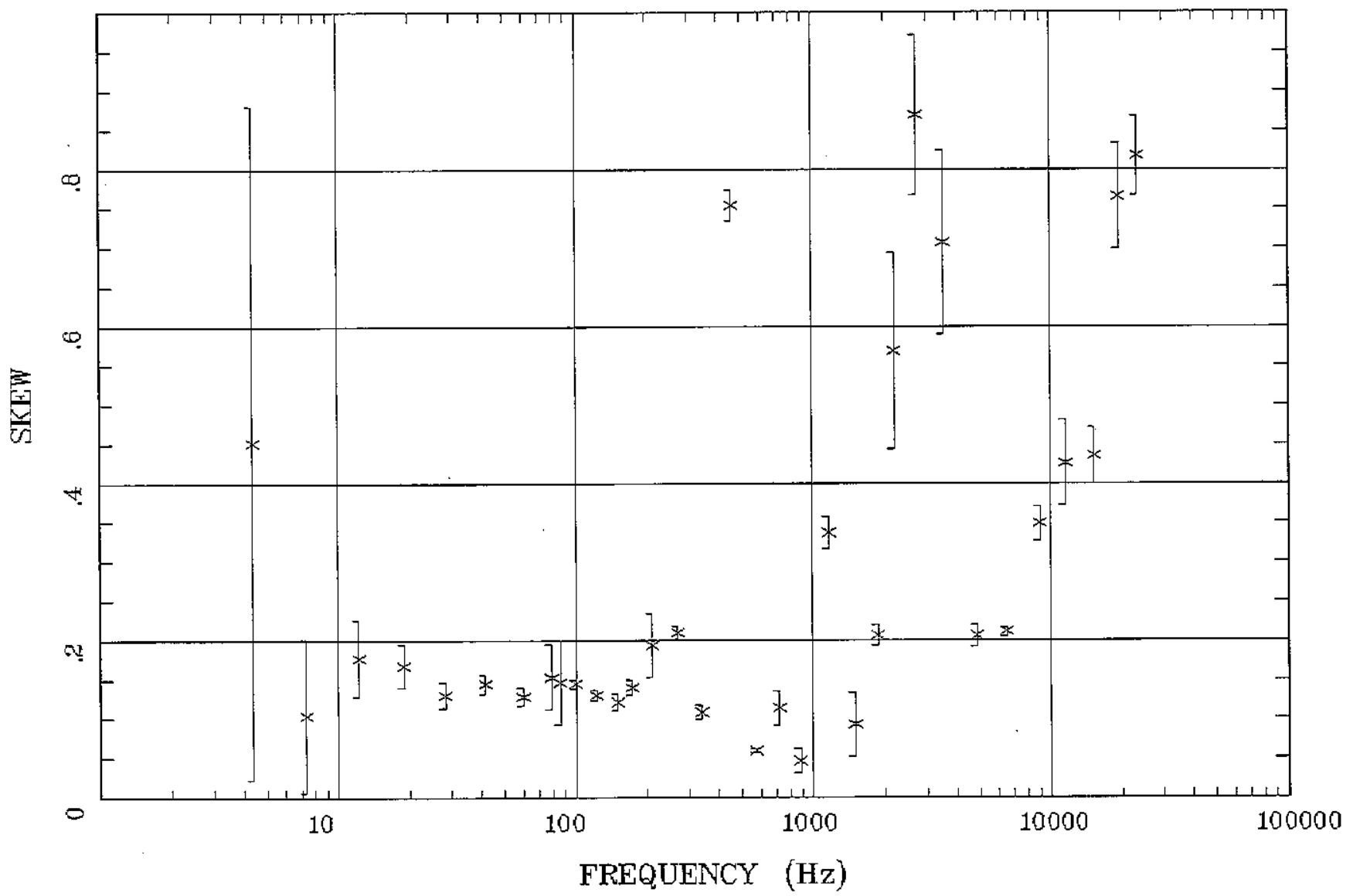

Client:

Remote: none

Acquired: 12:4 Jul 25, 2009

Survey Co:USGS
Rotation:

Filename: wp 04 a4.avg

Channels: $\mathrm{Ch} 1 \mathrm{Ch} 2 \mathrm{Ch} 3$ Ch 4 Ch5 $\mathrm{Ch} 3 \mathrm{Ch} 4$

Plotted: 15:10 Jan 04, 2011

< EMI - ElectroMagnetic Instruments 


\section{Station 4}

E MULT Coh.

Wheeler Peak Quad, NM

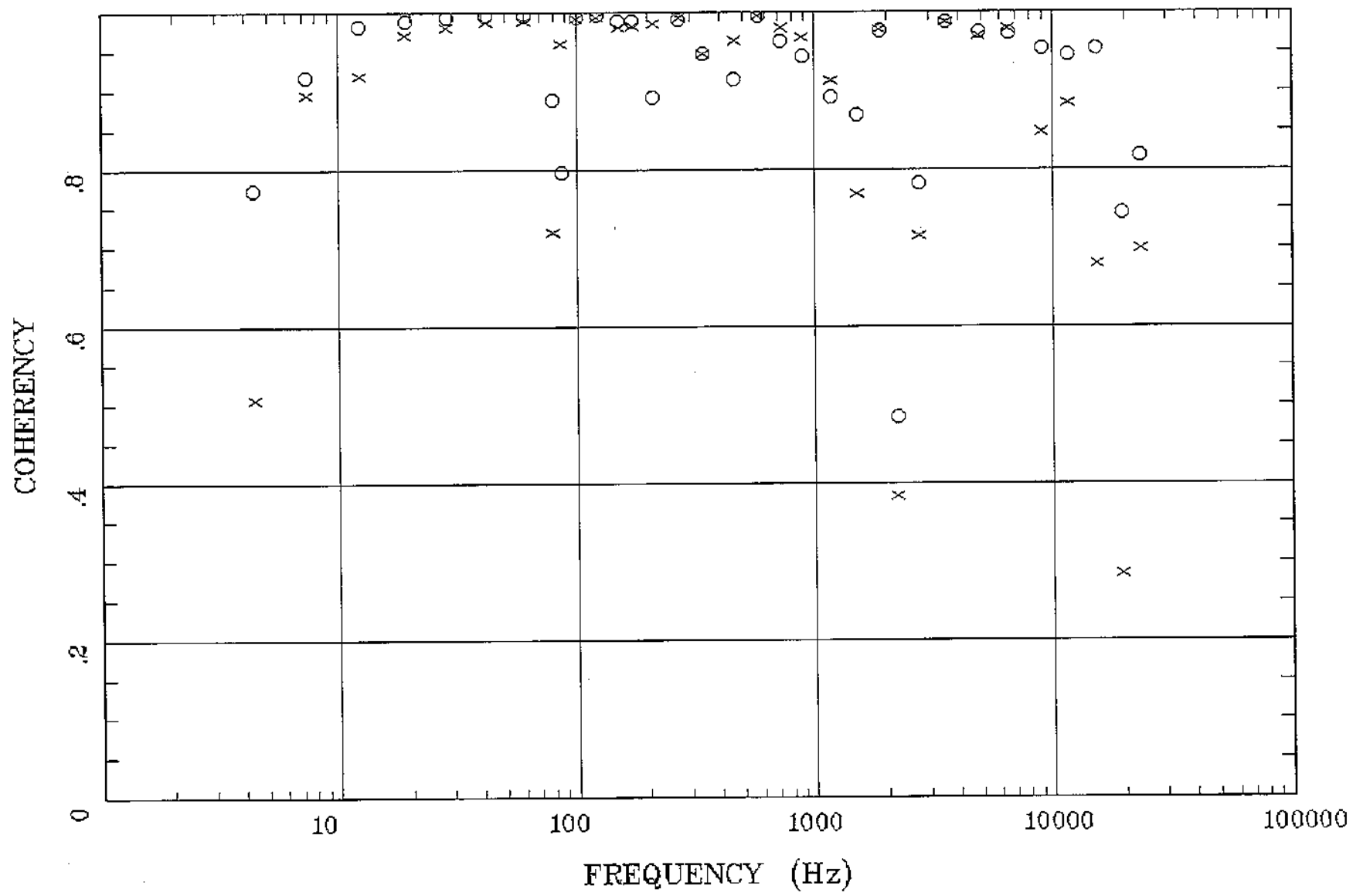

Client:

Remote: none

Acquired: 12:4 Jul 25, 2009

Survey Co:USGS

Rotation:

Filename: Fp04a4.apg

Channels: 'Ch1 Ch2 Ch3 Ch4 Ch5 Ch3 Ch4

Plotted: 15:10 Jan .04, 2011

< EMI - ElectroMagnetic Instruments 
Station 4

POLAR PLOTS

Wheeler Peak Quad, NM

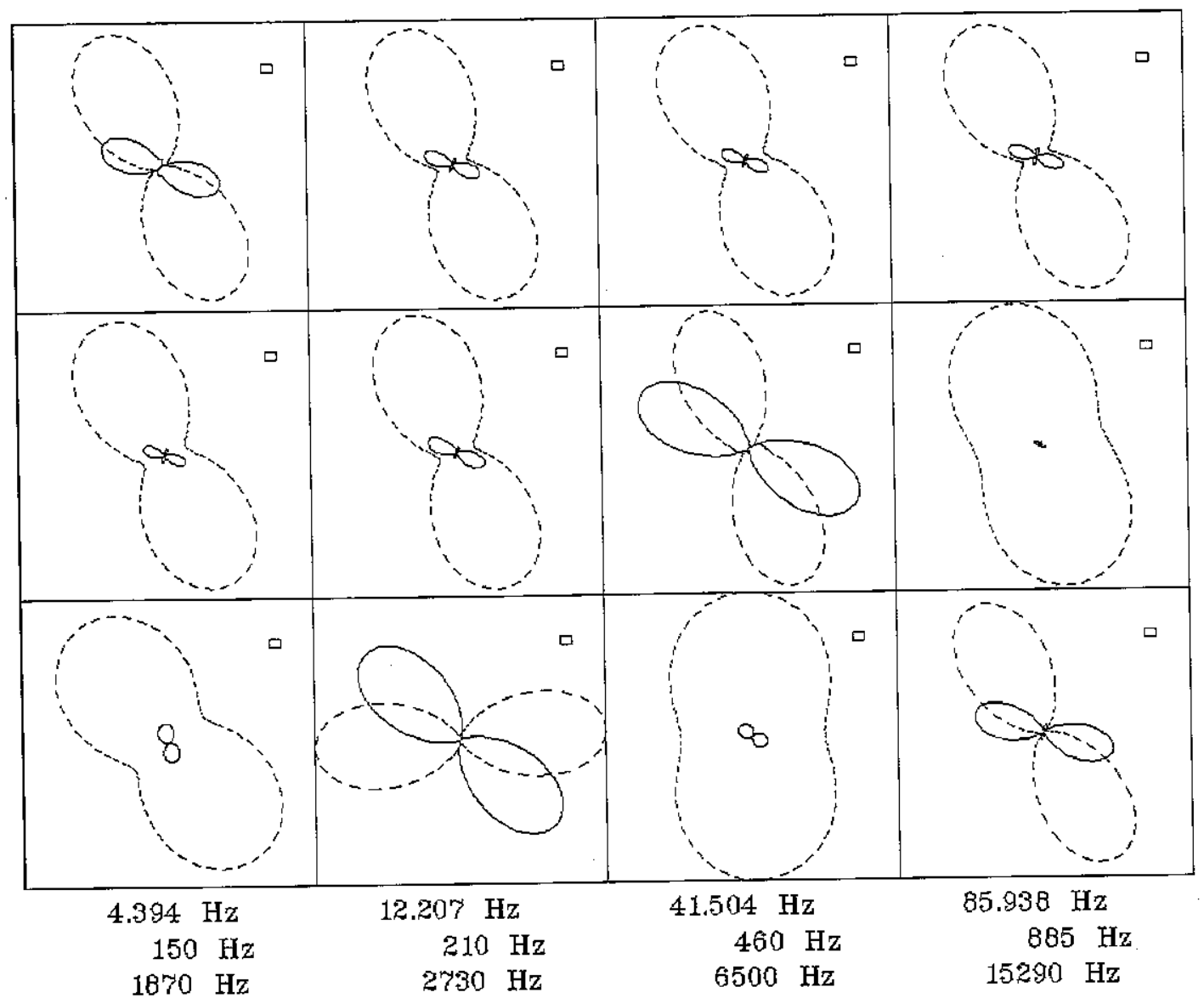

Rotation:

Client:

Remote: none

Acquired: 12:4 Jul 25, 2009

Filename: \$p04a4.avg

Channels: Ch1 Ch2 Ch3 Ch4 Ch5 Ch3 Ch4

Plotted: 15:11 Jan 04, 2011

Survey Co:USGS

< EMI - ElectroMagnetic Instruments 


\section{Station 4}

TIPPER MAGNITUDE

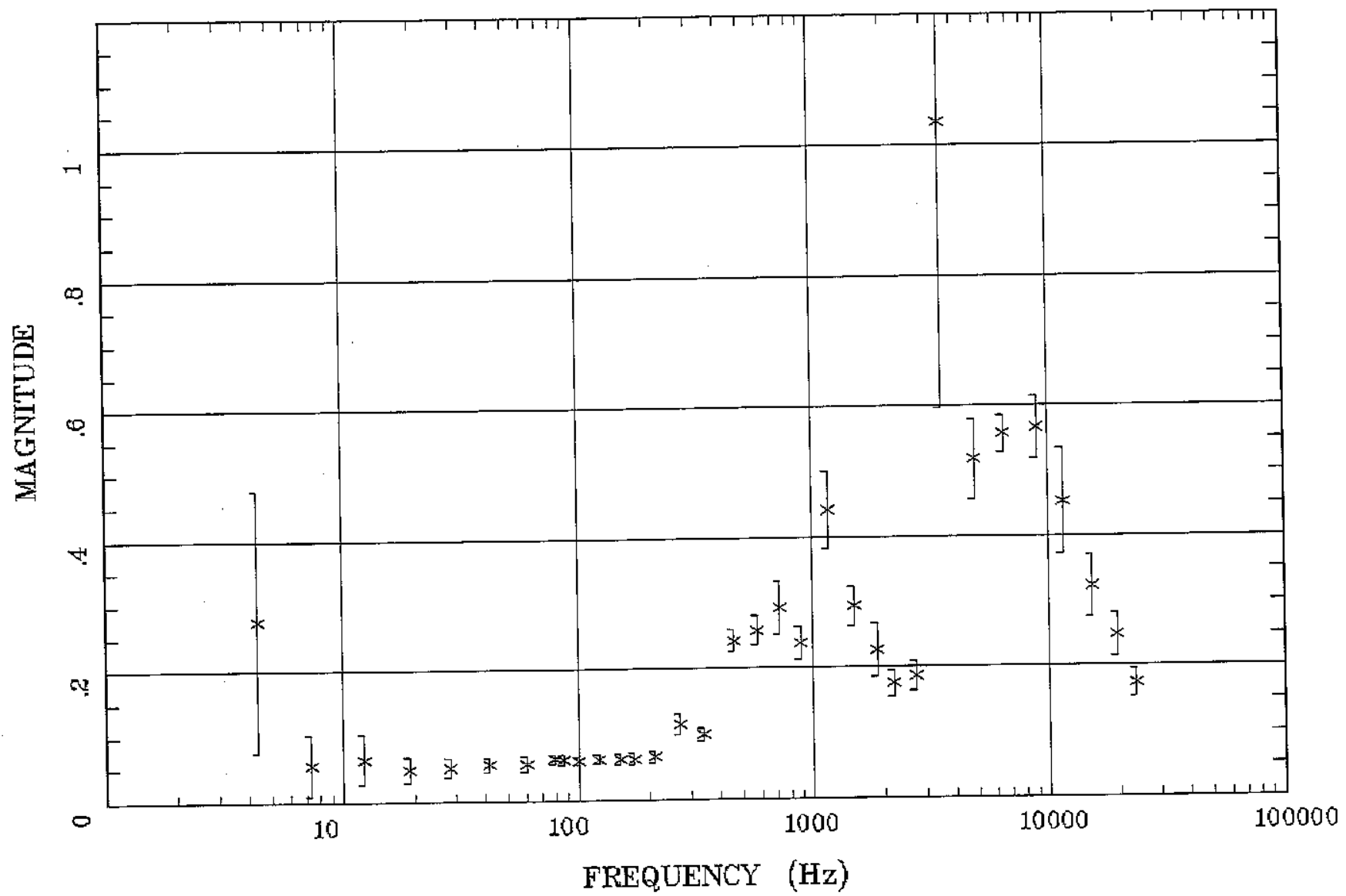

Client:

Remate: none

Acquired: 12:4 Jul 25, 2009

Survey Co:USGS
Rotation:

Filename: Folatavg

Chennels: Ch1 Ch2 Ch3 Ch4 Ch5 Ch3 Ch4 Plotted: 08:24 Jan 05, 2011

< EMI - ElectroMagnetic Instruments > 


\section{Station 4}

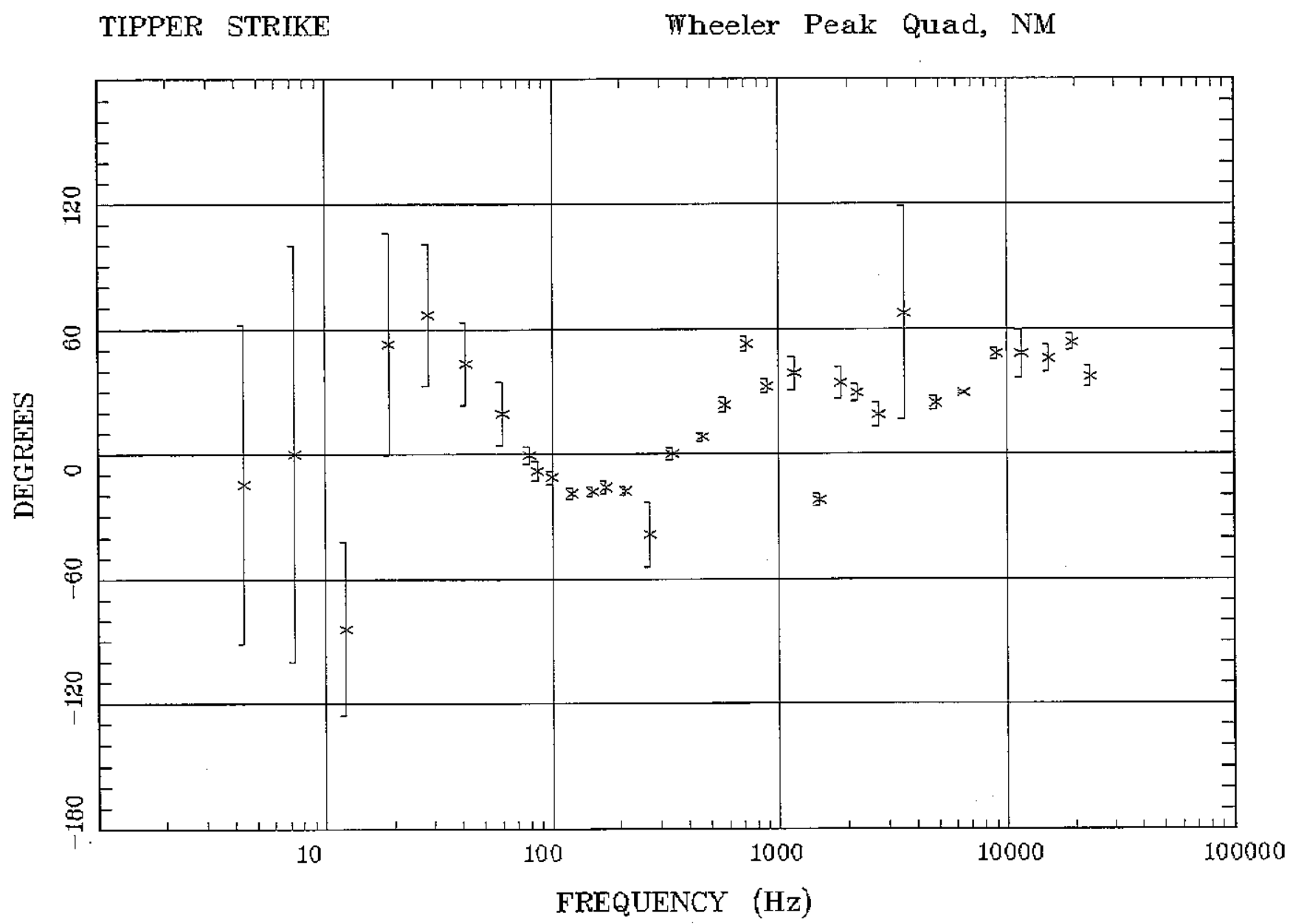

\section{Client:}

Remote: none

Acquired: 12:4 Jul 25, 2009

Survey Co:USGS
Rotation:

Filename: ppo4a4.avg

Channels: Ch1 Ch2 Ch3 Ch4 Ch5 Ch3 Ch4

Plotted: 08:38 Jan 05, 2011

< EMI - ElectroMagnetic Instruments > 
Station 4

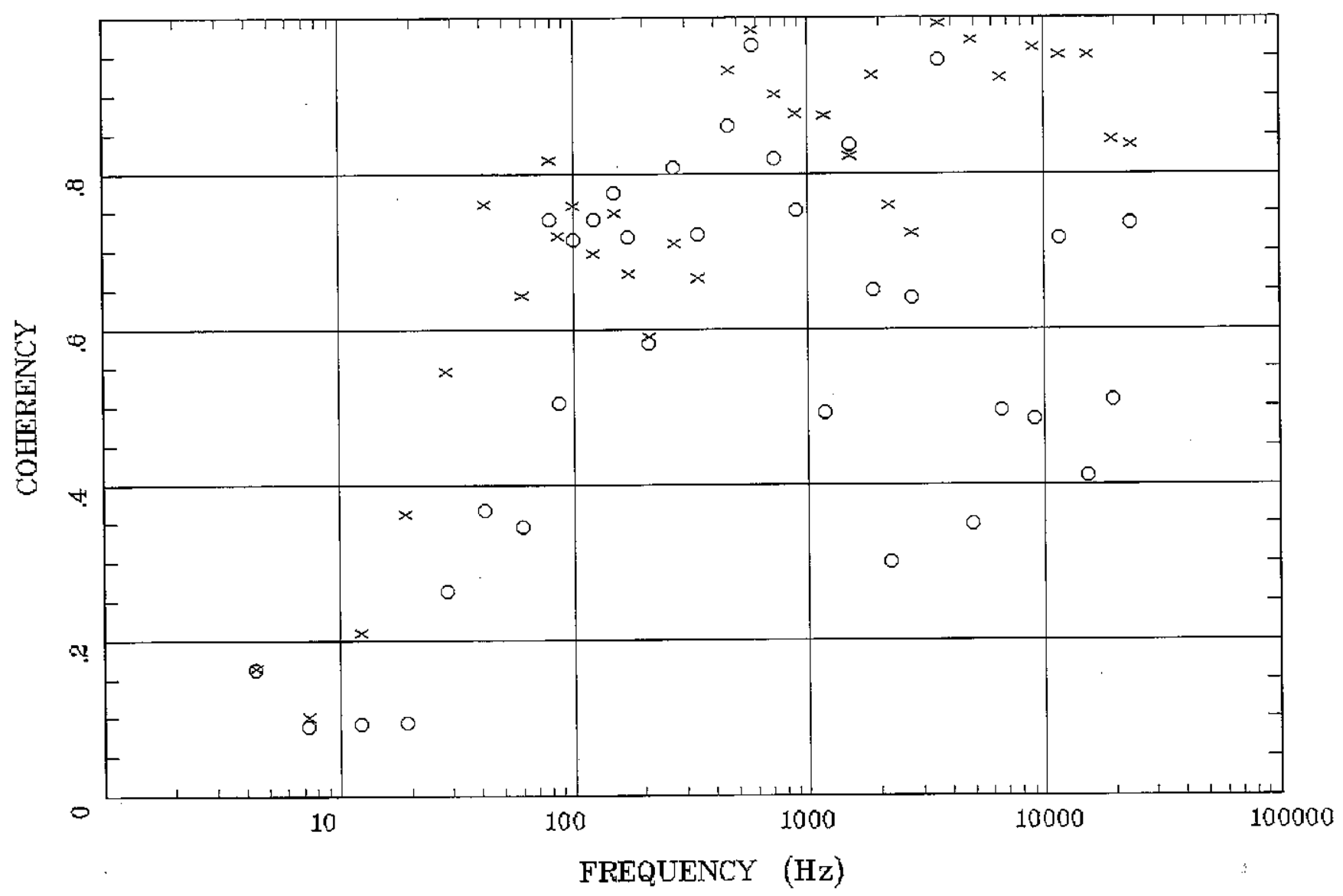

Client:

Remote: none

Acquired: 12:4 Jul 25, 2009 Survey Co:USGS

\section{Rotation:}

Filename: p04a4,avg

Channels: Ch1 Ch2 Ch3 Ch4 Ch5 Ch3 Ch4

Plotted: 12:13 Jan 21, 2011

< EMI - ElectroMagnetic Instruments > 
Station 5

Wheeler Peak Quad, NM

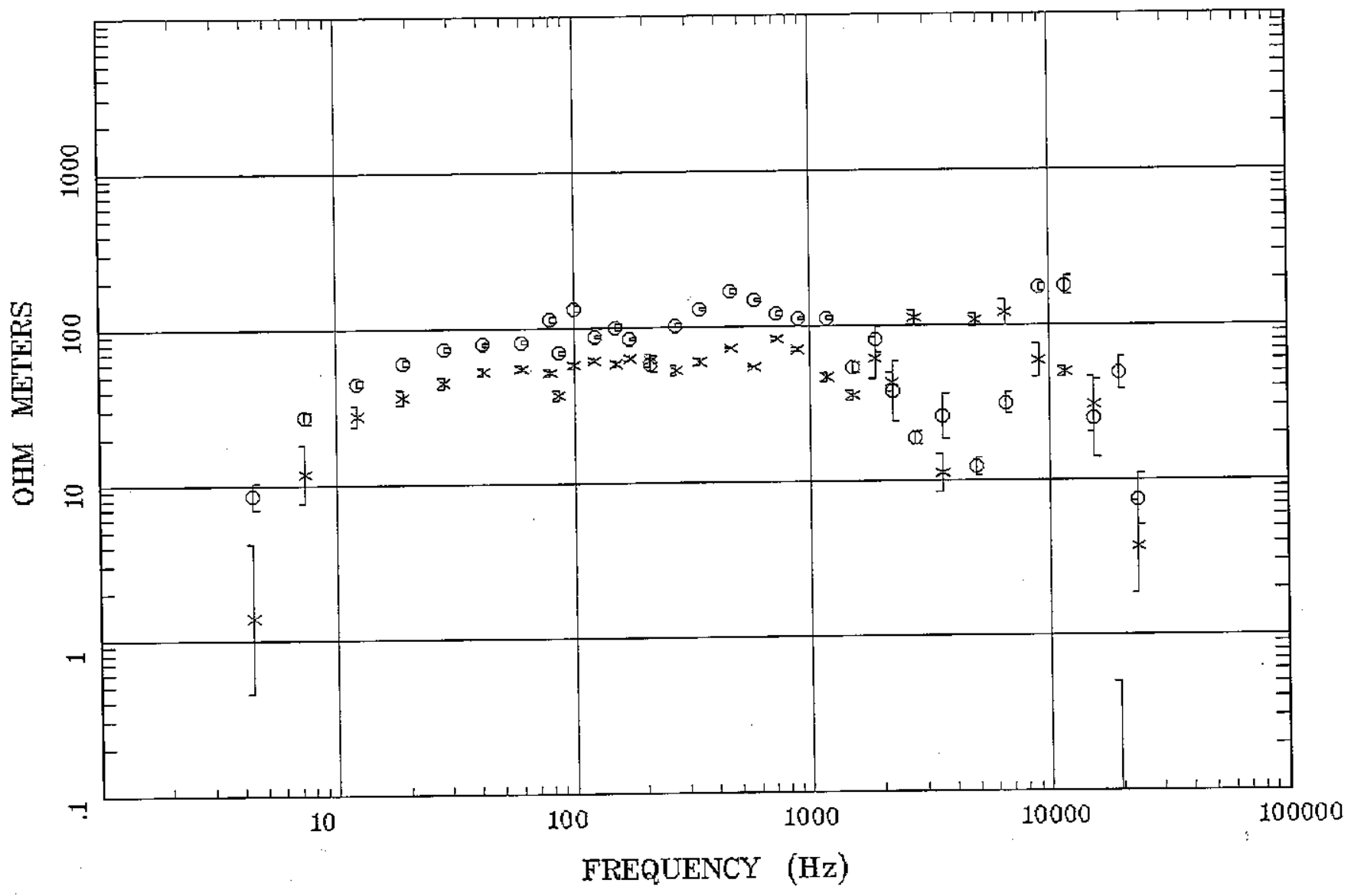

Client:

Remote: none

Acquired: 14:2 Jul 23, 2009

Survey Co:USGS
Rotation:

Filename: Fp05a3.avg

Channels: Ch1 Ch2 Ch3 Ch4 Ch5 Ch3 Ch4 Plotted: 15:59 Dec 03, 2010

< EMI - ElectroMagnetic Instruments > 
Station 5

IMPEDANCE PHASE Wheeler Peak quad, NM

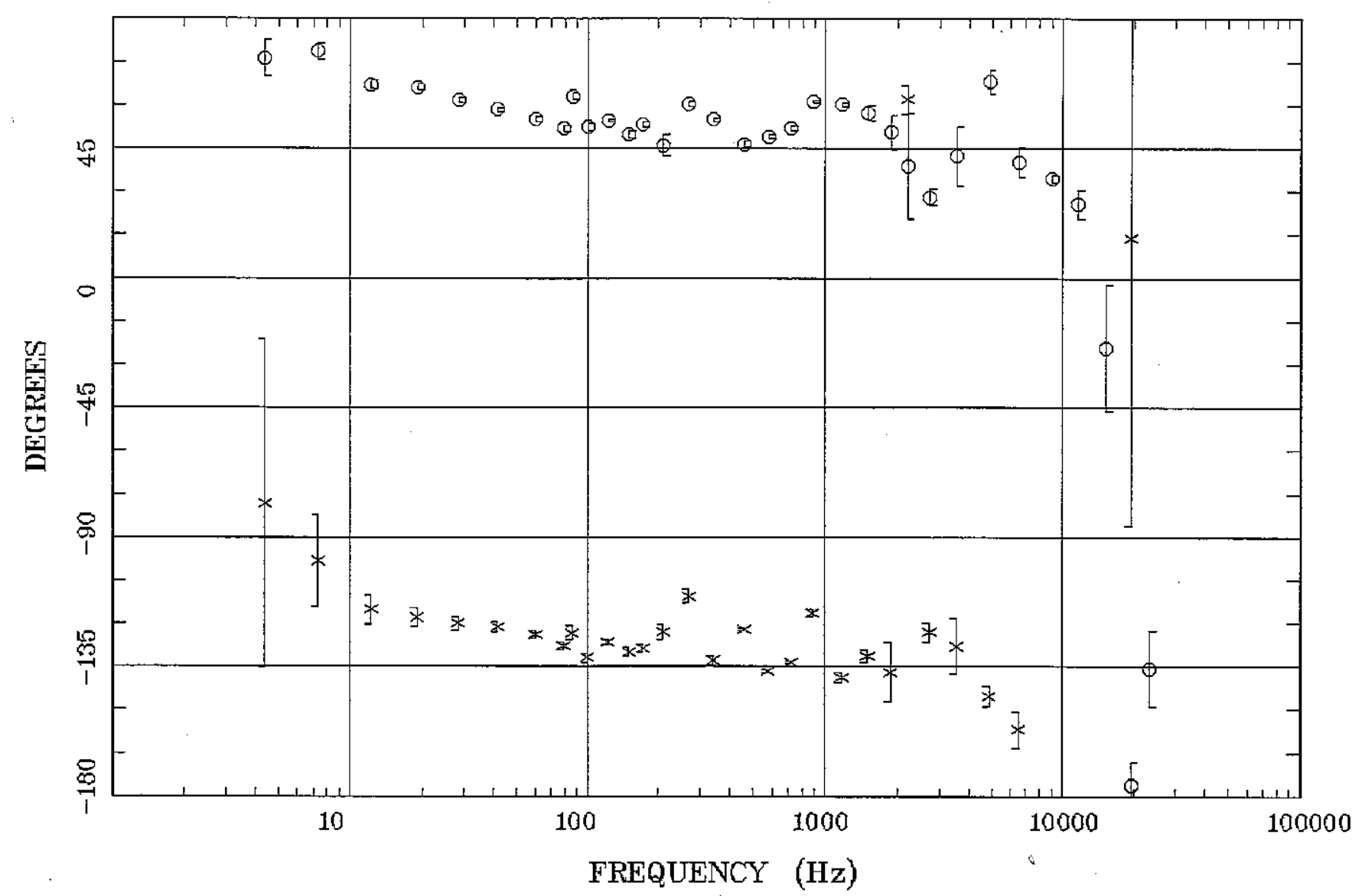

Client:

Rotation:

Remote: none

Acquired: 14:2 Jul 23, 2009

Survey Co:USGS

Filename: $05 a 3 . a v g$

Channels: Ch1 Ch2 Ch3 Ch4 Ch5 Ch3 Ch4

Plotted: 15:00 Jan 06, 2011

< EMI - ElectroMagnetic Instruments > 
Station 5

IMPEDANCE SKEW

Wheeler Peak Quad, NM

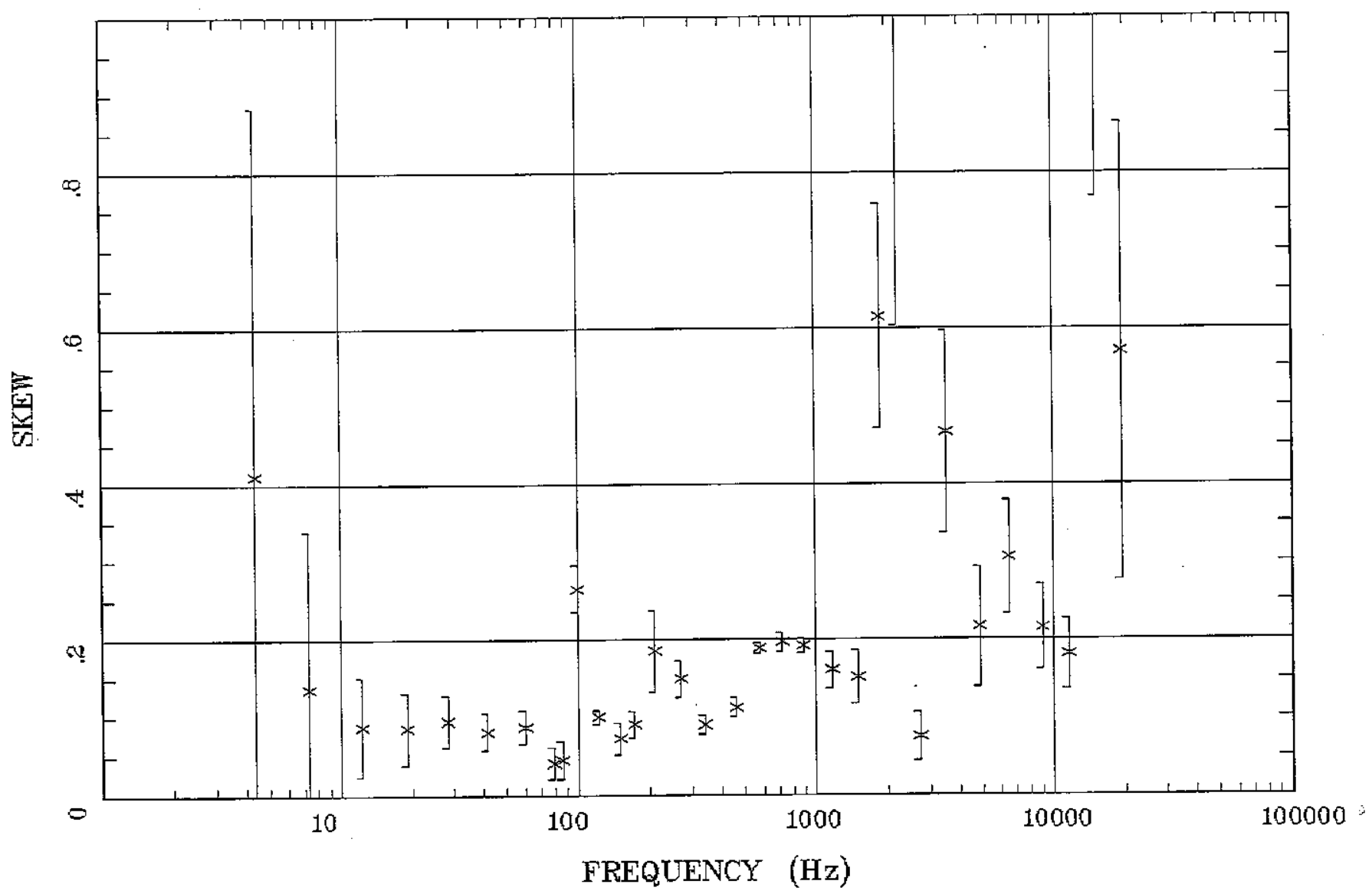

Client:

Remate: none

Acquired: 14:2 Jul 23, 2009

Survey Co:USGS

Ratation:

Filename: wp05a3.avg

Channels: Ch1 Ch2 Ch3 Ch4 Ch5 Ch3 Ch4

Plotted: 16:00 Dec 03, 2010

< EMI - ElectroMagnetic Instruments 
Station 5

E MULT Coh.

Wheeler Peak Quad, NM

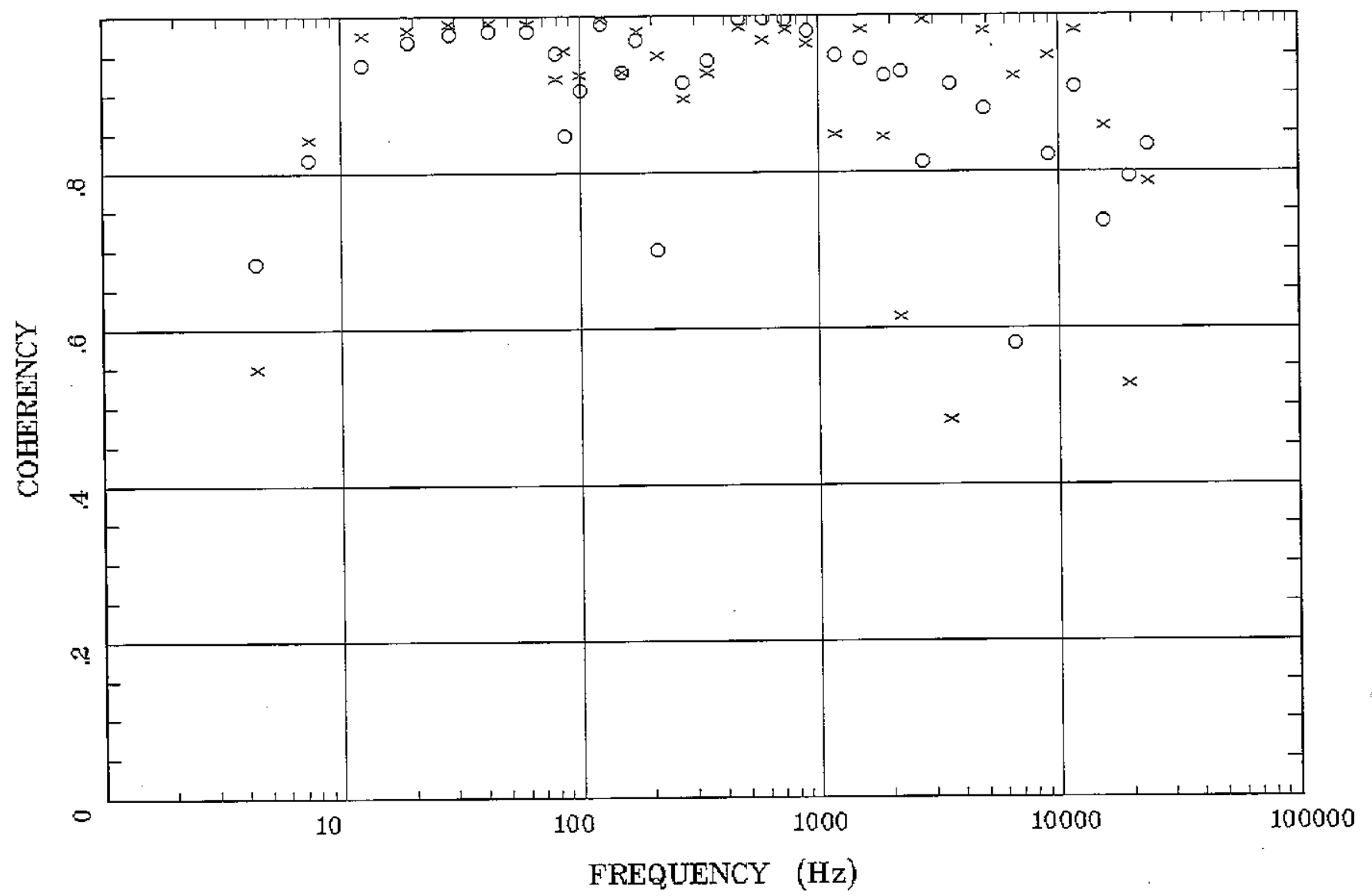

Client:

Remote: none

Acquired: 14:2 Jul 23, 2009

Filename: Tp05a3.avg

Channels: Ch1 Ch2 Ch3 Ch4 Ch5 Ch3 Ch4 Plotted: 16:00 Dec 03, 2010

Survey Co:USGS

< EMI - ElectroMagnetic Instruments 
Station 5

POLAR PLOTS

Wheeler Peak Quad, NM

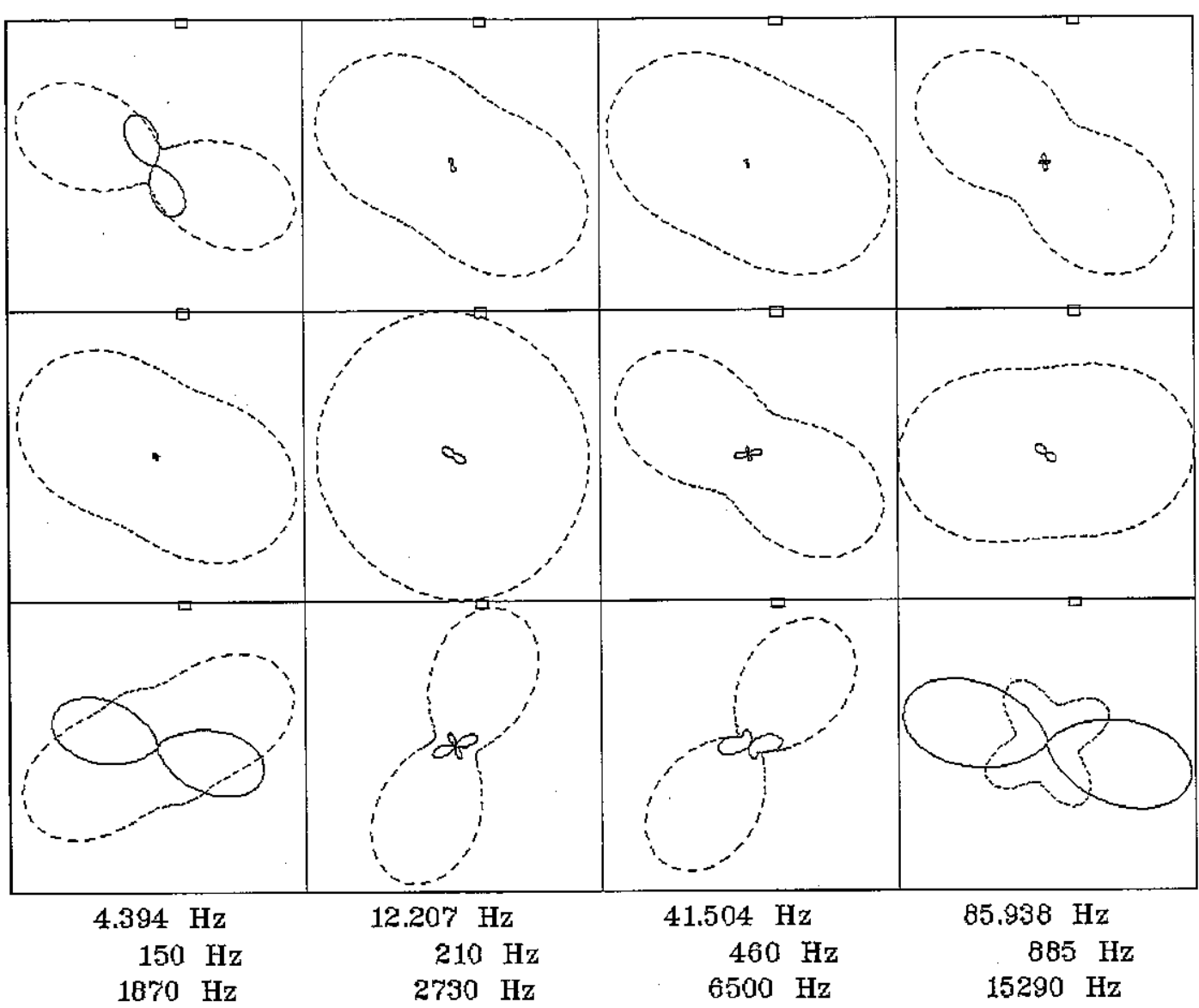

Client:

Rotation:

Remote: none

Acquired: 14:2 Iul 23, 2009

Survey Co:USGS

Filename: "p05a3.avg

Channels: Ch1 Ch2 Ch3 Ch4 Ch5 Ch3 Ch4

Platted: 15:00 Jan 06, 2011

< EMI - ElectroMagnetic Instruments > 


\section{Station 5}

TIPPER MAGNITUDE

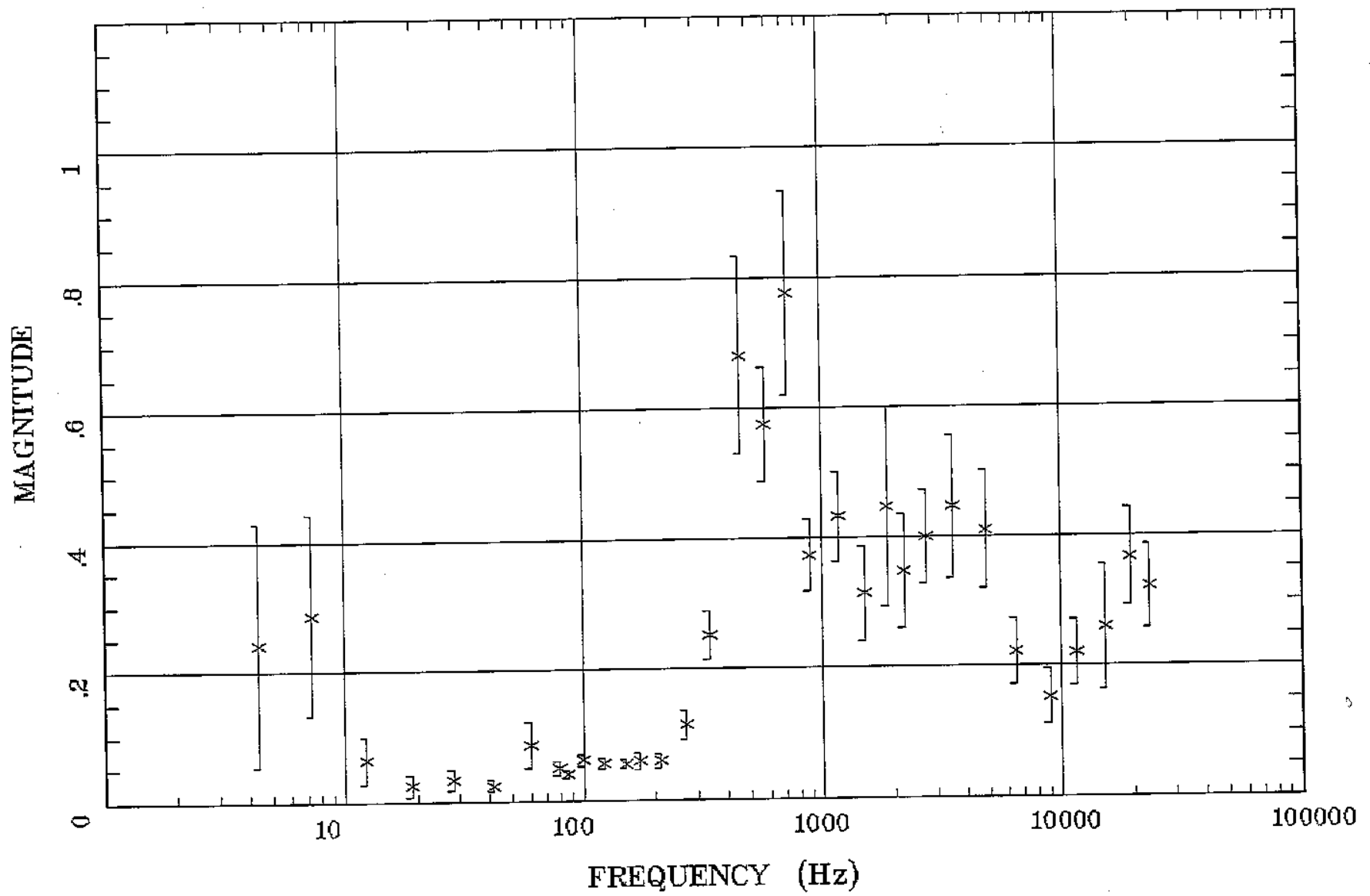

Client:

Remote: none

Acquired: 14:2 Jul 23, 2009

Survey Co:USGS

Rotation:

Filename: pp05a3.avg

Channels: Ch1 Ch2 Ch3 Ch4 Ch5 Ch3 Ch4

Plotted: 15:01 Jan 06, 2011

< EMI - ElectroMagnetic Instruments > 
Station 5

TIPPER STRIKE

Wheeler Peak Quad, NM

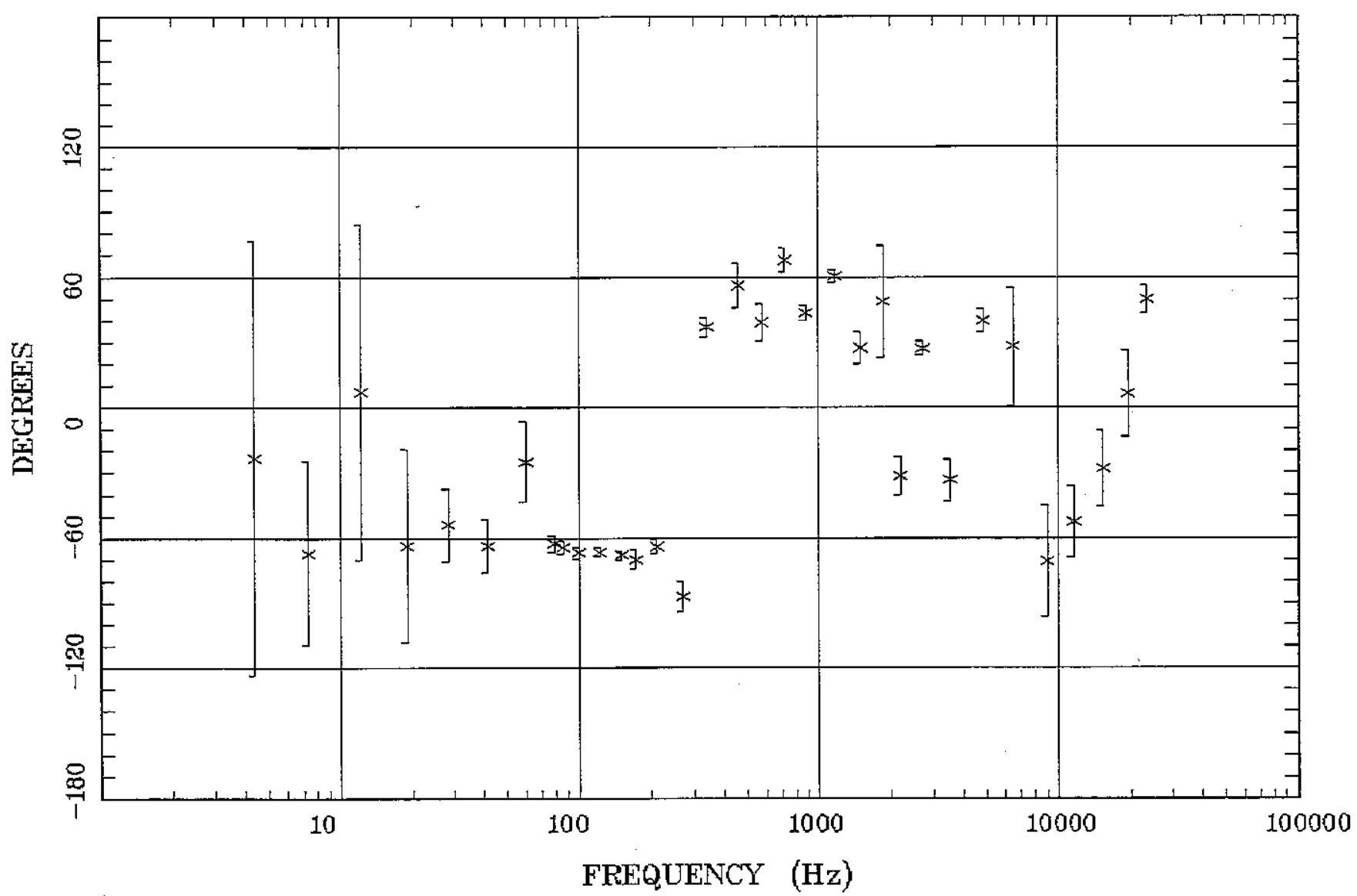

Client:

Remote: none

Acquired: 14:2 Jul 23, 2009 Survey Co:USGS
Rotation:

Filename: Fp05a3.avg

Channels: Ch1 Ch2 Ch3 Ch4 Ch5 Ch3 Ch4 Plotted: 15:01 Jan 06, 2011

< EMI - ElectroMagnetic Instruments > 
Station 5

HzHx.x Coh HzHy.o

Wheeler Peak Quad, NM

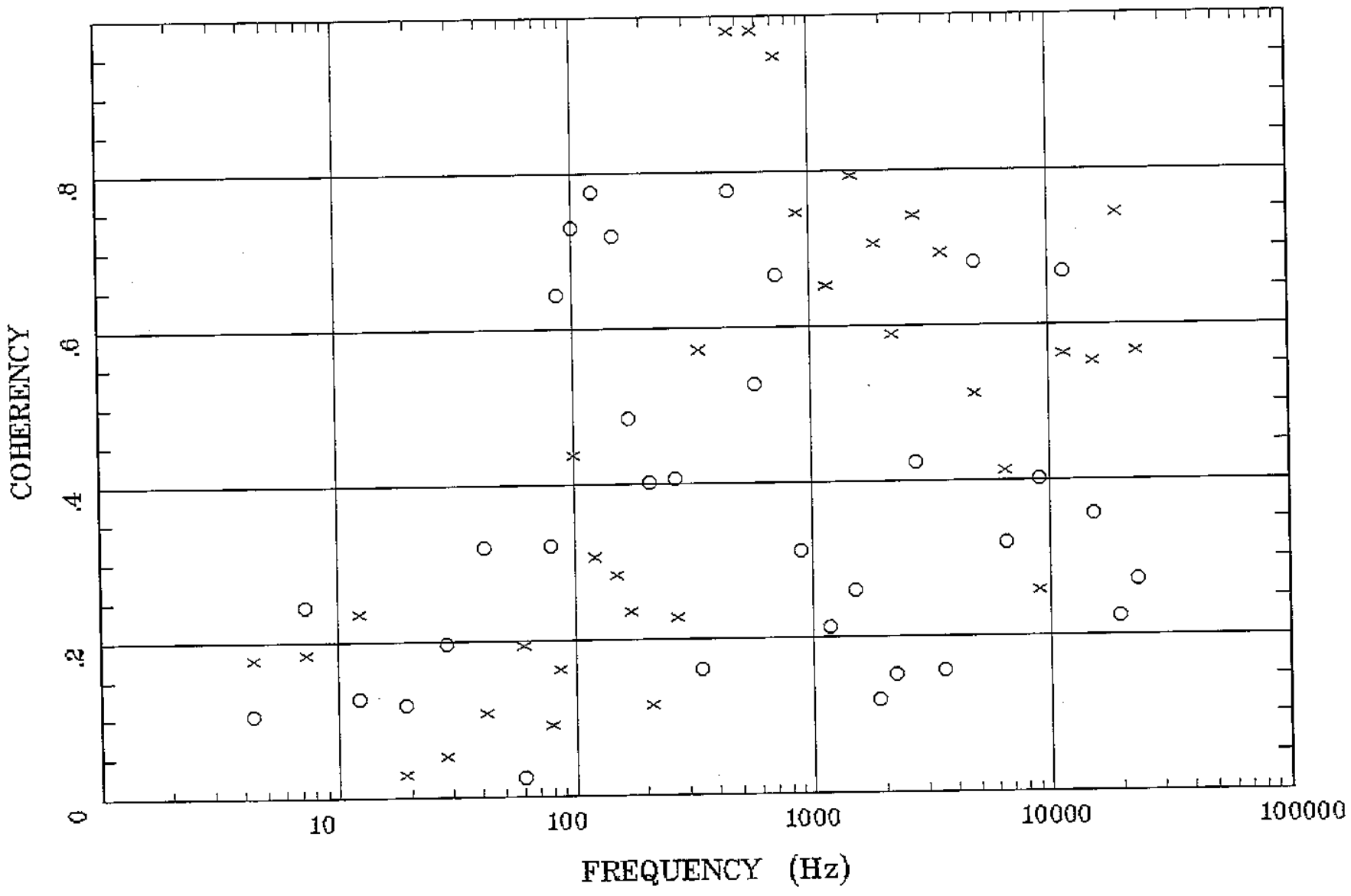

Rotation:

Filename: Tp05a3.avg

Client:

Remote: none

Acquired: 14:2 Jul 23, 2009

Surpey Co:USGS

Channels: Ch1 Ch2 Ch3 Ch4 Ch5 Ch3 Ch4

Platted: 15:01 Jan 06, 2011

< EMI - ElectroMagnetic Instruments 
Station 7

APPARENT RESISTIVITY

Wheeler Peak Quad, NM

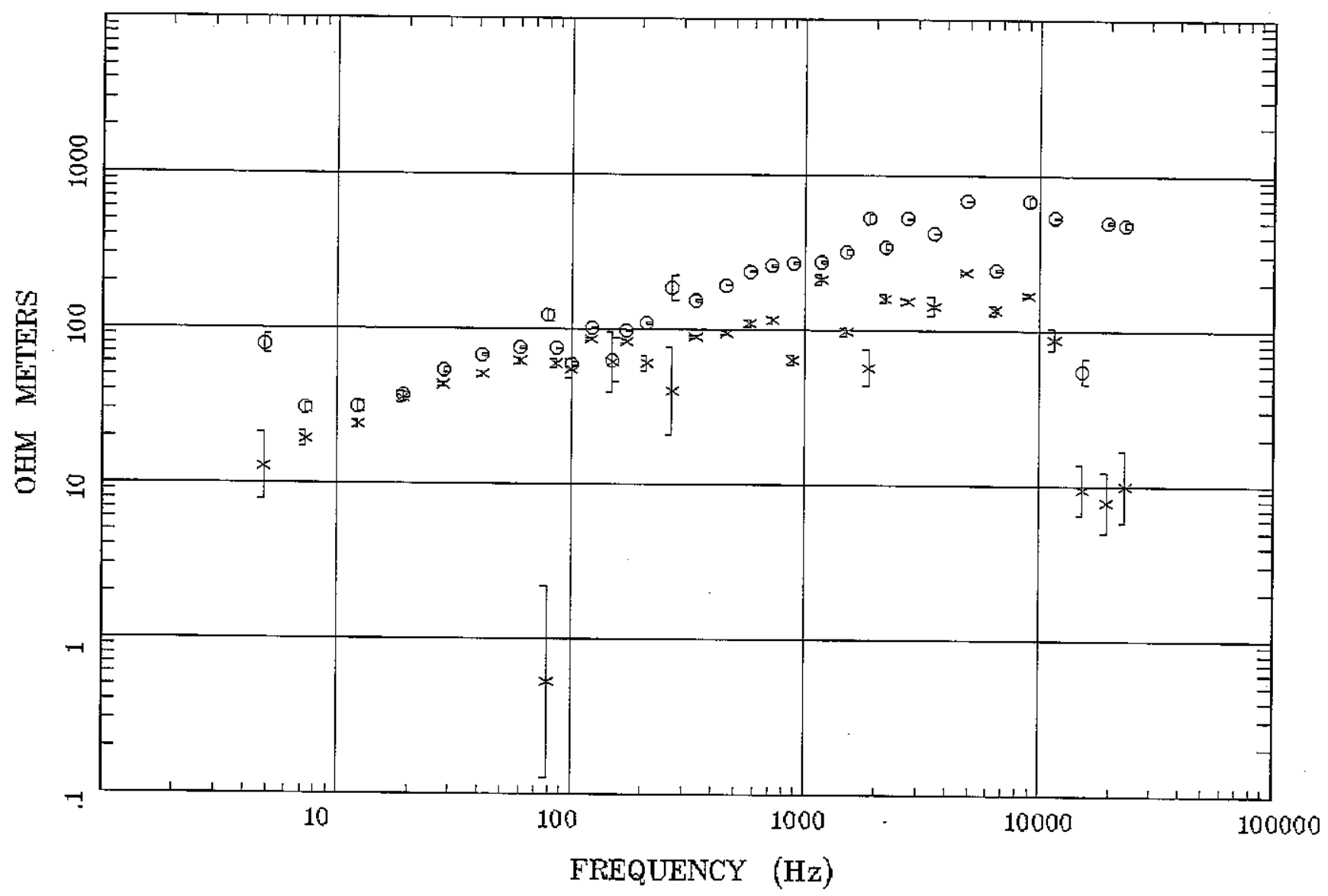

Client:

Remote: none

Acquired: 16:1 Jul 26, 2009

Survey Co:USGS
Rotation:

Filename: rp07a4.apg

Channels: Ch1 Ch2 Ch3 Ch4 Ch5 Ch3 Ch4

Plotted: 12:34 Jan 05, 2011

< EMI - ElectroMagnetic Instruments > 


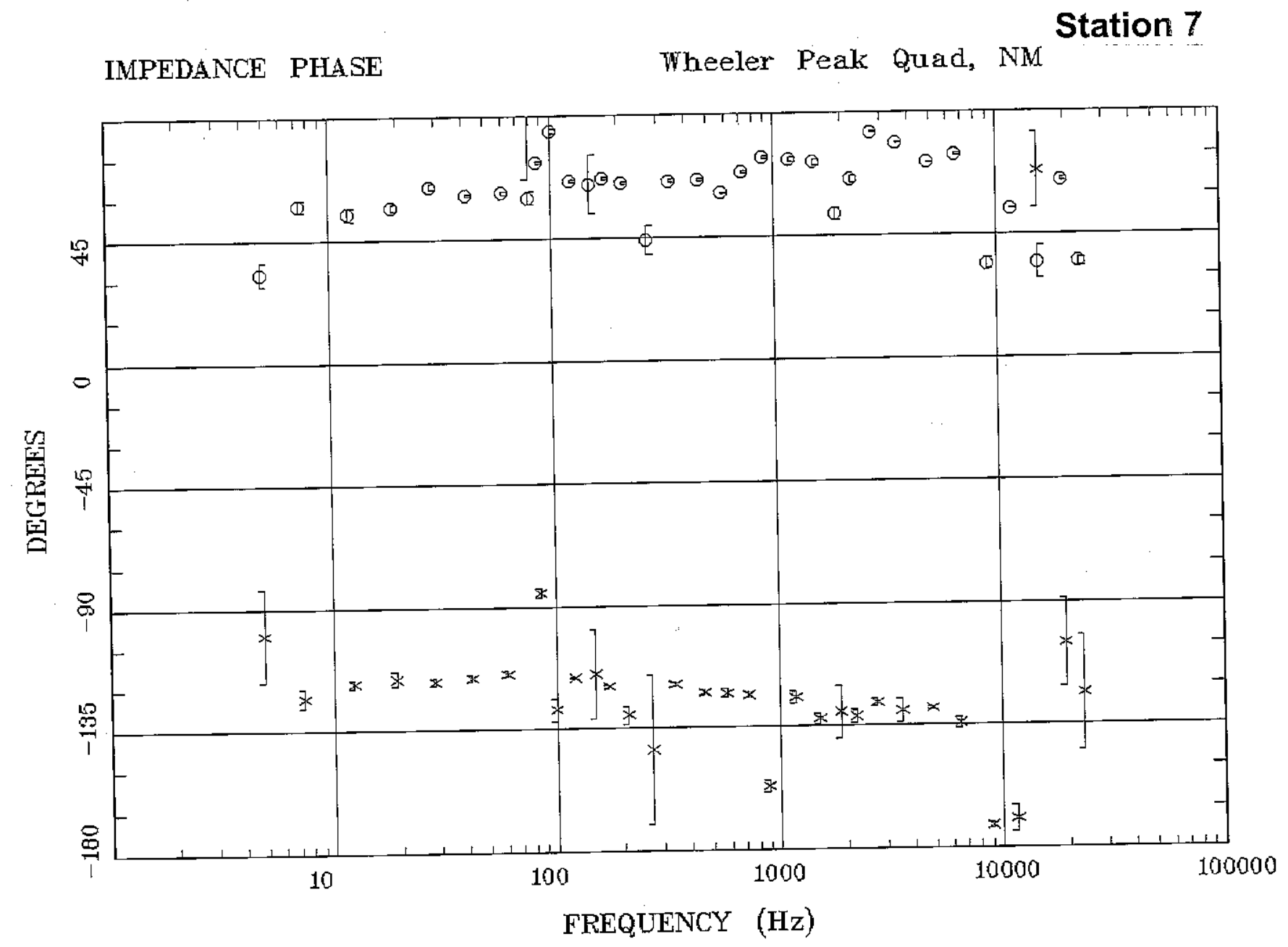

Client:

Remote: none

Acquired: 16:1 Jul 26, 2009

Survey Co:USGS

Rotation:

Filename: wp07a4.avg

Channels: Ch1 Ch2 Ch3 Ch4 ch5 Ch3 Ch4

Plotted: 12:34 Jan 05, 2011

< EMI - ElectroMagnetic Instruments > 


\section{Station 7}

IMPEDANCE SKEW

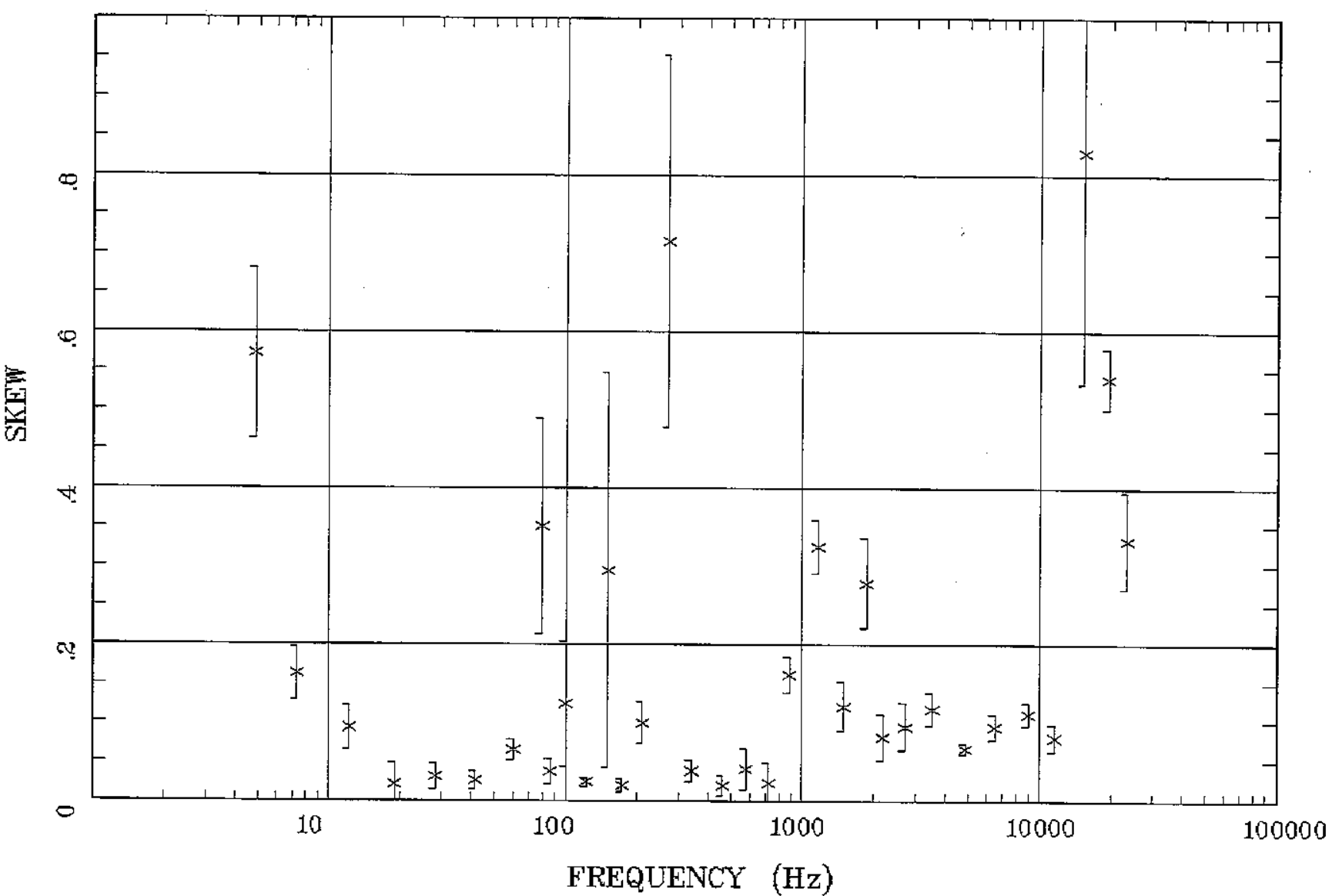

Client:

Remate: none

Acquired: 16:1 Jul 26, 2008

Survey Co:USGS
Rotation:

Filename: wp0\%a4.avg

Channels: Ch1 Ch2 Ch3 Ch4 Ch5 Ch3 Ch4

Plotted: 12:34 Jan 05, 2011

$<$ EMI - ElectroMagnetic Instruments 
E MULT Coh.

Station 7

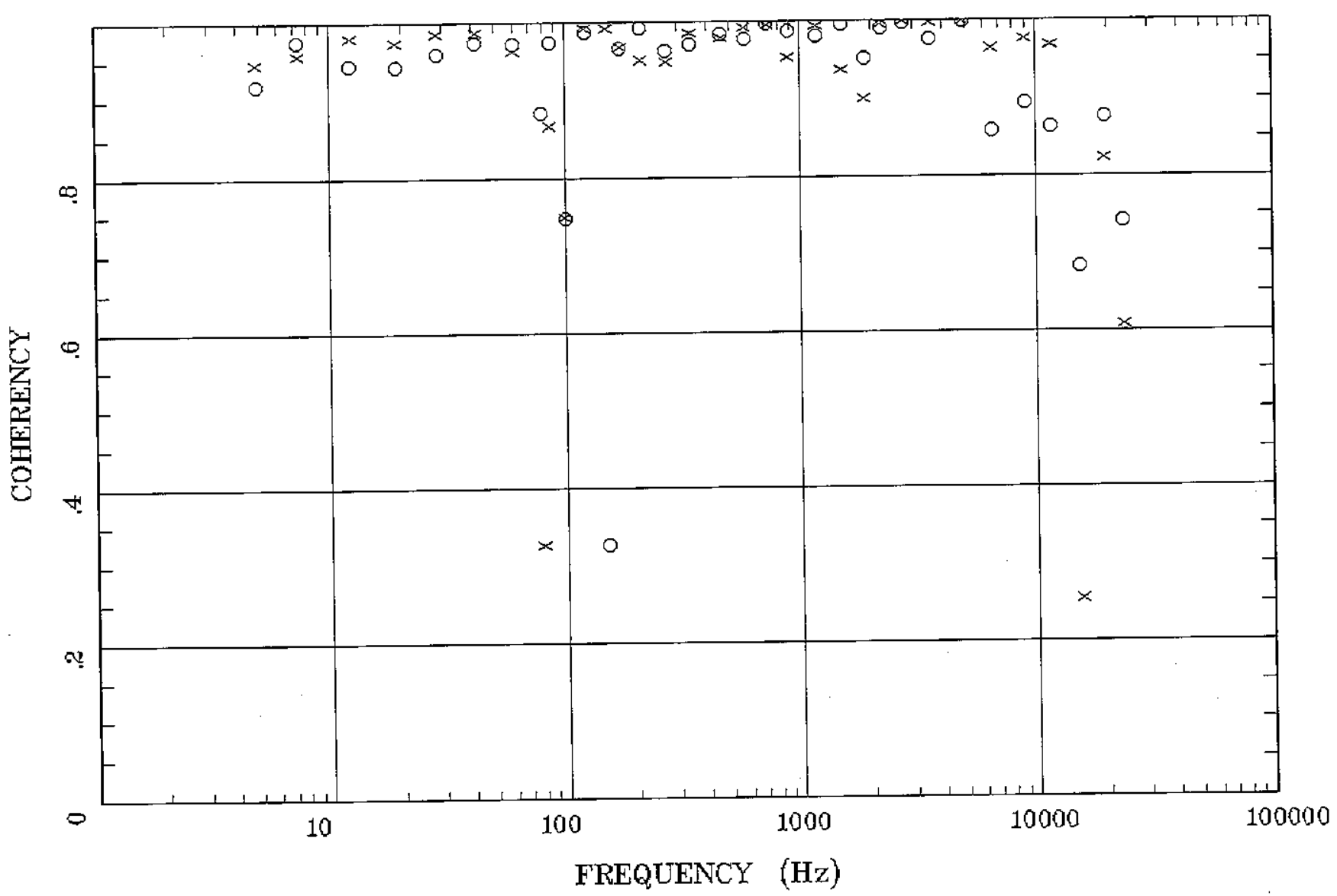

Client:

Remote: none

Acquired: 16:1 Jul 26, 2009

Survey Co:USGS
Rotation:

Filename: Np07a4.avg

Channels: Ch1 Ch2 Ch3 Ch4 Ch5 Ch3 Ch4

Plotted: 12:34 Jan 05, 2011

< EMI - ElectroMagnetic Instruments > 
Station 7

POLAR PLOTS

Wheeler Peak Quad, NM

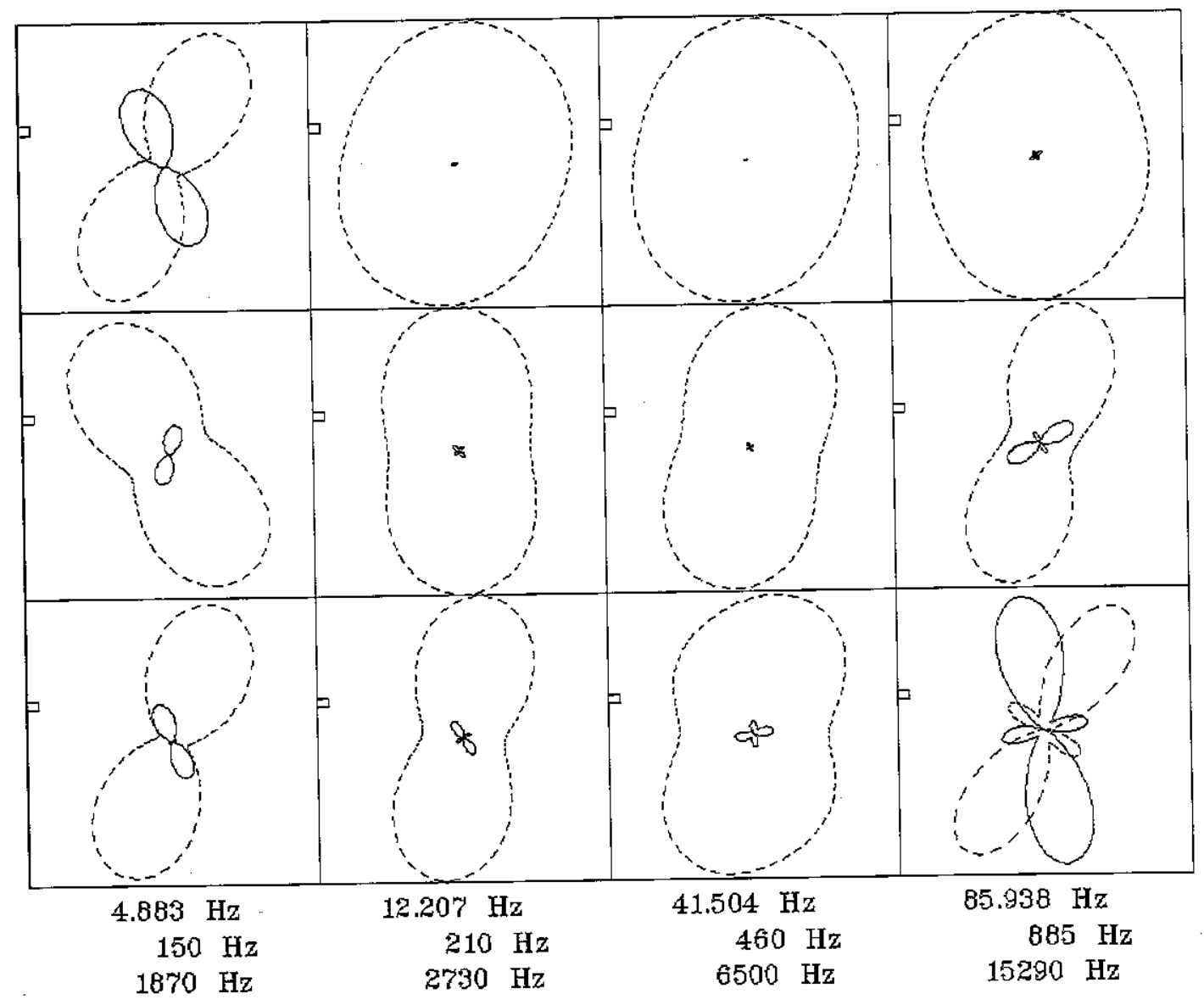

Client:

Remate: none

Acquired: 16:1 Jul 26, 2009

Survey Co:USGS

Rotation:

Filename: Fp07a4.avg

Channels: Ch1 Ch2 Ch3 Ch4 Ch5 Ch3 Ch4

Plotted: 12:34 Jan 05, 2011

< EMI - ElectroMagnetic Instruments 
Station 7

TIPPER MAGNITUDE

Wheeler Peak Quad, NM

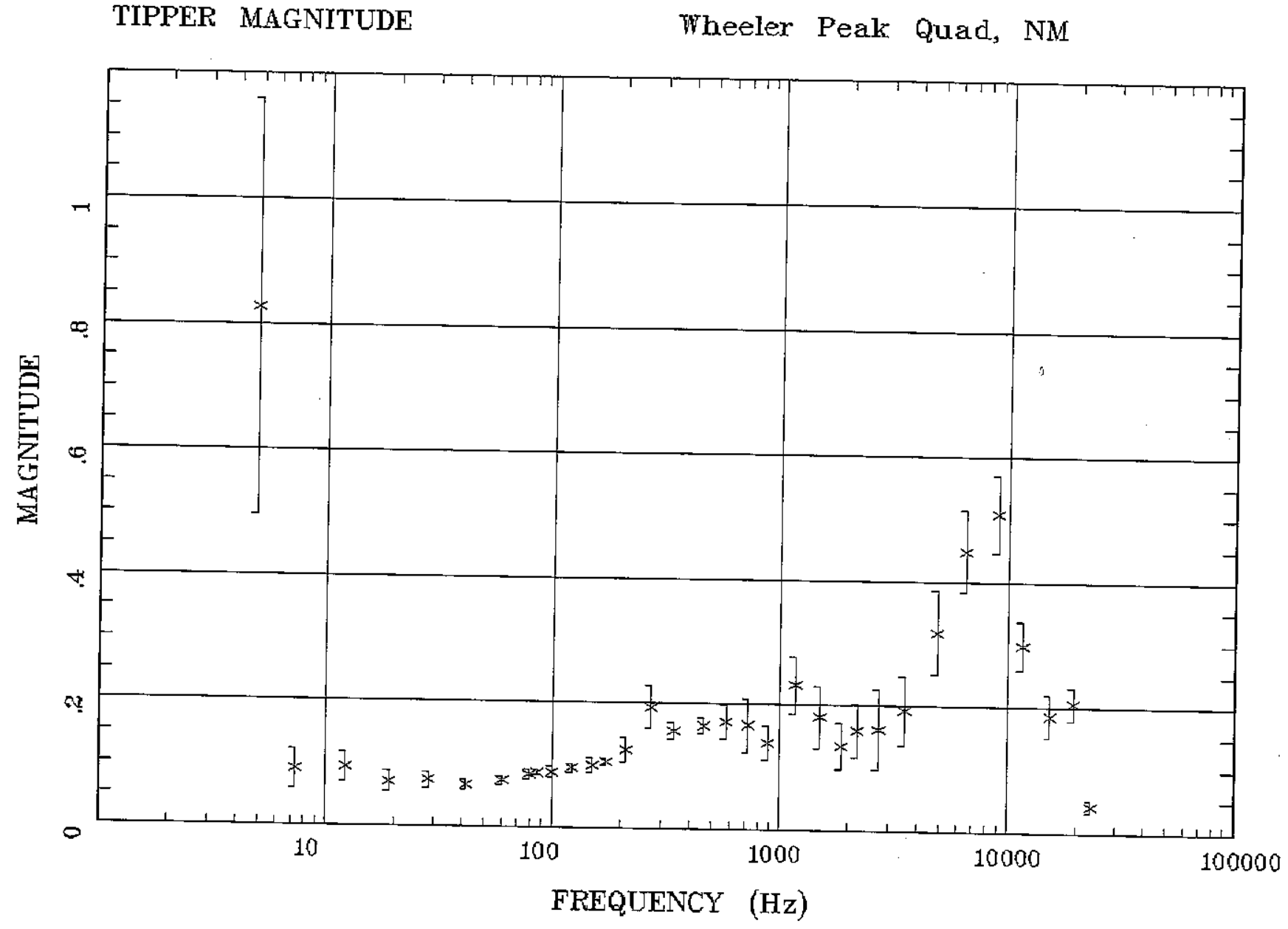

Client:

Remote: none

Acquired: 16:1 Jul 26, 2009

Survey Co:USGS

\section{Rotation:}

Filename: wp07a4.avg

Channels: Ch1 Ch2 Ch3 Ch4 Ch5 Ch3 Ch4

Platted: 12:58 Jan 05, 2011

< EMI - ElectroMagnetic Instruments 


\section{Station 7}

TIPPER STRIKE

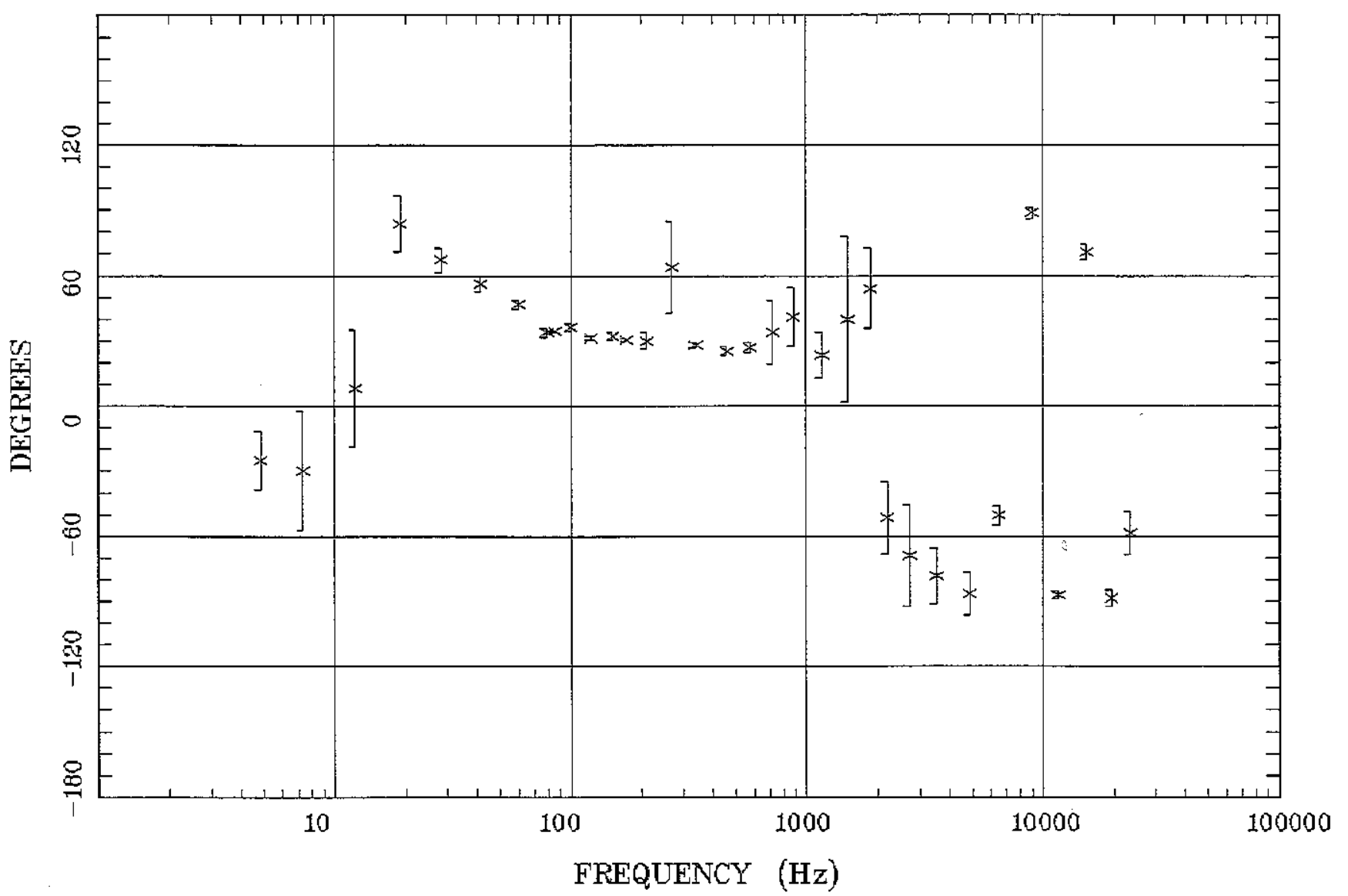

Client:

Remote: none

Acquired: 16:1 Jul 26, 2009

Survey Co:USGS
Wheeler Peak Quad, NM

Rotation:

Filename: Tp0ra4.avg

Channels: Ch1 Ch2 Ch3 Ch4 Ch5 Ch3 Ch4

Plotted: 12:57 Jan 05, 2011

< EMI - ElectroMagnetic Instruments 


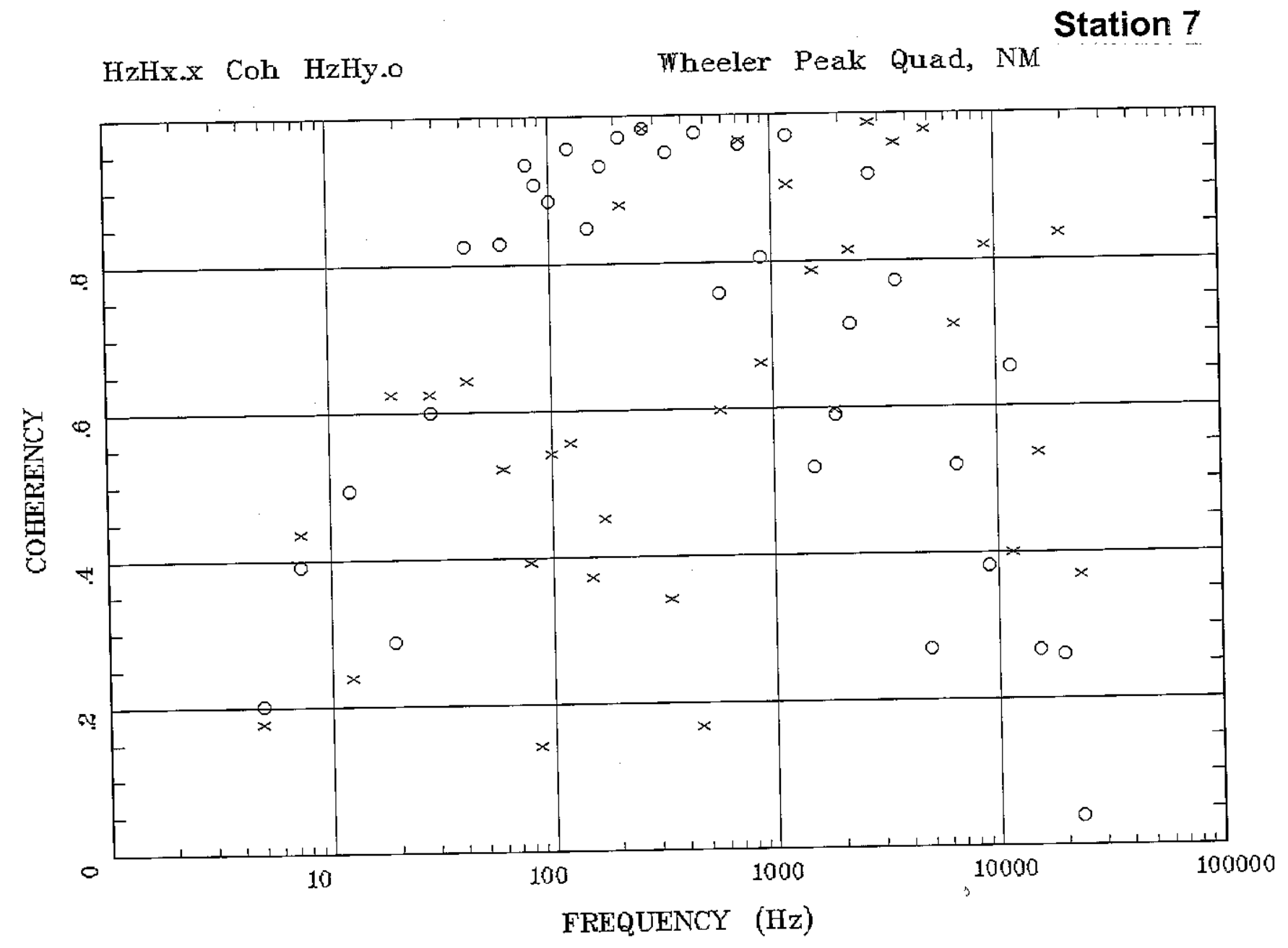

Client:

Rotation:

Filename: mpora4.avg

Channels: Ch1 Ch2 Ch3 Ch4 Ch5 Ch3 Ch4

Remote: none

Acquired: 16:1 Jul 26, 2009

Survey Co:USGS

Plotted: 1258 Jan 05, 2011

< EMI - ElectroMagnetic Instruments > 


\section{Station 9}

APPARENT RESISTIVITY Wheeler Peak Quad, NM

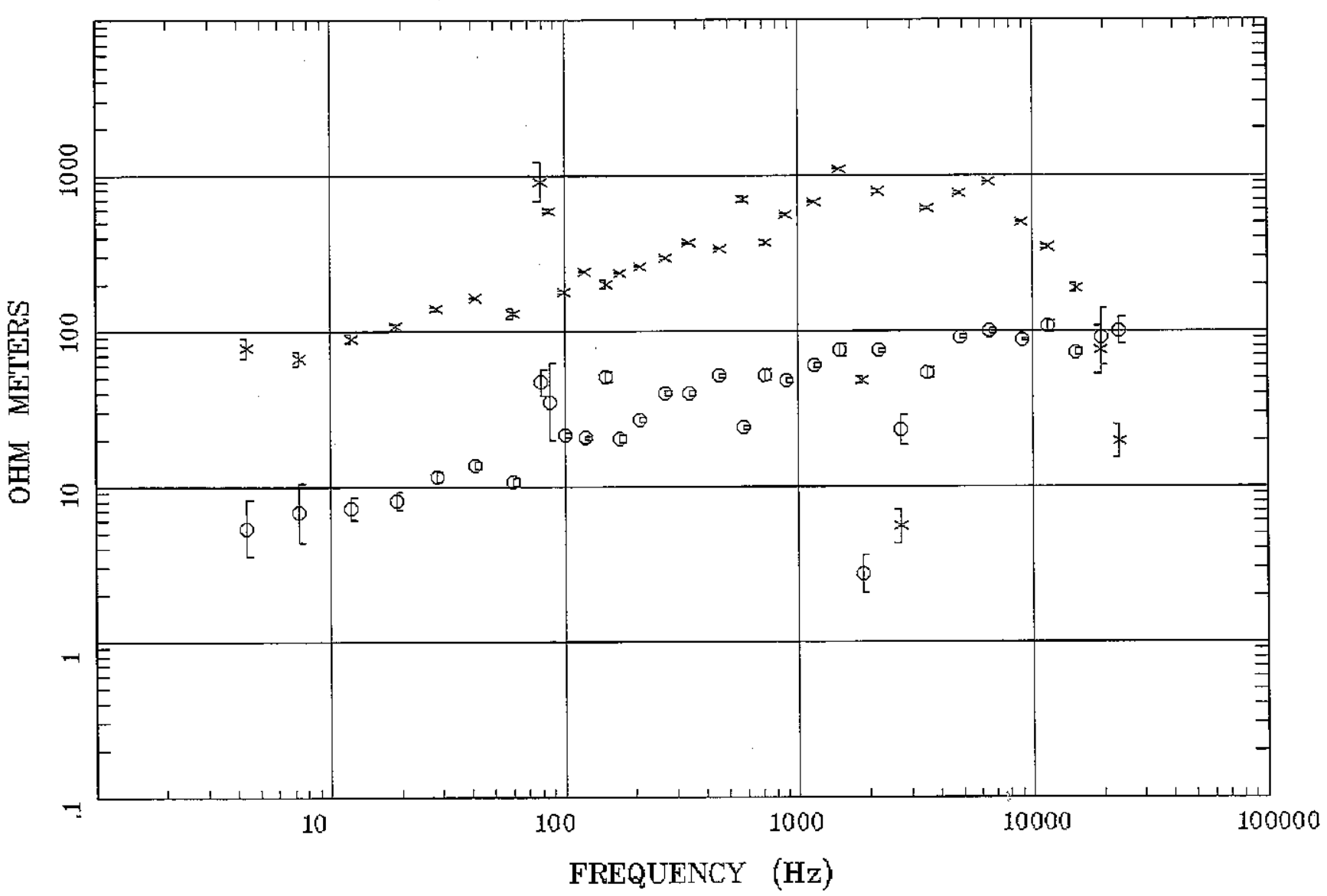

Rotation:

Client:

Remate: none

Acquired: 15:3 Jul 24, 2009

Filename: rpo9a4.avg

Channels: Ch1 Ch2 Ch3 Ch4 Ch5 Ch3 Ch4

Plotted: 11:47 Jan 05, 2011

Survey Co:USGS

< EMI - ElectroMagnetic Instruments > 


\section{Station 9}

IMPEDANCE PHASE

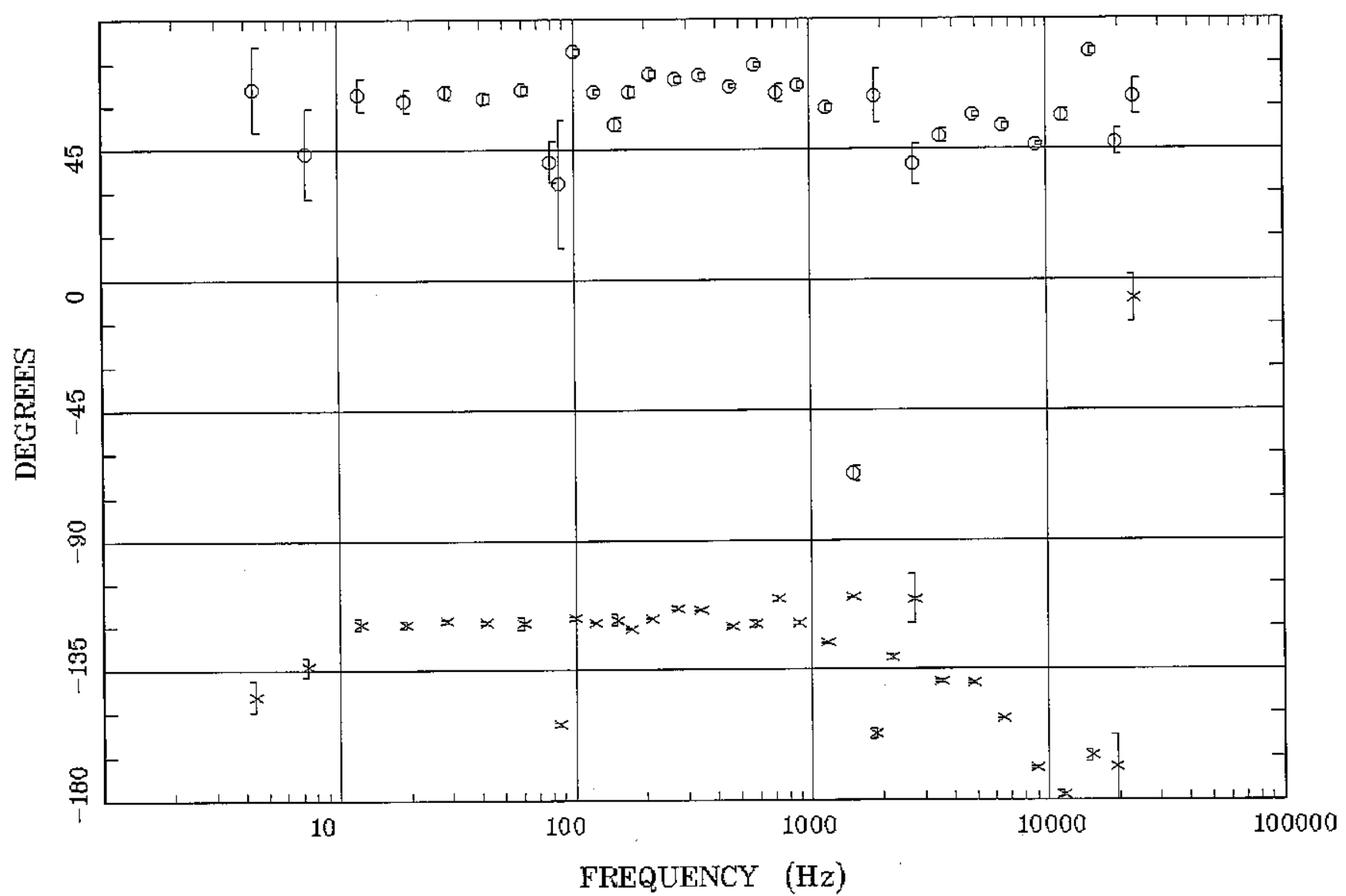

Client:

Remote: none

Acquired: 15:3 Jul 24, 2009

Survey Co:USGS
Rotation:

Filename: mp09a4.avg

Channels: Ch1 Ch2 Ch3 ch4 Ch5 Ch3 Ch4

Plotted: 11:47 Jan 05, 2011

< EMI - ElectroMagnetic Instruments > 


\section{Station 9}

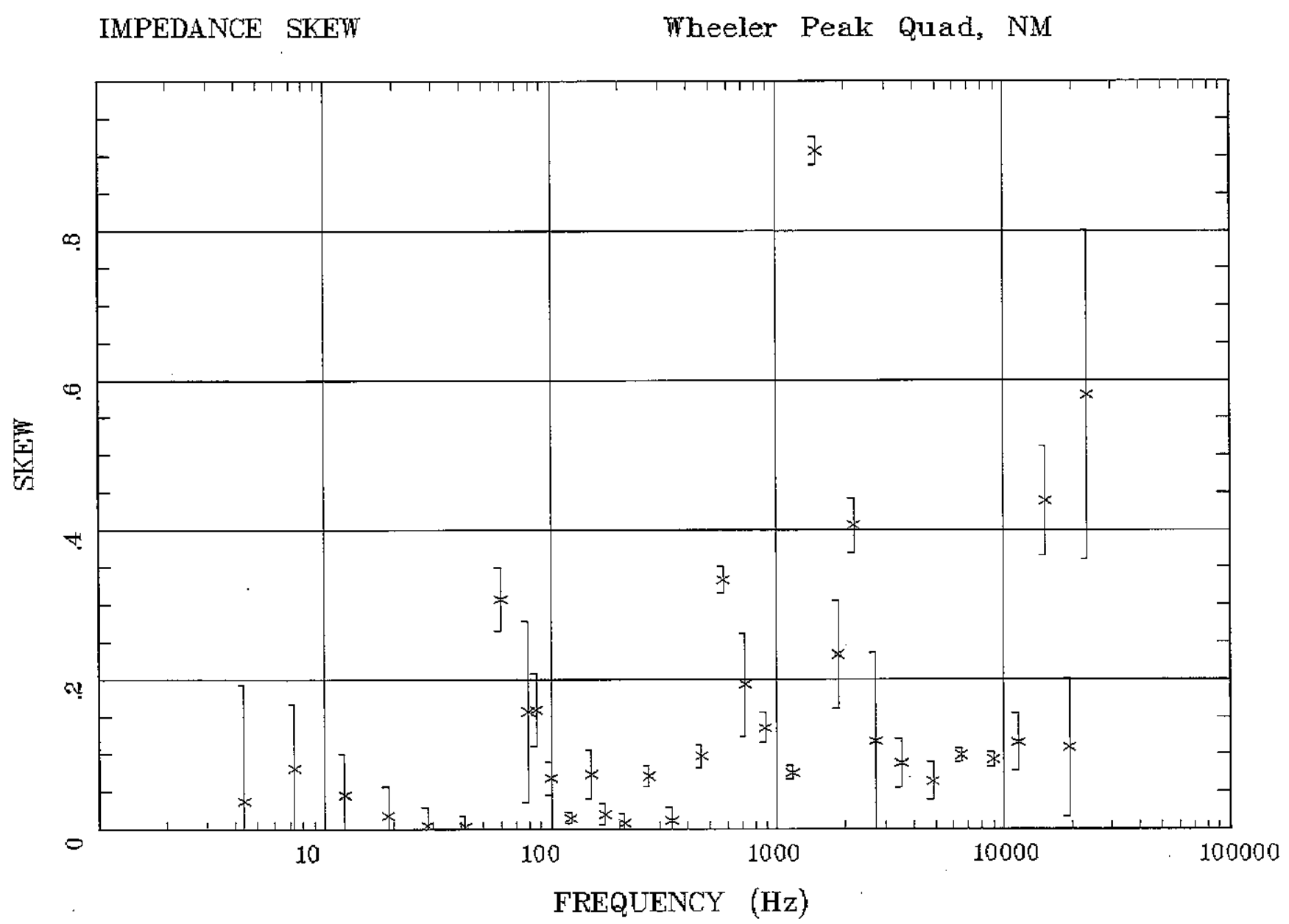

Client:

Remate: none

Acquired: 15:3 Jul 24, 2009

Survey Co:USGS

\section{Rotation:}

Filename: ppo9a4.avg

Channels: Ch1 Ch2 Ch3 Ch4 Ch5 Ch3 Ch4

Plotted: 11:47 Jan 05, 2011

< EMI - ElectroMagnetic Instruments > 


\section{Station 9}

E MULT Coh.

Wheeler Peak Quad, NM

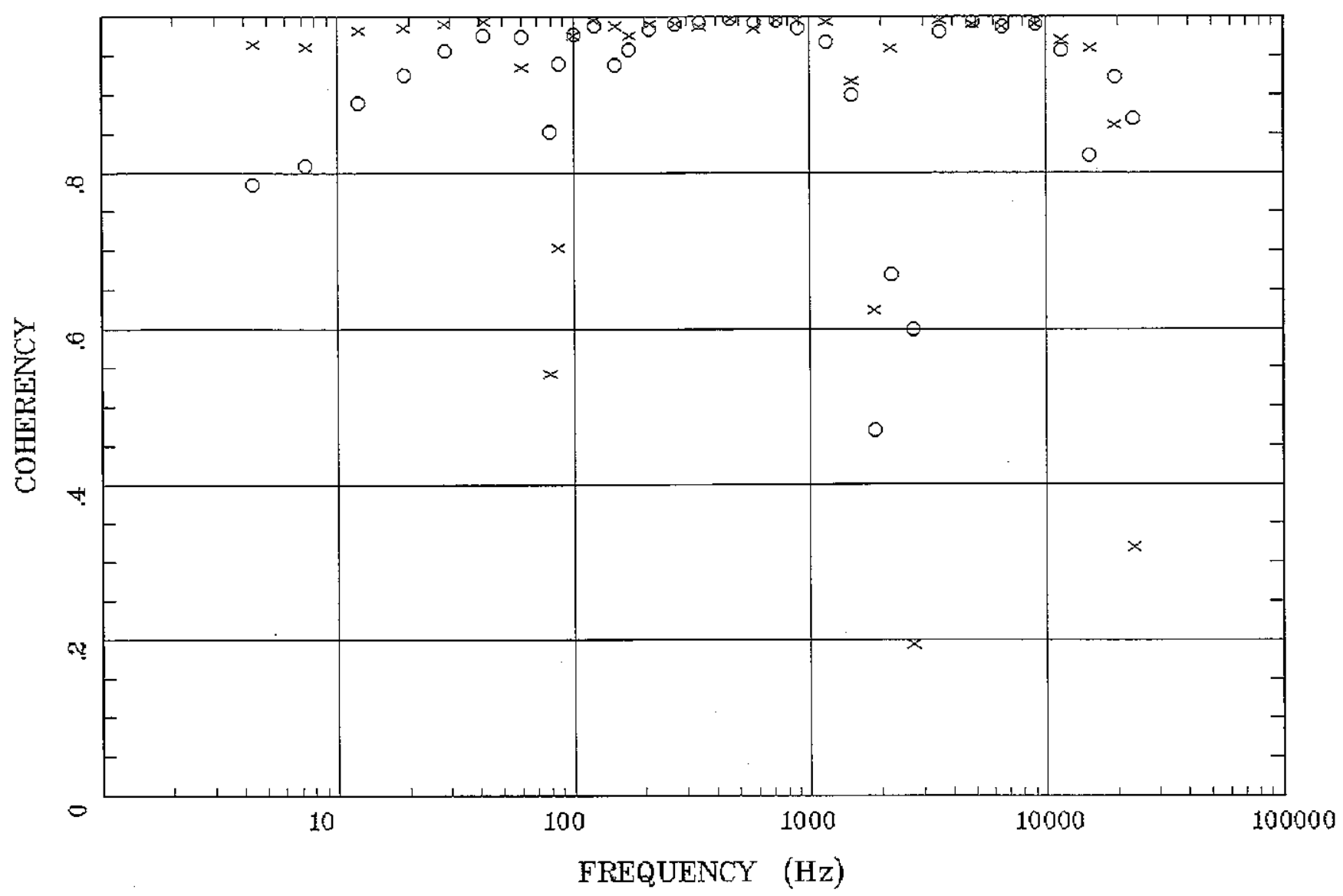

Client:

Remote: none

Acquired: 15:3 Jul 24, 2009

Survey Co:USGS
Rotation:

Filename: wp09a4.avg

Channels: Ch1 Ch2 Ch3 Ch4 Ch5 Ch3 Ch4

Plotted: 11:47 Jan 05, 2011

< EMI - ElectroMagnetic Instruments > 


\section{Station 9}

Wheeler Peak Quad, NM

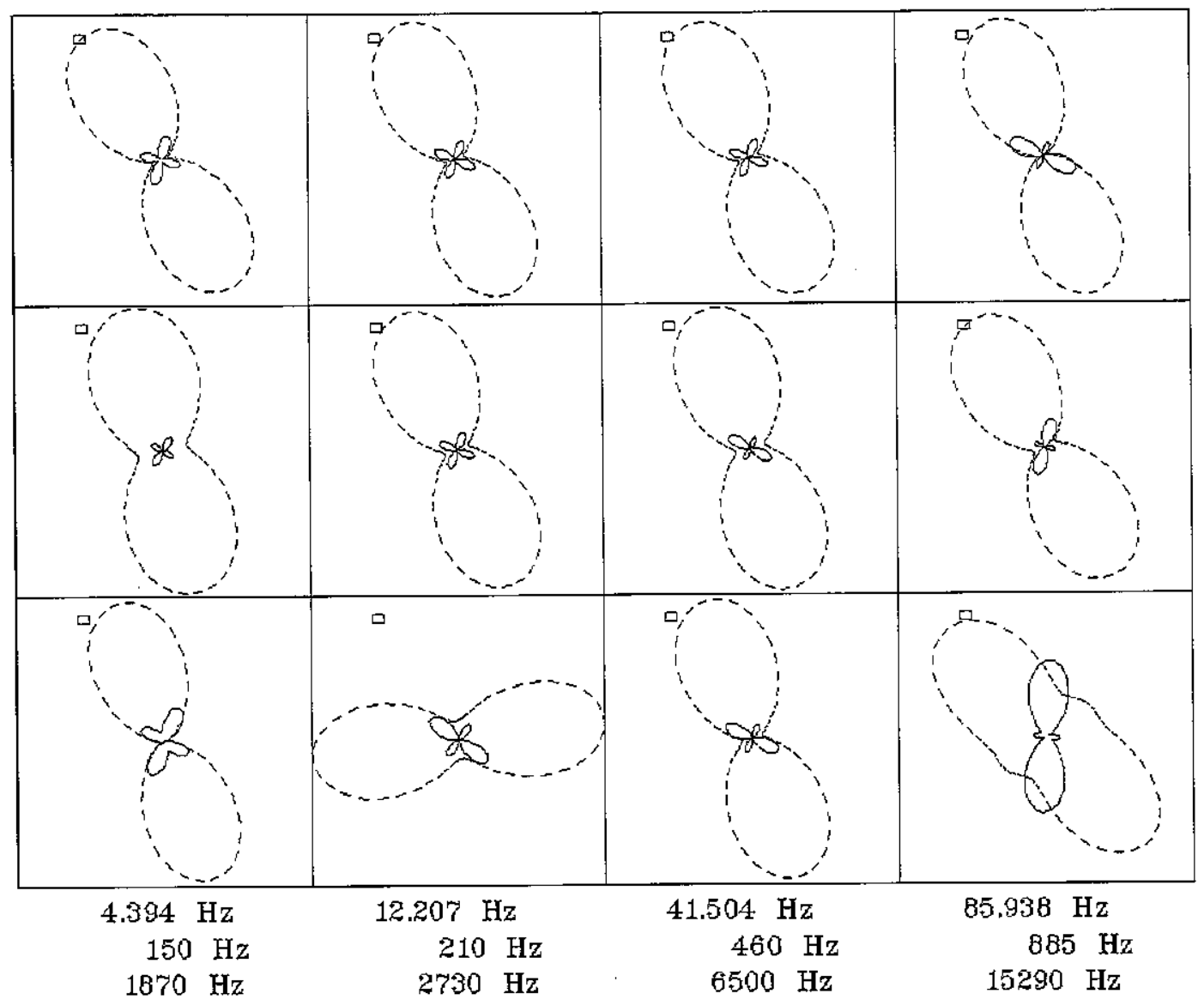

Client:

Rotation:

Remote: none

Acquired: 15:3 Jul 24, 2009

Filename: wp09a4.avg

Channels: Ch1 Ch2 Ch3 Ch4 Ch5 Ch3 Ch4

Platted: 11:47 Jan 05, 2011

Survey Co:USGS

< EMI - ElectroMagnetic Instruments 


\section{Station 9}

TIPPER MAGNITUDE

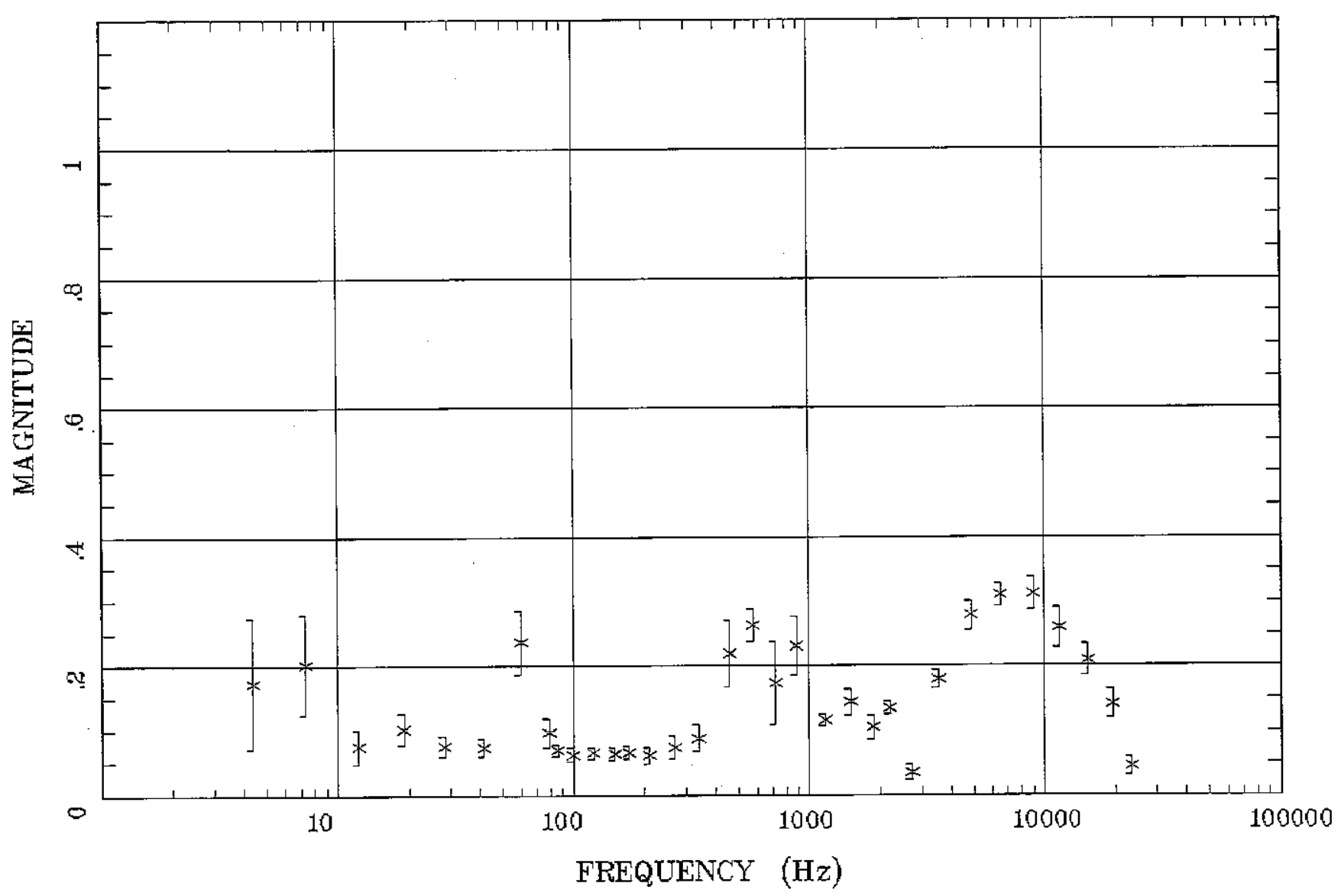

Client:

Remote: none

Acquired: 15:3 Jul 24, 2009

Survey Co:USGS
Rotation:

Filename: wp09a4.avg

Channels: Ch1 Ch2 Ch3 Ch4 Ch5 Ch3 Ch4

Plotted: 11:55 Jan 05, 2011

< EMI - ElectroMagnetic Instruments > 


\section{Station 9}

TIPPER STRIKE

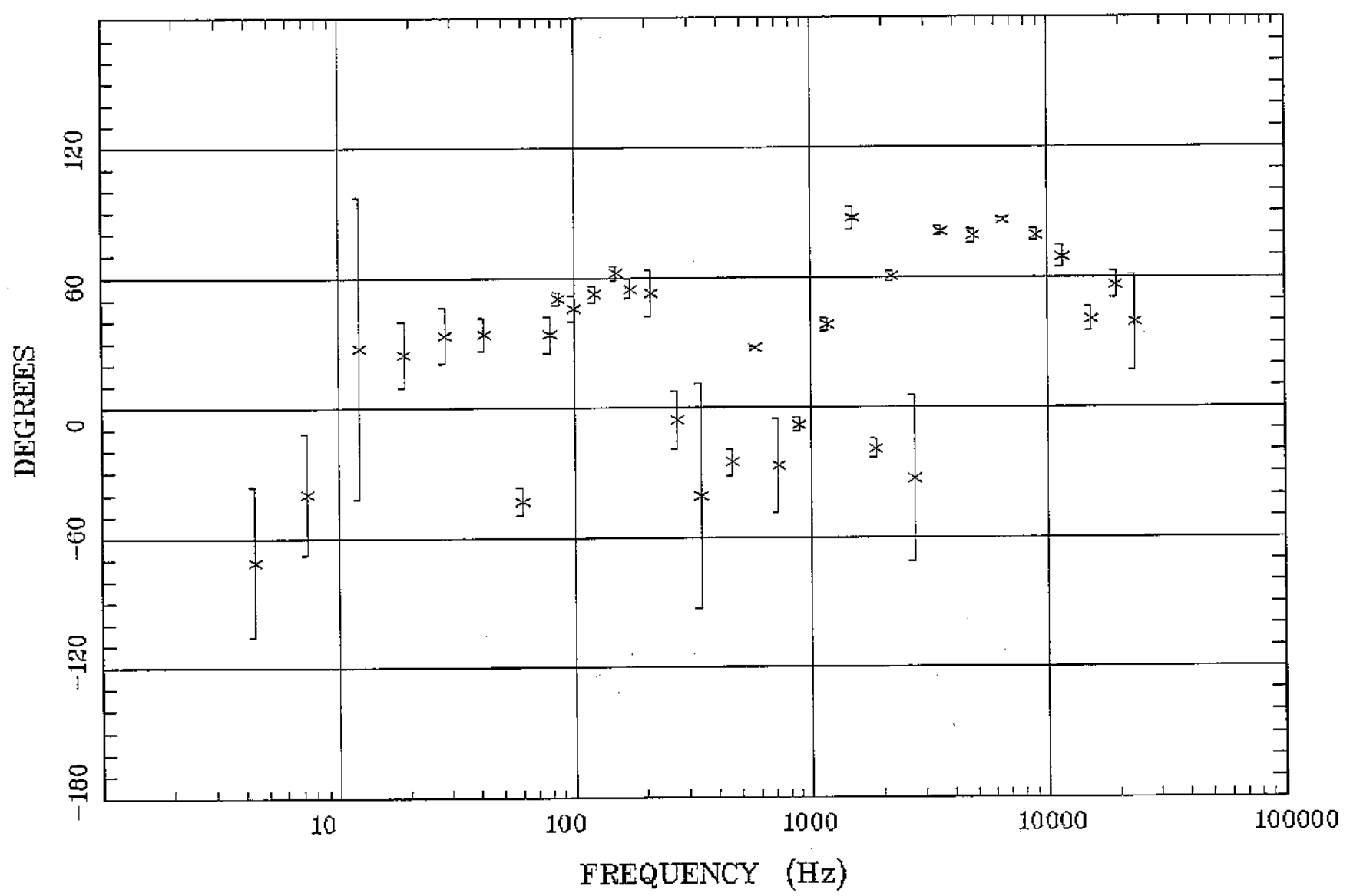

Wheeler Peak Quad, NM

Rotation:

Filename: wp09a4.avg

Channels: Ch1 Ch2 Ch3 Ch4 Ch5 Ch3 Ch4

Plotted: 11:55 Jan 05, 2011

< EMI - ElectroMagnetic Instruments
Client:

Remote: none

Acquired: 15:3 Jul 24, 2009

Survey Co:USGS 


\section{Station 9}

HzHx.x Coh HzHy.o

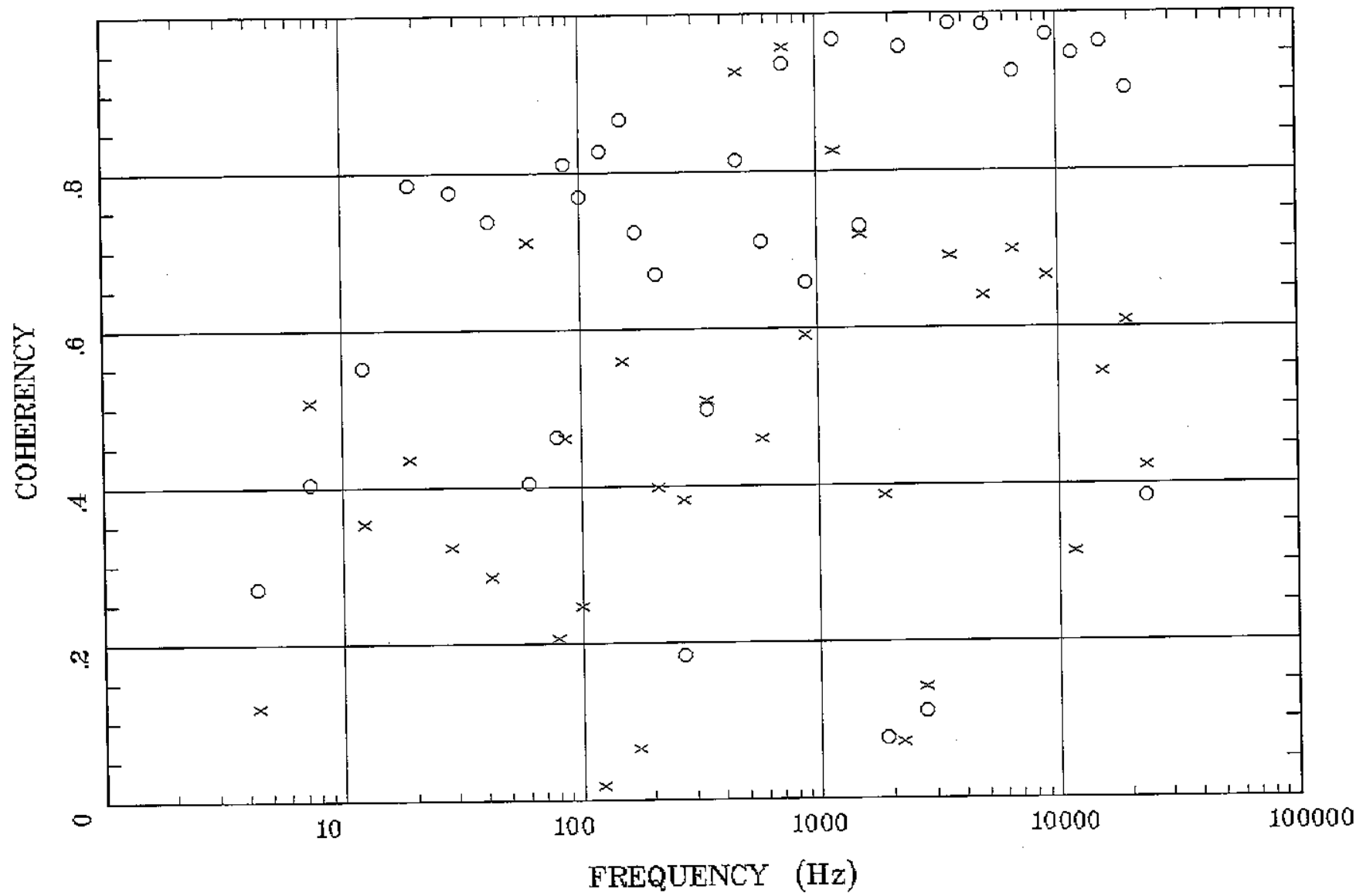

Client:

Remote: none

Acquired: 15:3 Jul 24, 2009

Survey Ca:USGS
Wheeler Peak Quad, NM

Rotation:

Filename: wp09a4.avg

Channels: Ch1 Ch2 Ch3 ch4 Ch5 Ch3 Ch4

Plotted: 11:56 Jan 05, 2011

< EMI - ElectroMagnetic Instruments > 